\title{
V Die „schimäre Gleichheit der Stände“ - Parallellektüre der Briefwechsel Gustav von Brinckmanns mit Rahel Levin Varnhagen und Luise von Voss
}

\begin{abstract}
Daß ich weit öfters, [...] mit meinem Geist in Ihrem freundlichen Dachstübchen zugegen bin, [...] Sie in dieser weiten Ferne vielleicht inniger und treuer liebe, als je. Gustav von Brinckmann an Rahel Levin Varnhagen, 1798

Die meisten Jüdinnen verrathen, möchte ich sagen, einen gewissen Egyptischen Styl, eine Härte der Umrisse, welche der ganzen Figur etwas unbeholfenes giebt; [...] Unsere berühmte Levin ist das wahre Musterbeispiel dieses Egyptischen Styls. Gustav von Brinckmann an Luise von Voss, $1805^{1}$
\end{abstract}

\section{Ein Habitué und viele Gastgeberinnen}

In diesem Kapitel wird eine Parallellektüre zweier umfangreicher und weitgehend unveröffentlichter Briefwechsel des Salongastes Gustav von Brinckmann mit zwei bedeutenden, zeitüberschneidend aktiven Gastgeberinnen und Korrespondentinnen unternommen: Rahel Levin Varnhagen und Luise von Voss.

Der Briefwechsel Rahel Levin Varnhagens mit Gustav von Brinckmann war und ist eine der wesentlichen Quellen für die Geschichte der Salongeselligkeit Rahel Levin Varnhagens. Mit dem Zeitraum 1792-1827 überspannt er die gesamte „Blütezeit“ des so genannten ersten und zweiten Salons. ${ }^{2}$ Luise von Voss, geborene von Berg (1780-1865) ${ }^{3}$ ist in der Literatur bekannt geworden als

1 Gustav von Brinckmann an Rahel Levin Varnhagen, 7. 10. 1798, SV 38, leicht modernisiert in: Wachtmeister 1871, S.4; ders. an Luise von Voss, 2. 10. 1805, ungedruckt, GSA 5/14, auch in: Hahn 1997(b), S.729. Das Zitat aus der Überschrift nach: Gustav von Brinckmann an Luise von Voss, 25. 2. 1798, ungedruckt, GSA 5/26,1. Siehe dazu ausführlich das Fazit dieses Kapitels.

2 Isselstein sieht Brinckmann als „Hauptzeugen“ der Anfänge. Isselstein 1997, S. 182. Vgl. Hahn 2002(a), S. 95.

3 Luise von Berg stammte aus einer politisch wie gesellschaftlich sehr gut vernetzten Familie. Sie heirate 1800 den Diplomaten Graf August Ernst von Voss, Enkel der Oberhofmeisterin Sophie von Voss, und teilte ihre Zeit mit ihrer Familie überwiegend zwischen Berlin und dem Landgut Giewitz in Mecklenburg. Die biografische Recherche zu ihr steht noch am Anfang, eine Biografie von Urte von Berg ist angekündigt. Am ausführlichsten zum ihrem Salon s. bisher den Eintrag bei Wilhelmy, die auch den Begriff „Salons der patriotischen Romantik“ geprägt hat. Wilhelmy 1989, S. 100-106 sowie 877-882. Einige ihrer Briefe an namhafte Persönlichkeiten wurden gedruckt. Vgl. die Nachweise ebd., S. 879. Den 
Gastgeberin eines patriotischen Salons nach 1807.4 Nach den hier untersuchten Quellen war sie aber spätestens seit 1798 gastgeberisch tätig und empfing gemischte Gesellschaft, nicht selten dieselben Gäste wie Rahel Levin Varnhagen. ${ }^{5}$

Der viel und prägnant formulierende Diplomat dient ironischerweise in der traditionellen Wertung der Salons als Beleg dafür, dass es im Salon keinen Standesunterschied gegeben habe, und Vertreterinnen der kritischen Salonforschung dient er zugleich für das Gegenteil, als Beleg wider die Vorurteilslosigkeit der Salongesellschaft. ${ }^{6}$ Beide Thesen werden dabei jeweils mit Zitaten aus anderen seiner Briefbeziehungen belegt. Als wesentliche Indizien gegen die

hier untersuchten Briefen zufolge war sie sehr belesen, las und schrieb mehrere Sprachen, interessierte sich für antike Schriften und europäische Geschichte. Ein zeitgenössisches Gemälde zeigt sie als zarte, schöne Erscheinung im antikisierenden Kostüm. (Das kleine, sehr eindrucksvolle Porträt „Louise von Voss-Giewitz“ von unbekannter Hand befindet sich heute im Privatarchiv Schloss Lübbenau. Ich danke Herrn Rochus Graf zu Lynar für die Möglichkeit, der Gräfin einmal persönlich ,gegenüber zu stehen').

4 Als Argumente dafür, ihren Salon als patriotischen zu bezeichnen, gelten die Verbindung zum Schillschen Aufstand 1809 sowie zu Mitgliedern der Deutschen Tischgesellschaft. Major Ferdinand von Schill zog 1809 ohne Abstimmung mit der Armeeführung initiativ mit seinem Corps gegen Napoleon, wurde von Franzosen getötet. Schill war im Hause Voss zu Gast gewesen. Allerdings deutet ein kaum bekanntes Memoir des Grafen von Voss zwar auf sein großes eigenes Interesse an diesem Mann, seine Frau wird aber überhaupt nicht erwähnt. [August von Voss]: Zur Geschichte des Schill'schen Zuges im Jahre 1809. Aus den hinterlassenen Papieren seines Vaters mitgetheilt von F. G. V., o. 0. 1854. Die Überschneidung des Gästekreises mit der Deutschen Tischgesellschaft, u. a. in den Personen Achim von Arnims und Clemens von Brentanos, ist kein singuläres Phänomen, und lässt sich auch für jüdische Salons bestätigen.

5 Wilhelmy listet sie auf als Gastgeberin eines patriotischen Salons nach 1807. Allerdings wurde von einigen Gästen bereits ab $1801 \mathrm{ihr}$ „Theetisch“ gerühmt und diese Begrifflichkeit änderte sich in den späteren Jahren nicht. (Zu Wilhelmys Datierung steht ihre eigene zutreffende Bemerkung im Widerspruch, dass Friedrich von Gentz seit $1801 \mathrm{im}$ „Salon Voß“ verkehrte. Wilhelmy 1989, S. 881). Da Brinckmann in seinen Briefen 1798 sich an beide Frauen des Hauses Berg als Gastgeberinnen erinnert, muss sie auch schon zu dieser Zeit ihrer Mutter zur Hand gegangen sein bzw. mit ihr gemeinsam empfangen haben - dabei unbewusst eine Tradition der Pariser Salons aufnehmend.

6 So sei etwa im Salon Levin Varnhagen „den Großen und Vornehmen [...] ihr Stand eher verziehen, als zugute gerechnet“ worden. Gustav von Brinckmann: Rahel. Briefe an Varnhagen von Ense, in: Karl August Varnhagen von Ense: Denkwürdigkeiten und verm. Schriften Leipzig 1854, Bd. 8, S.652, so als Beleg für die Ständemischung im Salon zitiert bei Seibert 1993(a), S.335. Dieser wiederum wird damit zitiert von Roberto Simanowski: Der Salon als dreifache Vermittlungsinstanz, in: Ders. / Turk / Schmidt 1999, S. 8-39, hier S. 6. Für Barbara Hahn und Deborah Hertz wurden hingegen Zitate aus Briefen Brinckmanns an Luise von Voss zum Anlass, den Salon als Ort der Emanzipation bzw. des offenen Austausches zu hinterfragen. Seine Formulierung vom „egyptischen Stil“ nimmt Hahn als 
Offenheit des Salons wurden Zitate aus dem Briefwechsel Brinckmanns mit Luise von Voss angeführt, beziehungsweise die Tatsache, dass der Diplomat darin für seine Verhältnisse ausfällig wurde, vom „egyptischen Styl“ einiger jüdischen Frauen sprach und vom „Auswurf an Gemeinheit, der in diesem Winter in ihrer Gesellschaft“ geherrscht habe. ${ }^{7}$ Diese Zitate wurden mit Recht als Hinweis darauf genommen, „wie wenig sogar in der ,Glanzzeit“ des Salons davon abgesehen wurde, daß man mit ,Juden“ verkehrte“ .8 Keineswegs ist die Ambivalenz Brinckmanns gegenüber seinen jüdischen Freundinnen, die in solchen Zitaten zum Ausdruck kommt, zu unterschätzen. Bei näherer Betrachtung des Briefwechsels stellt sich jedoch die Frage, welchen Stellenwert jene bisher bekannt gewordenen Zitate, die bis auf eines alle aus dem Jahr 1805 stammen, in der langen Beziehungsgeschichte zwischen Brinckmann und seinen aristokratischen und jüdischen Gastgeberinnen einnehmen. Während die bisher bekannten Bruchstücke als Hinweise darauf gelesen werden können, dass die Besucher jüdischer Salons ihre Geisteshaltung außerhalb derer vier Wände ins Gegenteil verkehrten, ergibt die Analyse der Gesamtkorrespondenz mit Luise von Voss ein wesentliches genaueres, wenn nicht ganz anderes Bild. Ein Ergebnis der Analyse vorwegnehmend ist festzuhalten, dass Brinckmann seinen jüdischen Bekannten und Freunden bzw. den Berliner Freunden und Freundinnen, von denen viele jüdischer Herkunft waren, nicht nur über zeitliche und räumliche Entfernung große Anhänglichkeit bewahrte, sondern auch zum Verteidiger einiger ihrer vorgeblich unpopulären Entscheidungen wurde.

Der Widerspruch zwischen der Verehrung für seine jüdischen Freundinnen und den antijüdischen Äußerungen nach außen, ist Anlass, aber nicht einziger Untersuchungspunkt. Es soll nicht primär um eine ,Verurteilung' oder einen ,Freispruch‘ Brinckmanns als (un)emanzipiertem Salongast gehen, sondern um einen Einblick in komplexe und sich wandelnde Wechselbeziehungen zwischen zwei gesellschaftlichen Szenerien, insofern sie am Nukleus zweier Freundschaftsbeziehungen ablesbar sind.

\footnotetext{
Ausdruck einer allgemein sich distanzierenden Gästeperspektive auf die Salons, „einer Perspektive, in der jene Frauen von vornherein als fremde, exotische Wesen erscheinen“. Hahn 2002(a), S.69. Hertz hingegen, die erstmals auf diesen Briefwechsel hinwies, vertritt die personalisiertere These, dass sich bei Brinckmann eine wachsende persönliche Antipathie in antisemitische Formulierungen gekleidet habe. Hertz 1991, bes. S. 287-289. (Die Adressatin wird unrichtig zitiert als Julie von Voss.) Hannah Arendt bietet eine dritte Sichtweise, wehrt sich gegen Brinckmanns Stilisierung, meint aber, dass es eine „Chance ihres gesellschaftlichen Outsidertums“ gegeben habe, der sich Rahel Levin Varnhagen bewusst gewesen sei. Arendt 2001, S. 69.

7 Gustav von Brinckmann an Luise von Voss, 2. 5. 1805 bzw. 28. 4. 1805, GSA 5/26,8. Hervorhebung im Original.

8 Hahn 1997(a), S. 231.
} 


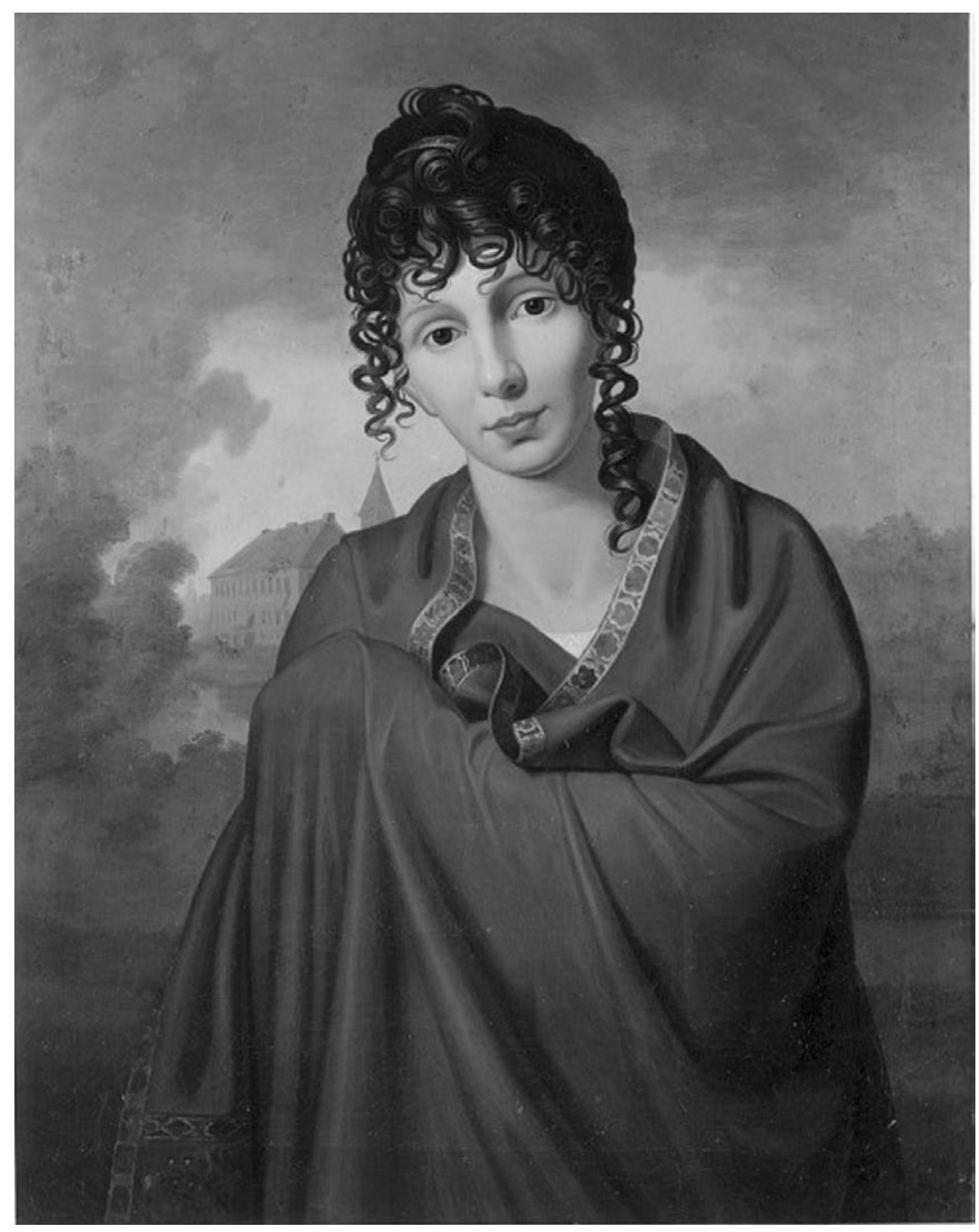

Abb. 24: Portrait der Salonière Luise von Voss (1780-1865).

Die Parallellektüre wird dafür punktuell ergänzt durch Brinckmanns Briefwechsel mit der Mutter der Gräfin von Voss, der gesellschaftlich ebenso engagierten wie anerkannten Karoline von Berg (1760-1826), ${ }^{9}$ sowie durch seine

9 Karoline Friederike von Berg, geb. von Haeseler, Hofdame der Königin Luise und später deren erste Biografin, wurde erst in allerjüngster Zeit Gegenstand einer ausführlichen 
Korrespondenz mit Lea Mendelssohn Bartholdy (1777-1842), ${ }^{10}$ die Brinckmanns wesentliche Ansprechpartnerin in den offenen Häusern der Familie Itzig war. Funktional gesprochen wird so der Briefwechsel zwischen der „berühmten Salonière“ Levin Varnhagen und ihrem Stammgast Brinckmann auf der einen Seite mit dessen Äußerungen gegenüber adligen Gastgeberinnen verglichen, auf der anderen Seite mit seiner Briefdiskussion mit einer bisher weniger untersuchten

Lebensbeschreibung, die auf dem Teilnachlass im GSA aufbaut. Urte von Berg: Caroline Friederike von Berg. Freundin der Königin Luise von Preußen. Ein Portrait nach Briefen, Göttingen 2008. Obwohl sie zahlreiche Gesellschaften gab - Jean Paul sprach von ihren „poetischen philosophischen Dinners“ - und zum Teil dieselben Personen wie ihre Tochter empfing, wurde sie kaum als Salonière betrachtet. Günter de Bruyn ist einer der wenigen, der sie so nennt. Günter de Bruyn: Preußens Luise. Vom Entstehen und Vergehen einer Legende, Berlin 2002, S. 42, Bildunterschrift. Überblickswerke zu den Salons im 19. Jh. führen sie selten auf. Ihre Geselligkeit ist fast nur aus den Primärquellen zu erschließen. Petra Wilhelmy erwähnt sie als „energische, literarisch und politisch interessierte Frau“ und Gast anderer Salons. Wilhelmy 1989, S. 880, 896. Auch ihre Biografin macht einen unerklärten - Unterschied zwischen ihren „Geselligkeiten“ und dem „Salon“ ihrer Tochter. „Dinners“ nach: Karoline von Berg an Jean Paul, 10.1. 1803, in: Berg 2008, S.74.

10 Lea Mendelssohn Bartholdy war die Tochter von Levin Jakob Salomon und Bella Salomon, geb. Itzig, damit Mitglied des Itzigschen Familiennetzes und Nichte mehrerer bekannt gewordenen Salonièren. Besonders berücksichtigt wurde sie in der Literatur als Mutter Fanny und Felix Mendelssohn Bartholdys. Vgl. als ersten Biografen Sebastian Hensel (Hrsg.): Die Familie Mendelssohn 1729-1847. Nach Briefen und Tagebüchern, 2 Bde., Leipzig 1924, bes. Bd.1, S. 89-130; in neuerer Zeit: Hans-Günter Klein (Hrsg.): „Die Liebe gleicht alles aus“. Briefe der Zuneigung, Fürsorge und Trauer aus der Familie Mendelssohn, Berlin 2004 sowie die Familienbiografie von Julius H. Schoeps: Das Erbe der Mendelssohns. Biographie einer Familie. Frankfurt/M. 2009. Selbstständige biografische Arbeiten zu Lea Mendelssohn Bartholdy wären lohnend. S. die zahlreichen Quellenhinweise in der Biografie ihres Ehemannes Abraham. Thomas Lackmann: „Der Sohn meines Vaters“. Biographische Studie über Abraham Mendelssohn Bartholdy, Göttingen 2008. Aus einem Teilnachlass in der Staatsbibliothek zu Berlin erschien zuletzt der Briefwechsel mit ihrer Cousine. Mendelssohn Bartholdy 2010. Obwohl sie bisher bei der Auflistung „berühmter Berliner Salonièren“ nur am Rande aufgeführt wurde, wird im Zuge tiefergehender Erforschung ihrer Geselligkeiten mit Recht der Begriff „musikalischer Salon“ diskutiert. Sie organisierte mit ihrer Familie, Berliner und durchreisenden Musikern qualitativ hochwertige Konzerte in ihrem Haus. Vgl. Wolfgang Dinglinger: Sonntagsmusiken bei Abraham und Lea Mendelssohn Bartholdy, in: Hans-Günter Klein (Hrsg.): Die Musikveranstaltungen bei den Mendelssohns - Ein musikalischer Salon? Die Referate des Symposions am 2. September 2006 in Leipzig (Leipzig - Musik und Stadt - Studien und Dokumente 2), Leipzig, Mendelssohn-Haus, 2006, S. 35-47; „MUGI“, eine Internetseite für Gender in der Musikgeschichte bezeichnet Lea Mendelssohn Bartholdy als „Kulturförderin, Mäzenin, Korrespondentin, Klavierlehrerin, Organisatorin musikalischer Geselligkeiten“. In: Musik und Gender im Internet, unter: http:// mugi.hfmt-hamburg.de/grundseite/grundseite.php?id=mend1777 (28. 8. 2008). Die Seite besticht durch eine umfassende Bibliografie und einen guten Forschungsüberblick. Die Briefe im Nachlass Brinckmanns sind nicht erwähnt. 
Gastgeberin jüdischer Herkunft. Mit allen vier Frauen verband ihn eine Jahrzehnte überspannende Korrespondenz, die nicht nur jahrelange Auslandsaufenthalte, sondern auch den endgültigen Weggang des Diplomaten aus Berlin überdauerte. Der Schwerpunkt der Untersuchung liegt hier auf dem Zeitraum des intensiven persönlichen und brieflichen Umgangs mit allen vier Frauen gleichzeitig, von 1797 bis $1806 .{ }^{11}$ Quellengrundlage dieses Kapitels ist die gesamte überlieferte Korrespondenz Brinckmanns mit den genannten vier Frauen, das sind über 1.000 Billets und Briefe, die bis auf ausgesuchte Exemplare oder Zitate ${ }^{12}$ noch komplett ungedruckt sind.13

11 Die überlieferte Korrespondenz von Rahel Levin Varnhagen und Gustav von Brinckmann umfasst die Jahre 1792-1827. Die überlieferten Briefwechsel mit Lea Mendelssohn Bartholdy und Luise von Voß setzen etwa zeitgleich 1797/98 mit Brinckmanns Abreise nach Paris ein, wohin er als Legationssekretär versetzt worden war. Mit Karoline von Berg schrieb sich der Diplomat 1794-1808, zu einem engeren Umgang scheint es aber erst nach 1797 gekommen zu sein. Alle vier Briefwechsel sind bis 1806/7 dicht überliefert und dünnen danach stark aus. Spätere Briefe entstanden meist aus Anlass eines Todesfalles von gemeinsamen Bekannten oder enthalten vor allem Reminiszenzen an die gemeinsame Vergangenheit. Mit „Lilla“ korrespondierte er der Überlieferung nach mindestens bis 1822 (von ihm sind nur Briefe bis 1799 überliefert, ihr letzter datiert von 1822, aus einem Brief an Henriette Pereira Arnstein lässt sich aber schließen, dass man noch 1836 eine Grußbekanntschaft aufrecht erhielt. Vgl. Mendelssohn Bartholdy 2010, S. 383). Der Briefwechsel Brinckmann-Voss ebbte ab, als der Diplomat preußischen Boden verließ. Nach 1809 ist nur noch ein Brief von 1827 erhalten. Eine Begründung dafür findet sich in den Briefen nicht. Da er aber formal an seine Tradition des Nummerierens anknüpfte, der letzte Brief die Nr. 377 trägt, ist Verlust auszuschließen und anzunehmen, dass das Ende des Briefwechsels bewusst in Kauf genommen worden war. Lediglich im Fall Rahel Levin Varnhagens kam es zum Austausch mehrerer Briefe nach 1806.

12 Von den Briefen Levin Varnhagens an Brinckmann wurden bereits im BdA einige auszugsweise gedruckt, von denen seitdem verschiedene neue Teildrucke erschienen. Vgl. GW I-III. Der Anlage des BdA nach wurden seine Briefe darin und dem folgend bisher ausgeklammert. Die Veröffentlichung des Briefwechsels im Rahmen der „Kritischen Edition“ ist geplant, aber noch nicht terminiert. Zitate aus Brinckmanns Briefen an Luise von Voss finden sich in Isselstein 1997 und Hahn 1997(b). Ich danke an dieser Stelle vielmals Barbara Hahn, die mich darauf aufmerksam machte, dass dieser lohnende Briefwechsel bisher aber noch nie komplett gelesen wurde. Für eine gute Charakteristik der Beziehung Brinckmanns zur Frau von Berg vgl. Berg 2008. Aus der Korrespondenz mit Lea Mendelssohn Bartholdy wurden unlängst Briefe aus den Jahren nach 1811 publiziert. Vgl. Klein 2007. Ein einziges, prägnantes Beispiel, seiner Briefe an „Lilla“ findet sich gekürzt im Anhang von Wachtmeister 1871, S. 8 f.

13 Der Nachlass der Familie Berg-Voss, im GSA Weimar enthält 436 Briefe Brinckmanns, davon ca. 380 an Luise von Voss aus dem Zeitraum 1797-1827. Ihre ca. 200 Gegenbriefe sind in seinem Nachlass verwahrt. Hier sind von Frau von Berg 82 Briefe zwischen 1794 und 1808 sowie sieben undatierte überliefert, im GSA liegen 48 Briefe Brinckmanns an sie zwischen 1797 und 1808. Vgl.: Nilsson 2004, o. S. und GSA 5/1 bzw. GSA 5/26,1-5/26,11. 
Ein formal-inhaltlicher Vergleich der Korrespondenzen zwischen 1797 und 1806 erlaubt die Rekonstruktion der Freundschaftsbeziehungen und möglicher Zäsuren [V.1], gefolgt von einer Analyse der diskutierten Geschlechterbilder [V.2]. Mit einer systematischen und chronologischen Analyse der Äußerungen Brinckmanns zu seinen jüdischen Bekannten bzw. seiner Definition „des Jüdischen“ [V.3] wird der Bogen zur Eingangsfrage zurückgeschlagen, inwieweit diese Äußerungen als symptomatisch gelten können [V.4].

\title{
1 „Ich kann nicht glücklich sein ohne Umgang mit einer geistreichen Freundin" - \\ Gustav von Brinckmann und die Teetische seiner „Musen“. Gemeinsamkeiten und Unterschiede
}

\begin{abstract}
Darum war und blieb sie für mich unter allen Umwälzungen meines Schicksals und meiner Verhältnisse- Friedrich die Einzige, wie ich sie wohl manchmal im Scherz nannte; die Freundin ohne Beiwort und Zusatz.

Gustav von Brinckmann über Rahel Levin Varnhagen

Luise! göttliches Mädchen! liebliche Schuzgöttin meiner Muse und des Dichters! Herrlichste meiner Korrespondentinnen!

Gustav von Brinckmann an Luise von Voss ${ }^{14}$
\end{abstract}

Nicht ohne Umgang mit einer geistreichen Freundin existieren zu können - der Satz, den Brinckmann über seine Bekanntschaft mit Caroline von Humboldt formulierte, zog sich wie ein Leitmotiv durch sein Dasein und die Briefwechsel: Er lebte fortwährend an und von den Teetischen mehrerer kluger Frauen und

Ebenfalls im BA finden sich 71 Briefe von Lilla Salomon Mendelssohn Bartholdy und Abschriften von 17 Gegenbriefen aus der Zeit 1798-1822. Die überlieferte Korrespondenz Brinckmann-Levin Varnhagen umfasst ca. 320 Briefe, Billets und Gedichte. (Die Zahl beruht auf Angaben der jeweiligen Sammlungswalter, der Herausgeberinnen der ERLV sowie eigenen Zählungen. Es handelt sich um eine Mindestzahl, da sich beide Partner oft auf nicht mehr überlieferte Nachrichten beziehen.) Wegen zeitlicher Beschränkung in Uppsala wurde dort der exakten Erfassung der Briefe Rahel Levin Varnhagens und Lea Mendelssohn Bartholdys Vorrang gegeben. Die Briefe der Luise von Voss wurden überwiegend regestenartig erfasst, die Inhalte lassen sich meist auch aus den detaillierten Antworten Brinckmanns erschließen.

14 Das Zitat aus der Überschrift: Gustav von Brinckmann an Karoline von Berg, 12. 3. 1798, ungedruckt, GSA 5/1. „Friedrich die Einzige“ nach: Brinckmann 1876, S. 239. Doppelte Betonung im Original; An Luise von Voss, 3. 3.1800, ungedruckt, GSA 5/26,3; 
bestätigte seinen Gastgeberinnen die Bedeutung dieses Umstands häufig. ${ }^{15}$ Dennoch scheint er Schwerpunkte gesetzt zu haben: Die Dichte der überlieferten Korrespondenz zwischen Brinckmann und Levin Varnhagen und die ihr ablesbare Intensität des Umgangs bis zu seinem Weggang nach Paris 1797 sind der besonderen Vertrautheit vergleichbar, die zwischen dem Diplomaten und Luise von Voss seit 1797 entstand und gepflegt wurde. ${ }^{16}$ Nannte er in den frühen 1790er-Jahren Rahel Levin Varnhagen seine „einzige“ Freundin, lebte er nach der Rückkehr aus Paris „beinah einzig im Haus der Gräfin Voß“. ${ }^{17}$ Das führt zu der Hypothese, dass Brinckmann, obzwar zeitlebens gleichzeitig Besucher mehrerer Salons, dennoch jeweils einer Salonière besonders huldigte. Im Status einer ,Lieblingsgastgeberin“ könnte Luise von Voss Rahel Levin Varnhagen abgelöst haben. Neben den chronologischen Vergleich der Korrespondenzen muss daher ein diachronischer der jeweiligen intensiven Phasen des Kontaktes treten, und gefragt werden, ob es neben der brieflichen Dichte auch andere Vergleichbarkeiten, etwa im Tonfall oder in der Wahl der Themen, gab. Interessant ist dabei die Frage, was Brinckmann „einzig“ fand, und wann und warum er begann, die Einzigartigkeit seiner Freundin Rahel Levin Varnhagen doch durch Beiworte zu charakterisieren und relativieren bzw. andere Freundinnen ihr vorzuziehen. ${ }^{18}$

15 So schrieb er, das Eingangszitat variierend, an Luise von Voss: „Ich kenne nun einmal kein größeres Vergnügen als das geistreiche Gespräch mit einer denkenden Freundin“, 30. 1. 1799, ungedruckt, GSA 5/26,2. Die These Urte von Bergs, dass Brinckmann im Salon Berg einen „Familienersatz“ gefunden habe, kann bestätigt, muss aber insofern erweitert werden, als dass Brinckmann diesen Familienanschluss, zu verschiedenen Zeiten, in verschiedenen offenen Häusern suchte und fand. Berg 2008, S. 128.

16 Von den ca. 320 überlieferten Briefen und Billets des Briefwechsels Brinckmann-Levin Varnhagen stammen knapp 200 aus der Zeit vor Brinckmanns Abreise nach Paris 1797.

17 Gustav von Brinckmann an Friedrich Schleiermacher, 13. 1. 1804, in: Heinrich Meisner / Erich Schmidt: Briefe von Karl Gustav von Brinckmann an Friedrich Schleiermacher. Für die Litteraturarchiv-Gesellschaft in Berlin herausgegeben. In 100 Exemplaren für die Mitglieder gedruckt (Mitteilungen aus dem Litteraturarchive in Berlin. Neue Folge 6), Berlin 1912, S.57; schon 1801 war Luise von Voss seine „einzige Gräfin“, ders. an Karoline von Berg, 22. 8(?). 1801, ungedruckt, GSA 5/1. Goethe gegenüber sprach er 1803 von seinem „Kindesrecht“ in diesem Haus. Ders. an Johann Wolfgang Goethe, 4. 10. 1803, in: Geiger 1896(a), S. 37. 18 Zur detaillierten Analyse dieser Korrespondenz s. Isselstein 1997. Sie vertritt u. a. die These, „dass sich Inhalt, Stil und Frequenz des Briefwechsels im Laufe der Jahre wandeln und dass beide Partner diese Veränderung ausdrücklich mit Rahel Levins Geselligkeitspraxis in Verbindung bringen.“Ebd. 1997, S. 184. Dabei muss m. E. noch betont werden, dass sich Levin Varnhagen gegen Brinckmanns Analyse ihrer Geselligkeit deutlich wehrte. 


\subsection{Salonièren oder Musen - Vom Kennenlernen zur Korrespondenz}

Wer liebte, bewunderte, verstand, feierte $\mathrm{u}$ verehrte Sie fortdem wie ich; ohne daß je einziger Misston den ewigen Einklang unsrer Denk= und Empfindungsweise gestört hätte. Gustav von Brinckmann an Rahel Levin Varnhagen ${ }^{19}$

Für alle vier hier ausgewählten Korrespondenzpartnerinnen, wie für viele andere, gilt, dass Brinckmann sie zunächst als geistreiche Gesprächspartnerin kennen und schätzen gelernt hatte und kaum einen Brief verstreichen ließ, in dem er nicht ihrer Intelligenz seine Reverenz erwies. Damit brachte er eine Eigenschaft ins Spiel, die nicht unbedingt zum Weiblichkeitsideal der Zeit gehörte, wusste sie aber meistens mit anderen Charaktereigenschaften wie Liebenswürdigkeit oder Grazie elegant zu ummänteln.

Dazu kam, dass Brinckmann es sich selbst nicht gering anrechnete, dass er an den Frauen ihre jeweiligen Besonderheiten erkennen und schätzen könne. Sein „Kennerblick“, so versicherte er ihnen und sich mehrfach, mache ihn zu ihrem ganz besonderen Freund. Dieser Blick beziehungsweise seine Art der Unterhaltung führten dazu, dass er sowohl „die kleine Levin“ wie „Miss Lilla“ und „Fräulein Luise“ als junge Frauen im Rahmen einer größeren Gesellschaft, von der sie sich abhoben, ,fand‘.

Auf Rahel Levin Varnhagen wurde er aufmerksam, weil sie ihm widersprach: „Ich besinne mich noch sehr gut - Sie wahrscheinlich nicht - eines Abends bei Herz, ehe wir näher bekannt waren, wo ich im Grunde etwas affectierte, worüber Sie mich gleich zurechtwiesen, und zwar mit dem Zusatz ,Ich sollte Ihre Freundin sein. Ich ließe Ihnen wahrlich so vieles nicht durchgehen. Wohl mir daß Sie es geworden sind“. ${ }^{20}$ Vom ersten Billet an kennzeichneten alle seine Texte Rahel Levin Varnhagen als eine für ihn reizvolle ,Autorität‘ im Gespräch, das Verhältnis zueinander war und blieb ein wesentliches Thema dieses Briefwechsels. ${ }^{21}$ Die Entwicklung von einer freundlichen Bekanntschaft

19 Gustav von Brinckmann an Rahel Levin Varnhagen, 10. 3. 1819, ungedruckt, SV 38.

20 Gustav von Brinckmann an Rahel Levin Varnhagen, 5. 4. 1794, ungedruckt, SV 38.

20 Jahre später bot er eine längere Darstellungsvariante, die nicht ihn, sondern Humboldt als den zur Ordnung Gerufenen und seine Freundin weniger als vorwitzig denn als Philosophin präsentierte, bei der er „ganz andere Wahrheiten hören, u. einsehen“ würde. 10. 3. 1819, ungedruckt, SV 38. Im Nachruf, den Ludmilla Assing drucken ließ, liest sich die Begegnung schließlich mythologisiert. Vgl. Brinckmann 1876.

21 Nach Isselstein wären bis 1794 Brinckmanns Liebesgeschichten Hauptthema gewesen, gefolgt von Nichtigkeiten, Bekannten, Klatsch und ihrer Freundschaft. Isselstein 1997, S. $184 \mathrm{f}$. Zwar ist ihrer quantitativen Analyse durchaus zuzustimmen, aber die kontinuierliche Betonung und Beschwörung ihrer ganz besonderen Freundschaft über 30 Jahre hinweg hinterlässt qualitativ den stärksten Eindruck. Ein weiteres Merkmal, mit dem Brinckmann 
zur wichtigsten Freundschaft ging schnell, und nicht zu geringem Teil über schriftliche und praktische Aufmerksamkeiten, die Rahel Levin Varnhagen einmal mit dem passenderen Begriff „attentionen“22 belegte. Neben den Begegnungen in anderen jüdischen Häusern, Debatten mit ihrer Familie oder gemeinsamen Besuchen öffentlicher Orte wie dem Theater - eine Leidenschaft, die er mit den anderen hier untersuchten Frauen nicht teilte - war das wesentliche verbindende Element von Anfang an das Gespräch mit ihr allein. Wie ein roter Faden zieht sich Brinckmanns Überzeugung durch die Briefe, dass hier eine einmalige Chance für eine echte Freundschaft unter Gleichgesinnten vorläge. Er gab sich durchgängig davon überzeugt, dass niemand Rahel Levin Varnhagen so schätzen könne wie er selbst und niemand ein so unerschütterliches Interesse an ihrer ganz eigenen Art zu denken habe. $\mathrm{Zu}$ diesem ,Glaubensbekenntnis‘ sollte er allen Krisen zum Trotz immer wieder zurückkehren. „Einzige Freundin“ nannte er sie schon im ersten Jahr ihrer Bekanntschaft und noch (oder wieder) im Nachruf. 23

Es ist nicht ganz genau zu rekonstruieren, wann Brinckmann die Bekanntschaft Lea Mendelssohn Bartholdys, geborene Lilla Salomon, machte, die er als seinen besten „Fund im Ozean der Itzigs“ bezeichnete. ${ }^{24}$ Die Nichte der

seine jeweils beste Freundin auszeichnete, könnte sein, dass er ihr „minuziös Rechenschaft“ über sein Tun ablegte. Isselstein 1997, S. 184. Dieser Befund lässt sich für den späteren Briefwechsel mit von Voss bestätigen.

22 Rahel Levin Varnhagen an Gustav von Brinckmann, 22. 9. 1793, ungedruckt, DV BdA, SV 207. Mit „attentionen“ war hier ein mitten in der Nacht verfasstes Billet gemeint. Hinzu kamen galante und komische Gedichte ebenso wie Aufmerksamkeiten, etwa ein medizinisches Hausmittel. Diese zugleich innige und praktische Anteilnahme wurde noch einmal besonders deutlich in der Zeit seiner Hamburger Krankheit. Levin Varnhagen schrieb „Ende Mai's“ 1800 mehrere dringliche Briefe, Brinckmann nach Berlin zu Markus Herz in die Behandlung zu holen. Sie pries sich zugleich als beste Pflegerin und machte ihm fast eine Liebeserklärung: „[...] wenn ich Sie verlöre, verlör’ ich einen großen Teil von mir selbst. Denn eine Seite kennen Sie in mir, die niemand kennt außer Sie.“ Zit. nach: Isselstein 1997, S. 198.

23 Gustav von Brinckmann an Rahel Levin Varnhagen, 4. 6. 1793, ungedruckt, SV 38. Brinckmann erklärte sein Kompliment mit einem Vergleich mit Friedrich II.: „Meine beste einzige Freundin!, (in dem Sinne wie man Friedrich den Einzigen sagt; nicht daß es nicht noch Friedrichs gäbe, aber nur solche nicht [...]).“An Rahel Levin Varnhagen, 25. 3. 1794, ungedruckt, SV 38. Obwohl sie sich explizit gegen das Epitheton „einzig“ wehrte, verteidigte er seine Zuschreibung und sollte auch noch mehrfach auf den Vergleich zurückkommen. 1819 beispielsweise gab er seiner Freude darüber Ausdruck, „daß solche Kleinigkeiten wie die grossen Weltbegebenheiten keinen wesentlichen Einfluß haben könnten auf eine sittlichgenialische Friedrich den Einzigen! wie Sie!“ Gustav von Brinckmann an Rahel Levin Varnhagen, 10. 3. 1819, ungedruckt, SV 38.

24 Gustav von Brinckmann an Lea Mendelssohn Bartholdy, 17. 5. 1799, ungedruckt, BA M. 
Salonièren Fanny von Arnstein, Sara Levy und Caecilie Wulff Eskeles war wie Brinckmann häufiger Gast im „Theezirkel der Tanten“, wo es vermutlich zur ersten Begegnung kam und wo, wie sie selber bestätigte, Brinckmann wesentlich dazu beitrug, ihre Zurückhaltung in Gesellschaft aufzugeben. ${ }^{25}$ „Die Itzigs“ verglich Brinckmann gern mit großen Phänomenen oder Organismen, wie besagtem Ozean oder aber der französischen Staatspost: „Hier in Frankreich ist das Prinzip der Itzigschen Familie, alles gemeinschaftlich zu lesen, so gar bis auf die ganze Staatsfamilie ausgedehnt worden, $\mathrm{u}$ daher ist hier die Post eigentlich als ein Theezirkel der Tanten anzusehen“. ${ }^{26}$ Zitate wie diese deuten auch darauf hin, dass Geselligkeit auch im Hause Itzig als Gemeinschaftsprojekt unternommen wurde. Brinckmann, der dies nicht selten genossen hatte, dankte seiner Freundin dennoch für das intimere Gespräch: „Auch mir, liebste Miß! wurden die Theezirkel Ihrer Tante nicht wenig dadurch interessant, dass Sie mich so willig $u$ freundlich Ihres vertrauteren Gesprächs würdigten“. ${ }^{27}$ Luise von Voss gegenüber bestätigt er „Miß Lillas“ Rolle als Ansprechpartnerin im Familienbetrieb Itzig so: „Diese kenne ich seit vielen Jahren, wo ich im Zirkel der Izigschen Damen wie Kind im Hause war; Durch sie wurde ich mit Arnsteins in Briefwechsel verflochten, kante die Geheimsten Familienanekdoten“. ${ }^{28}$ Er ging anscheinend davon aus, dass sie seine Briefe anderen Frauen des Hauses bekannt machte, da er gelegentlich bat, einen Brief nicht als „Zirkulärschreiben“ zu verwenden.29 Der Salon, in dem sie sich vermutlich kennenlernten, und wo Brinckmann nach seiner Abreise besonders vermisst wurde, war „T. Wolffs Zirkel, der so ziemlich leer, trotz dem größtenteils angefüllten Zimmer“.30 Gemeint ist Cäcilie Wulff Eskeles, die damit nicht, wie in der Literatur oft behauptet, erst in Wien Salonière wurde,

25 Gustav von Brinckmann an Lea Mendelssohn Bartholdy, 22. 3. 1798, ungedruckt, BA M. Früher sei sie ein „armes schüchternes Ding“ gewesen und „unausstehlich“ in ihrer Zurückhaltung, doch „denken Sie, jetzt, da man mir noch diesen Fehler vorwirft, bin ich wahrhafter Itzigscher Art dagegen." Lea Mendelssohn Bartholdy an Gustav von Brinckmann, 10. 12. 1798, ungedruckt, BA M.

26 Allerdings konkretisiert er den Vergleich als Kompliment: „Indessen hat die Republik nur diese Einheit $u$ Untheilbarkeit mit Ihrer Familie gemein, keineswegs die schwungvolle Nachsicht gegen alle ihre Mitglieder, u noch weniger die übertrieben Güte gegen Fremde.“ Gustav von Brinckmann an Lea Mendelssohn Bartholdy, 22. 3. 1798, ungedruckt, BA M.

27 Gustav von Brinckmann an Lea Mendelssohn Bartholdy, 20. 3. 1798, ungedruckt, BA M.

28 Gustav von Brinckmann an Luise von Voss, 23. 9. 1801, ungedruckt, GSA 5/26,4.

29 Gustav von Brinckmann an Lea Mendelssohn Bartholdy, 9. 2. 1799, diese Stelle ungedruckt, BA $M$.

30 Lea Mendelssohn Bartholdy an Gustav von Brinckmann, 24. 2. 1798, ungedruckt, BA M. 
sondern bereits in Berlin Gastgeberin eines gefüllten Salons war. ${ }^{31}$ Rahel Levin Varnhagen wie Lea Mendelssohn Bartholdy schätzte Brinckmann nach seiner ,Entdeckung' sowohl als Einzelperson wie auch als Teil eines Familienbetriebes, sandte Grüße an „alle Ihre Haus u Witz=genossen“ bzw. „alle Tanten einzeln". 32

Ein ähnlicher familiärer wie geselliger Zusammenhang bestand für ihn bei Luise von Voss und Karoline von Berg, bei denen er wohl davon ausging, dass sie einander seine Briefe zeigten, da er manchmal mitten im Brief die Adressatin wechselte. Luise von Voss hatte Brinckmann Ende 1797 auf einer Assemblée ihrer Großmutter ${ }^{33}$ kennengelernt, „wo ich die Freude hatte, Ihnen bis zum Einsteigen in den Wagen als Kammerherr zu dienen, blos weil - die Höflichkeit es doch anforderte, die Enkelin des Hauses zu unterhalten“. ${ }^{34}$ Wenn Brinckmann ihr ausführlich dankte, dass sie daraufhin die Korrespondenz eröffnet habe, heißt das in diesem Falle, dass sie angelegentlich eines Auftrags ihrer Mutter an Brinckmann ein paar Zeilen hinzugefügt hatte, was er als den Auftakt einer Korrespondenz zu deuten sich angelegen sein ließ.35

Dem geschätzten Zeilenumfang nach gehörte zu den wichtigsten Themen aller hier untersuchten Briefwechsel der jeweilige Briefwechsel beziehungsweise die Beziehung der beiden Briefpartner selbst. Von Anfang an dienten die Briefe als Pflege- oder Bindemittel der Beziehung, im Falle Luise von Voss' allerdings eher dazu, eine Freundschaft zu etablieren als sie zu halten. ${ }^{36}$ Durchweg betonte er seine unverbrüchliche Treue ebenso wie die Bedeu-

31 Cäcilie Wulff, spätere Cäcilie von Eskeles, geborene Zippora Itzig (1760-1836), war die Schwester Fanny von Arnsteins und wird als solche meist nur im Anhang zu dieser oder als Itzigtochter in Wien behandelt. In den Briefen der Salongesellschaft wird sie hingegen häufig als Gastgeberin schon in Berlin genannt. Eine Untersuchung ihres eigenen geselligen Engagements wäre lohnend.

32 Gustav von Brinckmann an Rahel Levin Varnhagen, 25. 10. 1793, auch bei: Isselstein 1997, S. 191. Ders. an Lea Mendelssohn Bartholdy, 18. 3. 1799, ungedruckt, BA M.

33 Sophie Cristine Dorothea Gräfin von Hårdt war bekannt als Gastgeberin anregender und gemischter Gesellschaften. Ein Teilnachlass ihrer umfänglichen Familienkorrespondenz - sie war viermal verheiratet - liegt in Berlin: GStA I. HA Rep NL Hordt.

34 Gustav von Brinckmann an Luise von Voss, 10. 4. 1799, ungedruckt, GSA 5/26,2.

35 Brinckmann versuchte wohl auf direktem und indirektem Wege den Kontakt zum Haus Berg-Voss zu festigen. Gewissermaßen ist auch der Teil seiner Briefe an die Tochter zum Briefwechsel mit der Mutter zu rechnen, der überwiegend Komplimente an letztere enthält, bzw. an „das Idealische Verhältnis zwischen Ihnen und ihrer trefflichen Mutter“. Gustav von Brinckmann an Luise von Voss, 26. 4. 1798, ungedruckt, GSA 5/26,1. Anders als Urte von Berg sehe ich ihn aber nicht primär als Verehrer der Mutter, sondern, gemessen an der Quantität und Intimität der Briefe als Freund der Tochter, der der Mutter als kluger Frau mit Einfluss seine Reverenz erwies. Berg 2008, S. 134.

36 Brinckmann reiste kurz nach dem Beginn der Bekanntschaft mit Luise von Voss nach Paris ab. Abgesehen von wenigen persönlichen Begegnungen, vor allem im Haus ihrer 
tung ihrer Briefe und Güte für ihn - eine Art Beschwörungsformel, die die Korrespondenz eher auf das gewünschte Intensitäts- und Intimitätsniveau zu bringen, als ein bereits erreichtes Niveau zu halten scheint.

Neben der Freude an ihren Briefen spricht noch eine anderes Motiv aus Brinckmanns Anhänglichkeit: die Freude an geistreichen Frauen selbst. Sie wird deutlich in seiner Ablehnung jeder „Etikettenhöflichkeit“, ${ }^{37}$ besonders der falschen Scham gebildeter Frauen, sich in Gesellschaft oder brieflich nicht zu äußern. Alle vier genannten Frauen ermutigte Brinckmann, ihre Gedanken selbstständig schriftlich zu formulieren. Sein Grundmotiv dafür formulierte er so:

\footnotetext{
Was aber die Korrespondenz betrifft, so halt' ich für ein sich wirkl. ausbildendes Mädchen durchaus keine Uebung für nüzlicher. Das eigene Schreiben ist bei weitem der beste Probirstein des eigenen Denkens. Manches liebenswürdige Geschöpfchen, das in der Geselschaft wegen eines angenehmen Geplauders für äusserst geistreich gilt, und auch in der That so scheint, wird sich oft mächtig wundern, wie wenig Inhalt und Verbindung ihre Ideen haben, wenn Sie plözlich versuchen sollte, sie schriftlich zu entwickeln. ${ }^{38}$
}

Der Diplomat war ein wesentlicher Agent der geselligen Bildung insofern, als er alle vier Frauen mit Literatur versorgte, sie zu bevorzugten Leserinnen seiner eigenen Gedichte machte, zu Korrekturen ermunterte und auch ihre Texte korrigierte. In der Brinckmannschen Formulierung dankte er den Damen für die „schwesterliche Aufnahme seiner Muse“ und versprach, den ihren ebenfalls einen Tempel zu errichten. ${ }^{39}$ Während er sich mit der Überzeugung, dass Frauen selbst schreiben sollen, implizit und explizit gegen zeitgenössische Schicklichkeitsforderungen wehrte, sollte er sich weitaus ambivalenter äußern, wenn es um die Veröffentlichung von Texten ging [s. V.2.4].

\footnotetext{
Mutter, entwickelte sich die Freundschaft zunächst als Brieffreundschaft. Allerdings wurde, über das Medium Brief, die Bindung zu Luise von Voss so stark, dass nach Brinckmanns Rückkehr aus Paris sie, und nicht eine seiner alten Freundinnen, auch nicht Rahel Levin Varnhagen, zu seiner bevorzugten Gastgeberin wurde.

37 Gustav von Brinckmann an Luise von Voss, 10. 4. 1799, ungedruckt, GSA 5/26,2.

38 Gustav von Brinckmann an Luise von Voss, 10. 4. 1799, ungedruckt, GSA 5/26,2.

39 So an Luise von Voss, [vermutlich Dezember] 1797, ungedruckt, GSA 5/26,1. [Eingeordnet als dritter Brief der Korrespondenz]. Brinckmann schickte Luise von Voss ihre Verse zurück mit dem Vermerk: „Sie haben unleugbar poetisches Genie“, er habe nur das Silbenmaß korrigiert. Ebd.
} 


\title{
1.2 Wochenschriften und Billets, Witz und Tugend - Unterschiede in Form und Ton
}

\author{
,Was wäre denn die nähere Freundschaft, wenn sie nicht an Kleinigkeiten \\ mehr Theil nähme als an Weltbegebenheiten?‘ schrieb mir Einmal die kleine Levin \\ bei einer ähnlichen Gelegenheit, und ihre Bemerkungen der Art \\ sind selten ohne Wahrheit. \\ Gustav von Brinckmann an Luise von Voss, $1800^{40}$
}

Brinckmann nannte seine Briefe an Luise von Voss nicht ohne Grund „Wochenschriften“ oder „Quart-Band“:41 Der erste auffällige Unterschied zwischen dieser und allen anderen Korrespondenzen aus seiner Pariser Zeit liegt im Umfang und in der raschen Folge der Brinckmannschen Briefe an die Aristokratin. ${ }^{42}$ Aber auch das Format jedes einzelnen Briefes macht ihn von solchen an Levin Varnhagen oder Mendelssohn Bartholdy unterscheidbar. Ob er von Migräne oder einer Kriegserklärung berichtete, vier, acht oder 32 Blatt füllte, Brinckmann kam immer exakt am Ende eines Quartbogens zum Schluss. Die Briefe an Luise von Voss, und nur diese, waren zudem durchgehend nummeriert. ${ }^{43}$

Diese formalere Herangehensweise spiegelt sich auch in der Briefdramaturgie, seine Briefe an die Gräfin Voss enthalten längere Herleitungen, ausführlichere Begründungen und Berichte. Neben standardisierten Verbeugungen vor der jeweiligen Gesprächskultur - Komplimente dieser Art finden sich in Abstufungen in allen seinen Briefen an weibliche Korrespondenzpartnerinnen - ist auffallend, dass Brinckmann verschiedenen Frauen gegenüber unterschiedliche Vorzüge des Gesprächs zu schätzen angab. Das wesentliche verbindende Element der Korrespondenz mit Levin Varnhagen, das sowohl

40 Gustav von Brinckmann an Luise von Voss, 15. 7. 1800, ungedruckt, GSA 5/26,3.

41 Einen Brief von 14 Bogen, also 56 Seiten, der unter anderem das Staël-Porträt enthielt, nannte Brinckmann selbst eine „ungeheure Depesche“ und „Quartband“. „Wochenschrift“ nannte er seine Reisebeschreibungen, weil sich Prosa und Poesie abwechselten. Gustav von Brinckmann am Luise von Voss, 10. 4. 1799 und 12. 4. 1799, ungedruckt, GSA 5/26,2. „Wochenschrift“" nach: 25. 2. 1800, ungedruckt. GSA 5/26,3.

42 Der Umstand, dass so viele Briefe überliefert sind, ist sicher auch der Empfängerin geschuldet bzw. der Tatsache, dass die Papiere auf dem Gut Giewitz bleiben konnten und weder in der Diplomatenkutsche durch Europa fahren mussten noch nach Polen ausgelagert wurden.

43 Die Nummerierung beginnt mit Brinckmanns Abreise nach Paris und endet mit dem letzten Brief. Ganz selten nur hat sich der Diplomat dabei verzählt, was ebenfalls auf ein Briefbuch deutet. Zwar nummerierte Brinckmann auch gelegentlich Briefe an andere Brieffreundinnen in Berlin, aber nur, wenn diese auf Reisen waren. Er hielt die Nummerierung nicht für die gesamte Korrespondenz aufrecht, wie er es im Falle von Voss tat. 
theoretisiert wie kontinuierlich eingesetzt wurde, war der Witz. Von Anfang an war ihr Briefgespräch neben Ironie und Hyperbeln von Wortspielen vor allem aus dem Bereich der Religion geprägt, allerdings durchaus konfessionsübergreifend. Bereits die erste größere Büchersendung hatte Brinckmann von dem Wunsch begleiten lassen: „Ich schicke Ihnen hier 12 Bde Romane!! aber ich darf Sie wol nicht gut bitten, sie nicht so wie Christus die Apostel in alle Welt auszusenden um die Heiden zu bekehren, indem mir der Verlust der Apostel unlieber wäre wie das Heidenthum“. ${ }^{44}$ Rahel Levin Varnhagen verwendete, wenn auch nicht in seinem Ausmaß, ähnliche Metaphern und Vergleiche. Ihr Kommentar zur Häufung von Taufen in Berlin „Leider bleibt kein Stein, kein Jude aufeinander“, aus unbekanntem Grund von Varnhagen für den Druck gestrichen, war eine durchaus passende Antwort auf Brinckmanns vorangehende Frage: „Stürzt denn der ganze Tempel Salomonis auf Einmal in Trümmer"?45 Eine andere bemerkenswerte Stelle, die Varnhagen für den Druck kürzte, betraf einen Vergleich mit Friedrich II., den Rahel Levin Varnhagen selbst aufstellte: „Ich bin noch stolz, wie Friedrich II., der doch kein Jude war, und also um so viel leichter etwas Besseres sein konnte - noch immer mit allem einverstanden und mit nichts“.46 Der Stil ihrer Korrespondenz mit Brinckmann wurde zurecht als „Freigeisterei“ 47 und Grenzüberschreitung bezeichnet, wobei aber nochmals betont werden muss, dass gerade die (un)religiösen Wortspiele kein Spezifikum dieses Briefwechsels waren, sondern dass andere Mitglieder der Salongesellschaft sich auf ähnliche Weise verbal von der Tradition distanzierten, beispielsweise Lea Mendelssohn Bartholdy, die traditionell lebende Juden gelegentlich als „die Waßerscheuen“ bezeichnete. ${ }^{48}$

44 Gustav von Brinckmann an Rahel Levin Varnhagen, 16.1.1793, BA V. Dies Billet ist in der SV mit Datum 16.6. 1793 einsortiert.

45 Rahel Levin Varnhagen an Gustav von Brinckmann, 11. 2. 1799, diese Stelle ungedruckt, BA V. Gustav von Brinckmann an Rahel Levin Varnhagen, 7. 1. 1799, ungedruckt, SV 38.

46 Rahel Levin Varnhagen an Gustav von Brinckmann, 1808, hier zitiert nach der Abschrift Brinckmanns für Luise von Voss, 20. 1. 1808, ungedruckt, GSA 5/26,11. Vgl. Rahel Levin Varnhagen an Gustav von Brinckmann, 8. 1. 1808, in: GW I, S. 329 f. In der Druckfassung fehlen die für den Tonfall dieser Briefbeziehung wesentlichen Elemente: der witzige Vergleich, die Anspielung auf das Judentum und das Widerständige.

47 Isselstein 1997, S. 191. Sie bezeichnet die Art der Konversation auch als „transgressives Umkehrspiel“. Ebd., S. 192.

48 Lea Mendelssohn Bartholdy an Gustav von Brinckmann, 10.12. 1798, ungedruckt, BA M. 
Wenn nicht ein förmliches „Es schickt sich“ in der Welt herumliefe und den Ton angäbe, so wäre ich jetzt bei Ihnen.

Rahel Levin Varnhagen an Gustav von Brinckmann ${ }^{49}$

Auch andere Grenzüberschreitungen wurden brieflich in Erwägung gezogen. Brinckmann ,zitierte‘ in seiner brieflichen Selbstdarstellung Posen eines Liebhabers, etwa wenn er Levin Varnhagen entgegenritt, oder einen ihrer Briefe noch auf der Rampe vor seinem Haus las. ${ }^{50}$ Sie antwortete nicht selten in ähnlich übertreibender Manier. ${ }^{51}$ Dies Spiel mit den Rollen darf nicht darüber hinwegtäuschen, dass beide, aller Freigeisterei zum Trotz, Schicklichkeitsregeln, wenn auch widerwillig, einhielten:52 Brinckmann konnte einen unangekündigten Besuch bei ihr zwar noch mit Sehnsucht entschuldigen, sie ihm aber eine Medizin nicht bringen, wenn keine begleitende Freundin oder „chaperonneuse“ verfügbar war. ${ }^{53}$ Ernst schrieb sie: „Wenn ich ein Mann wäre würd ich Sie besuchen; rühmen Sie die Einrichtung wenn Sie können, ich kann nicht“. 54 Die Überwindung der Standes-, Schicklichkeits- und Geschlechtergrenzen hinweg blieb letztlich auf den verbalen Bereich beschränkt, und konnte vielleicht eben deswegen über Jahre fortgesetzt werden.

Die Briefe Lea Mendelssohn Bartholdys an Brinckmann sind ihrerseits wegen des in ihnen zum Ausdruck kommenden Selbstbewusstseins der 20Jährigen bemerkenswert, beispielsweise, wenn sie den Schweden für seine „preußisch-militärische Genauigkeit“ im Beantworten ihrer Fragen lobte und

49 Rahel Levin Varnhagen an Gustav von Brinckmann, Dez. 1793, in: GW I, S: 67. Der Brief ist in der Ausgabe fälschlich auf 1794 datiert.

50 Gustav von Brinckmann an Rahel Levin Varnhagen, 21. 8. 1795, ungedruckt, SV 38. Bei einer anderen Gelegenheit schrieb er so ekstatisch von einer Zollstation, dass der Einnehmer gedacht habe, er schriebe an seine Braut. 27. 5. 1794, ungedruckt, ebd.

51 So dankt sie für galante Verse mit dem Zusatz: „[...]wie könnt ich vor schreck leben bleiben, müsst ich so etwas von Ihnen in prosa lesen!“, Rahel Levin Varnhagen an Gustav von Brinckmann, 20. 8. 1793, ungedruckt, SV 207.

52 Die Schicklichkeitsregeln wurden u. a. durch Koketterie gebrochen. Einen sehr langen und persönlichen Brief endete sie: „Nun hör ich auf; ein Mädchen, die erzogen ist, muß mit keinem fremden Herrn von der Gesandtschaft $z u$ aufrichtig werden, und zeichnete sie ihn in Gesellschaft noch so sehr aus." Rahel Levin Varnhagen an Gustav von Brinckmann, 15. 7. 1794, SV 38. Diesen Absatz strich Varnhagen für den Druck.

53 „[...] von ungefähr begegnete ich Ihren jungen Bruder, der mir erzählte, Sie wären so eben angekommen. Ich flog Ihre Treppe hinauf um Sie zu sprechen, wiewohl ich selbst die kleine Indiskretion davon fühlte.“ Gustav von Brinckmann an Rahel Levin Varnhagen, 3. 8. 1793, ungedruckt, SV 38. „Chaperonneuse“ nach: Rahel Levin Varnhagen an Gustav von Brinckmann, undatiertes Billet, ungedruckt, SV 38.

54 Rahel Levin Varnhagen an Gustav von Brinckmann 25.11. 1793, auch in: GW I, S. 63, hier aber nach dem Original zitiert, BA V. 
zugleich genauere Antwort einforderte. ${ }^{55}$ Sie spielte mit Brieftraditionen und Metaphern, gab Themen vor, die sie interessierten und ironisierte zugleich ihre eigene Neugier. Als er ihr einmal zwei Monate nicht geschrieben hatte, gab sie ihrer Befürchtung Ausdruck, „Ihr außerordentlicher, denkender, geistreicher, heller, großer, feiner, witziger, kluger, etc. etc. etc. etc. etc. etc. etc. etc. etc. etc. etc. etc. etc. etc. etc. etc. etc. etc. etc. Kopf hätte - ach! unter der guillotine bluten müssen“. 56

Lea Mendelssohn Bartholdys Billets gehören, gemeinsam mit denen ihrer Cousine Henriette Arnstein Pereira, zu den spielerischsten und frechsten, die der Diplomat erhielt. ${ }^{57}$ Sie scheute weder Klatsch noch deutliche Worte, etwa wenn sie die Fähigkeit Schlegels zur ehelichen Treue analysierte (s. u.). Vor allem sind ihre Briefe gekennzeichnet durch Anspielungen auf das Zeitgeschehen, direkte Fragen nach seiner Meinung und gelegentlichen deutlichen Widerspruch zu dieser. Sie war es, die ihn zu ihrem Berichterstatter aus der Pariser Welt machte, nicht er, der sich dazu ernannte:

\begin{abstract}
Erzählen Sie mir doch etwas von dem schönen Museum, in dem die aus Italien gekommenen Kunstwerke geordnet sind, vom Theater, von Ihren interessanten Bekanntschaften: ich möchte so gern mit Ihnen in Paris eingewohnt sein! - Was sagen Sie denn zu dem Tod des guten Fürsten Reus? zu der verwitweten Prinzeßin u doch nicht Prinzeßin Marianne? zu Baron Brentanos Reise in die elsässischen felder? (Aber nicht in die bei Paris); zu Friedrich Schlegels neuem Roman Lucinde, über den die Kritik gar arg herfällt? $\mathrm{u}$ zu meinen Quodlibetfragen endlich? - nur noch eine: was giebts hübsches u neues in Ihrer litterarischen Welt?58
\end{abstract}

In Luise von Voss hingegen behauptete Brinckmann von vornherein einen moralischen Maßstab zu erkennen und zu schätzen. Eine nicht näher definierte Tugend, die sie für ihn verkörperte, wurde zur Konstante ihrer Freundschaft und vermutlich auch der Anlass für ausführliche Erörterungen über Charakter,

55 Lea Mendelssohn Bartholdy an Gustav von Brinckmann, 10. 12. 1798, ungedruckt, BA M. 56 Lea Mendelssohn Bartholdy an Gustav von Brinckmann, 24. 7. 1798, ungedruckt, BA M. Das „Etc.“ wurde genau eine Briefzeile wiederholt.

57 Mit diesem Briefwechsel im Blick muss auch Felix Gilbert widersprochen werden, der ihren Briefstil als „preziös“ abwertete. Felix Gilbert: Bankiers, Künstler und Gelehrte. Unveröffentlichte Briefe der Familie Mendelssohn aus dem 19. Jahrhundert, Tübingen 1975, S. XXXII. Anders als oft dargestellt, erhielt Lea Mendelssohn Bartholdy sich diesen ungezwungenen und amüsanten Umgangston bis ins Alter. Wie die von Klein veröffentlichten Briefe der Jahre 1811-1822 zeigen, kehrte sie, wie Rahel Levin Varnhagen, auch über die Entfernung nach Schweden immer wieder zum vertrauten, bisweilen frechen Umgangston zurück, dazwischen geschaltete Familienberichte ironisierte sie als „das putige Geschwätz“. Lea Mendelssohn Bartholdy an Gustav von Brinckmann, 6. 2. 1816, in: Klein 2007, S. 257. 58 Lea Mendelssohn Bartholdy an Gustav von Brinckmann, 15. 4. 1799, ungedruckt, BA M. 
Menschlichkeit und individuelle wie gesellschaftliche Moral im Briefwechsel.59 Anders formuliert, es wurde in diesem Briefwechsel auffallend wenig gelästert. Der Informationsfluss über gemeinsame Bekannte war zwar beständig, nahm aber nur sehr selten einen spöttischen Tonfall an. In auffallendem Gegensatz zum früheren Briefwechsel mit Rahel Levin Varnhagen versuchte Brinckmann Luise von Voss ein Kompliment zu machen mit der Bemerkung, daß sie nicht witzig sei. ${ }^{60}$ Ihre Antworten sind lang und gewissenhaft, deuten auf eine intensive, internationale Lektüre und großes Bildungsinteresse. Ihr Stil ist bisweilen langatmig und moralisierend, sie wusste ihre Meinung aber durchaus prägnant $\mathrm{zu}$ formulieren, wenn sie auch sich und Brinckmann hinterher entschuldigend fragte, ob sie „eine zu strenge nemesis“ gewesen sei. ${ }^{61}$

\section{Paris als Zäsur}

Der Unterschied in der Korrespondenzhaltung manifestierte sich bereits mit Brinckmanns Abreise nach Paris. Luise von Voss erhielt ausführliche Reiseberichte, die seine Schwierigkeiten mit Verkehrsmitteln ebenso behandelten wie Bekanntschaften und persönliche Empfindungen dies- und jenseits des Rheines. An Rahel Levin Varnhagen ist von der Reise kein Brief überliefert und an Lea Mendelssohn Bartholdy erging eine einmalige, eher ironische Zusammenfassung im Telegrammstil: „eine heftige Migräne, eine ähnliche Liebe zu der kleinen Niemeyer, erbärmliche Wege und der noch erbärmlichere Ludwig 18.

59 Ein Teil der wiederholten Anregungen Brinckmanns, sich intellektuell zu betätigen, könnte im Falle Luise von Voss' dem Umstand geschuldet sein, dass sie zu Beginn der Korrespondenz erst 17 Jahre alt war. Für den Altersunterschied von 16 Jahren ist der Briefwechsel allerdings äußerst partnerschaftlich gehalten, Brinckmann kehrte zu keinem Zeitpunkt den poetischen oder gesellschaftlichen Lehrer heraus, seine Literaturtipps bewegen sich in demselben Rahmen und Format wie in anderen seiner Briefwechsel und die Diskussion moralischer wie gesellschaftstheoretischer Fragen, in denen er sie als gleichwertige Partnerin adressierte, nahm hier wesentlich mehr Platz ein als in Briefwechseln mit älteren Freundinnen und Freunden.

60 Gustav von Brinckmann an Luise von Voss, 18. 12. 1799, ungedruckt, GSA 5/26,2. Ähnlich hatte er ihrer Mutter bestätigt: „Der Grosse Charakter ist immer schön u. edel u. hält es unter seiner Würde die Bosheit zu Hülfe zu nehmen, um witzig zu scheinen.“ Gustav von Brinckmann an Karoline von Berg, 13. 3. 1797, ungedruckt, GSA 5/01.

61 Ihre Briefe aus Giewitz enthielten schließlich breit gefächerten Literaturbestellungen, so begann sie das Jahr 1804 etwa mit einer Bestellung von „2 pfd The“ und einer beigelegten Bücherliste, die u.a. „Büsch, Meusel, Hülse, Euripides“, David Hume, Lessings sämtliche Werke, und Tiecks Minnelieder enthielt. Luise von Voss an Gustav von Brinckmann, 1. 1. 1804 und 8. 3.1804, ungedruckt, BA V. 
der alle Pferde in Beschlag genommen“.62 Diesen Stil hielt Brinckmann auch in Paris aufrecht. Obwohl er in seinen Briefen an „Lilla“ fast dieselben Schwerpunktthemen behandelte wie gegenüber von Voss, waren die Briefe meist auffallend kürzer, die Wertungen prägnanter und pointierter als in den zeitgleich verfassten „Quartbüchern“ an die Aristokratin.

Generell ist für Brinckmanns Pariser Aufenthalt auffallend, dass man trotz seiner Funktion als gesellschaftlich aktiver Diplomat - über die Salons, die in Paris in den Jahren 1797/98 existierten, fast nichts erfährt.63 Schwärmerisch und ausführlich schrieb er von „deutschen Zirkeln“, als Reminiszenz an Berlin oder etwa vom Ehepaar Humboldt. Am ehesten äußerte sich Brinckmann in kulturvergleichenden Anmerkungen, und hier wird ein weiterer Unterschied zwischen den Korrespondenzen deutlich: Der zeitgenössischen Verwendung von Stereotypen entsprechend charakterisierte Brinckmann Paris als „frivol“ - wobei der Begriff allerdings je nach Adressatin bei ihm eine unterschiedliche Wertung erhielt: Mit Lea Mendelssohn Bartholdy ,lästerte“ Brinckmann über die vornehme Welt Paris' und die modischen Ansprüche der vornehmen Damen, fasste seinen Eindruck aber positiv zusammen: „Der Franzos lässt sich zwar seinen Gott und seinen König, aber nicht sein Modegenie und seine elegante Frivolität nehmen“. ${ }^{64}$ Rahel Levin Varnhagen gegenüber definiert er Frivolität als rhetorisches Mittel, das man zu nutzen wissen müsse und das auch in Berlin einige beherrschten: „Aber Sie, Gottlob! verstehen sich doch auch auf Frivolität, ohne deswegen im ernsten Gespräch nicht zu gestehen, daß nur bei denjenigen ächtes Heil zu suchen sei, die Goethen' in der Ursprache lesen können““.65 Bei Luise von Voss hingegen kontrastiert er die „Sitten des frivolen Volkes“ in Frankreich mit der Ehrfurcht, die ihm ihre, Lui-

62 Gustav von Brinckmann an Lea Mendelssohn Bartholdy, 17. 2. 1798, ungedruckt, BA M. 1797, als die überlieferte Korrespondenz mit Lea Mendelssohn Bartholdy einsetzte, muss das Verhältnis zu ihr bereits sehr vertraut gewesen sein, man schrieb sich unverhohlen witzige Kommentare über Dritte wie über sich selbst. Trotz dieser und ihres offen eingestandenen großen Interesses an Paris kam es aber anscheinend zu keiner vergleichbaren Regelmäßigkeit.

63 Über Julie Récamier (1777-1849), wurde gar nicht - und aus dem Haus de Staël vor allem der Charakter der Hausherrin diskutiert.

64 Gustav von Brinckmann an Lea Mendelssohn Bartholdy, 9. 2. 1799, ungedruckt, BA M. Brinckmanns Briefe verbanden geschickt solche Aphorismen mit Elementen der Modereportage und Klatsch: „Une toilette fraiche - das heißt ein Kleid das noch nie angewesen, ist eine unerlässliche Bedingung für jede, die in einer Gesellschaft des femmes du bon ton leben will. Die recht Eleganten wechseln mehrmals des Tages, u nur so lässt es sich erklären, daß die Bürgerin Buonaparte in Zeit von etwa 5 Monaten sich 340!! neue Kleider machen ließ.“ Ebd.

65 Gustav von Brinckmann an Rahel Levin Varnhagen, 25. 3. 1798, ungedruckt, SV 38. 
ses „trefliche Deutschheit“ eingeflößt habe, und bei der er schwören wolle, dass er niemals „französisch“ würde.66 Wenn man die These Ruth Floracks übernimmt, nach welcher der Rekurs auf nationale Stereotype der Sicherung einer gemeinsamen Kommunikationsebene dient, könnte man sagen, dass Brinckmann sich mit der unterschiedlichen Nutzung des Begriffspaars „Frankreich-frivol“ mit jeder Frau eine eigene Kommunikationsebene schuf. ${ }^{67}$

Sie, Humboldts, Burgsdorff und ich in Paris beisammen!

Bei welchem Nachtthee hätten wir solche Plane nur zu träumen gewagt!

Gustav von Brinckmann aus Paris an Rahel Levin Varnhagen68

Ein regelmäßiger Briefwechsel mit Rahel Levin Varnhagen scheint in seiner Pariser Zeit nicht zustande gekommen zu sein. ${ }^{69}$ Die briefliche Flaute war möglicherweise darin begründet, dass beide hofften, dass Rahel Levin Varnhagen zu dem deutschen Zirkel in Paris dazustoßen könne bzw. in der Enttäuschung, dass sie erst nach Paris kommen konnte, als Brinckmann schon fort war. ${ }^{70}$ Möglicherweise lässt sich die geringe Briefdichte auch auf die Überzeugung Rahel Levin Varnhagens zurückführen, dass „man [...] nur viel und mit Annehmlichkeit schreiben [kann], wenn man denselben Vormittag Antwort haben kann“, wenn also der Brief einem Gespräch nahe komme. ${ }^{71}$ Tatsächlich lesen sich die wenigen überlieferten Briefe so, als lägen nicht über 1.000 Meilen zwischen ihnen. Wenn er schrieb, begann Brinckmann in medias res, unmittelbar, ohne Anrede und Einleitung. „Was ist denn das für ein verfluchter Paradiesvogel, den die Unzelmann in den Haaren gehabt haben soll, und der mir als ein Beweis zitiert wird, wie barok man sich in Berlin kleidet"?72 Die

66 Gustav von Brinckmann an Luise von Voss, 28. 11. 1799, ungedruckt, GSA 5/26,2. Mit dieser Interpretation von „frivol“, allerdings nur mit dieser, nutzt Brinckmann ein um 1800 gängiges nationales Stereotyp.

67 Ruth Florack: Tiefsinnige Deutsche, frivole Franzosen. Nationale Stereotypen in deutscher und französischer Literatur, Stuttgart 2001, S. 46.

68 Gustav von Brinckmann an Rahel Levin Varnhagen, 29. 3. 1799, ungedruckt, SV 38.

69 Von Anfang 1798 bis Sommer 1801 sind 18 Briefe von ihm überliefert und diese deuten nicht auf eine große Anzahl verlorener.

70 Die vielfach geäußerten Wünsche, alle Freunde in der französischen Hauptstadt zu einem Nachttee zu versammeln, blieben Rhetorik, da von keiner praktischen Hilfe begleitet. Rahel Levin Varnhagen bekam erst im Juli 1800 Gelegenheit zu reisen, als Begleitung der Gräfin Schlabrendorf, die nach Paris fuhr, um die Folgen eine Schwangerschaft für die Berliner „unsichtbar“ zu halten.

71 Rahel Levin Varnhagen an Gustav von Brinckmann, 11. 1. 1813, in: GW II, S. 77.

72 Gustav von Brinckmann an Rahel Levin Varnhagen, 25. 11. 1798, ungedruckt, SV 38. Die Bemerkung bezieht sich auf eine Kopfbedeckung der Schauspielerin. 
überlieferten Briefe deuten weiterhin auf eine unveränderte Nähe der Ansichten oder zumindest den Glauben daran. Brinckmann räsonierte demnach lieber retrospektiv über das „Dachstübchen“, in dem er „mit seinem Geist“ anwesend sei, als von Paris zu berichten.

Seine Verherrlichung dieses „Dachstübchens“, die mit dem ersten Brief aus Paris begann und nach der er „nie aufhören werde, die Stunden zu segnen, die ich einst in dem Winckel Ihres Kanapees verplaudert habe“, ${ }^{73}$ lässt sich aber auch so lesen, dass er seine Zeit mit ihr als großartiges, aber unwiederholbares Erlebnis charakterisierte: „Eine solche Freundin - wo und wann werde ich sie wieder finden“? ${ }^{74}$ Zwar kann Nostalgie bis zu einem gewissen Grad als Stilmittel aller seiner Briefe aus Paris gelten, insofern er auch dem „traulichen Kabinette“ der Frau von Berg und dem „Theestündchen“ bei ihrer Tochter rückblickend verklärende Komplimente machte. ${ }^{75}$ Das „Dachstübchen“ aber wurde deutlich schon vor 1800 zum Erinnerungsort. ${ }^{76}$

Der wesentliche inhaltliche Unterschied zwischen den Korrespondenzen lag schließlich in der Behandlung politischer Themen bzw. im gewollten Fernhalten solcher aus den Briefwechseln mit den jüdischen Freundinnen. Zwar schrieb er emphatisch über seine Gefühle auf dem „klassischen Boden der Revolution“, aber kaum über Politik. ${ }^{77}$ Während Luise von Voss zumindest gelegentlich einen Eindruck von den „Trakasserien“ bekam, in die er an der schwedischen Botschaft verwickelt wurde, und ausführlichere Betrachtungen zum deutsch-französischen Gesellschaftsvergleich lesen konnte, blieb es mit Lilla nur beim Witzeln über Bonaparte und dem ausdrücklichen Wunsch: „Übrigens wollen wir übereinkommen, liebe Lilla! unsre Briefe durch keine Politik zu entedeln“!78 Ihr Kommentar zu diesem Wunsch ist nicht überliefert. Ihre Nach-

73 Gustav von Brinckmann an Rahel Levin Varnhagen, 7. 10. 1798, SV 38, in: Wachtmeister 1871, S. 4

74 Der Brief spricht von der Freundschaft in der Vergangenheit, liest sich wie ein Nachruf, und nimmt tatsächlich einige Formulierungen des Nachrufes von 1834 vorweg. Gustav von Brinckmann an Rahel Levin Varnhagen, 7. 10. 1798, in: Wachtmeister 1871, S. 4 f.

75 Gustav von Brinckmann an Luise von Voss, 16. 11. 1798 und 29.1.1799, ungedruckt, GSA 5/26,1 bzw. 5/26,2.

76 In der Forschung wurde Rahel Levin Varnhagen selbst als deutscher Erinnerungsort diskutiert, der mit verschiedenen Vorstellungen zu füllen war. Barbara Hahn: Rahel Levin Varnhagen, in: Francois / Schulze. 2001, Bd 3., S. 503-515. Im Zusammenhang dieses Kapitels ist allerdings zunächst die Perspektive der (ehemaligen) Gäste gemeint, die sich nostalgisierend an die Dachstube erinnerten und sie so in die Vergangenheit rückten. 77 Gustav von Brinckmann an Luise von Voss, 8. 3. 1798, ungedruckt, GSA 5/26,1. „Klassisch“ ist doppelt unterstrichen.

78 „Trakasserien“ nach: Gustav von Brinckmann an Luise von Voss, 16. 11. 1798, ungedruckt, GSA 5/26,1; „entedeln“ nach: ders. an Lea Mendelssohn Bartholdy, 20. 3. 1798, ungedruckt, BA $M$. 
fragen deuten aber auf ein anders gelagertes Interesse. Zum überwiegenden Teil lesen sich Brinckmanns Briefe aus Paris an die jüdischen Freundinnen wie eine konsequente Fortschreibung des leichten Umgangstones aus dem Salon. ${ }^{79}$

\section{3 „In Rücksicht der intimsten Freunde“ - Gemeinsame Bekannte, unterschiedliche Behandlung}

Auch in der Diskussion über Personen, die in allen Korrespondenzen einen wesentlichen Platz einnimmt, lassen sich bemerkenswerte Ähnlichkeiten und Unterschiede feststellen. Erwartungsgemäß fielen im Briefwechsel mit Luise von Voss mehr aristokratische Namen, aber auch in den Briefen mit den jüdischen Freundinnen wurden Personen des Hofes zum Teil aus guter Kenntnis besprochen. So ist am diskutierten Personenkreis abzulesen, an welchen Stellen und wie weit sich die Interessen und auch die Lebenskreise von Hofdame und jüdischen Kaufmannstöchtern in Berlin um 1800 überschneiden konnten. $\mathrm{Zu}$ den gemeinsamen, diskutierten Bekannten aller hier genannten Gastgeberinnen gehörten so unterschiedliche Persönlichkeiten wie die Aristokraten Wilhelm von Humboldt, Wilhelm von Burgsdorf, Fürst Heinrich Reuß, Prinz Louis Ferdinand, die Autoren Friedrich und August Wilhelm Schlegel und die Autorin Germaine de Staël ebenso wie die Salonfrauen Henriette Mendelssohn, Dorothea Mendelssohn Veit Schlegel, Marianne Meyer Eybenberg, Fanny von Arnstein und Henriette Arnstein Pereira.

Neue Erscheinungen auf dem Literaturmarkt, wie Friedrich Schlegel, wurden als Autor wie als Persönlichkeit mit allen diskutiert. Brinckmann stellte sich dabei, ohne auf eigene Meinung zu verzichten, auf den Lieblingsautor seiner jeweiligen Korrespondentin ein, den er dann zu „unserem gemeinschaftlichen Lieblingsschriftsteller“ ernannte. ${ }^{80}$ Mit Rahel Levin Varnhagen diskutiert er vor allem Goethe, mit Luise von Voss Jean Paul, mit Lea Mendelssohn

79 Ein Vergleich mit einem anderen Mitglied des deutschen Zirkels gibt Anlass zu der Frage, inwieweit diese Vermeidungsstrategie spezifisch für Brinckmann war. Ein hochinteressanter Brief Wilhelm von Burgsdorfs thematisiert unter anderem die Lage der Juden in Paris. Vgl. Wilhelm von Burgsdorf an Rahel Levin Varnhagen, 11. 3. 1798, in: Cohn 1907, S. 127-139. Burgsdorf ist meines Wissens der einzige Aristokrat, der dieses Thema in einem Brief an eine jüdische Gastgeberin sachlich anschnitt und sie direkt darauf ansprach: „Die Religion Ihrer Väter ist hier nichts weniger als geachtet, - das wollen Sie ja aber auch gar nicht, man soll nur nicht daran denken, daß sie die Ihrige ist.“ Ebd. S.133. Andere Briefe dieser Art von nichtjüdischen Salongästen sind mir nicht bekannt.

80 Gustav von Brinckmann an Luise von Voss, über Jean Paul, 26. 4. 1798, ungedruckt, GSA $5 / 26,1$. 
Bartholdy ein breites Spektrum zeitgenössischer Schriftsteller. Im Gesamtblick dieser vier Korrespondenzen erscheinen ,die Berliner Salons‘ weniger einem speziellen Kult anhängend, als auf dem neuesten Stand sich bewegend.

Brinckmann warb für weibliches Selbstdenken und weibliches Schreiben auch dadurch, dass er sich positiv über etablierte Autorinnen äußerte und seine gleich gesinnten Freundinnen zumindest brieflich miteinander bekanntmachte. Eine Autorin und Salonière, die Frau seines Pariser Vorgesetzten Germaine de Staël, hatte er ,studiert' und diskutierte sie mit allen hier genannten Frauen begeistert. ${ }^{81}$ „Die Staël“ war nicht nur das Beispiel, an dem weibliche Grenzüberschreitungen diskutiert wurden, sondern bot auch Einblicke in die Argumentationsmuster des Diplomaten. Seitenlange Lobpreisungen seiner „vergötterten Stael“ suchte er gewissermaßen dadurch auszugleichen, dass er erstens jeder Frau das Gefühl gab, nur ihr würde er so von der Staël berichten, ${ }^{82}$ und dass er zweitens die jeweilige Leserin mit der Staël verglich und sie dabei gewinnen ließ. ${ }^{83}$ So hieß es an Rahel Levin Varnhagen, dass er bei der „Baronne“ zwar ebenso spät wie in Berlin im Haus Levin verkehrte, aber es handele sich dabei nur um ,schlechte französische Übersetzungen von Nachtthees“. ${ }^{84}$ An Karoline von Berg schrieb er: „[...] in sehr vielen Dingen stehen Sie so hoch über ihr, dass wahrscheinlich eine ganz durchgeführte Parallele mässig zu ihrem Vortheile ausfallen müsste“.85

Ein Vergleich seiner Aussagen zur Staël bietet auch in anderer Hinsicht Einblick in die Werkstatt eines Autors: Das Resultat seines ,Studiums‘ war eine Charakterstudie der Staël, die er - beinahe wortgleich! - in Briefe an Rahel Levin Varnhagen und Luise von Voss einflocht. Dabei kam er auf zwei verschiedenen Wegen zum selben Text. Scheinbar spontan brachte ihn ein Vergleich zu französischen Frauen (im Brief an Luise von Voss) bzw. ein Hinweis auf seine Einsamkeit in Paris (im Brief an Rahel Levin Varnhagen) auf dasselbe Thema, und der Übergangssatz lautete gleich: „Nur Eine Pariserin hab’ ich

81 „Die Frau v. Stael ist ein ausserordentliches, grosses u. merkwürdiges Fänomen: Sie ist diesen Sommer mein einziges Studium gewesen, u. ich werde Ihnen nächstens die Resultate desselben mittheilen.“ Gustav von Brinckmann an Karoline von Berg, 19. 10. 1798, ungedruckt, GSA 5/1.

82 Beispielsweise glaubte Rahel Levin Varnhagen: „Ich dinstigire ganz allein den großen [Brief], wo von Mad. Staël die Rede ist. Was in dem steht, schreiben Sie nur mir!" Rahel Levin Varnhagen an Gustav von Brinckmann, 9.3.1799, in: GW I, S. 180. Das Gegenteil war der Fall. Gerade Madame de Staël war ein Thema, das er nutzte, um allen Korrespondentinnen persönliche Komplimente zu machen. „Vergötterte Staël“ an Luise von Voss, 10. 5. 1799, ungedruckt, GSA 5/26,2.

83 Gustav von Brinckmann an Luise von Voss, 10.5. 1799, ungedruckt, GSA 5/26,2.

84 Gustav von Brinckmann an Rahel Levin Varnhagen, 28. 11. 1799, ungedruckt, SV 38.

85 Gustav von Brinckmann an Karoline von Berg, 19. 10. 1798, ungedruckt, GSA 5/1. 
kennen gelernt, vor der ich mich ehrfürchtig in den Staub beuge, aber diese einzige gehört unstreitig ihrem Jahrhundert eigenthümlicher an, als ihrer Nazion.“

Bemerkenswert an den darauf folgenden Seiten, sind nicht nur die überwiegende Textgleichheit, sondern auch die haarfeinen Unterschiede. ${ }^{86}$ Während er von Voss hauptsächlich von der Unterhaltungskunst der Staël vorschwärmte, versuchte er Levin Varnhagen über die Seelenverwandtschaft zu gewinnen: „Ich bin überzeugt, daß sie Ihnen in einem hohen Grade gefallen müsste; aber wenn wir sie bewundert und vielleicht angebetet hätten, so würden wir beide zusammen doch plötzlich die Bemerkung machen: ,auch sie ist doch eigentlich nicht fertig““!87 Dazu kam: „Daß sie übrigens immerfort die Sklavin ihrer Liebhaber ist, werden wir beide ihr doch wohl eher zur Energie als zur Schwäche rechnen“.88 Auch diesen Appell an die Solidarität in Liebesdingen schrieb er nur Rahel Levin Varnhagen, in der Variante an die Gräfin Voss fehlten alle Hinweise auf Liebhaber.

Dieser doppelt verwendete Text resultierte möglicherweise aus der sorgfältigen Herangehensweise Brinckmanns an das Briefwesen, da er mehrfach Abschriften und Entwürfe seiner Briefe aufhob. Wahrscheinlicher ist jedoch, dass er ein Kapitel zur Staël in seine geplante, nicht zustande gekommene Veröffentlichung Briefe aus Paris aufnehmen wollte und sowohl Luise von Voss als auch Rahel Levin Varnhagen $\mathrm{zu}$ Testleserinnen machte. ${ }^{89}$ In jedem Falle sind diese Briefe ein Hinweis mehr darauf, dass der Diplomat sich nicht

86 „Sie wissen / Sie erinnern sich wol, wie groß mein Enthusiasmus schon für die Schriftstellerin war; als Mensch ist sie eine noch seltenere Erscheinung, und als Französin einmal völlig unerklärbar. Im Äußeren möchte ich ihr alles Nationalgepräge der schönen Frauen unbarmherzig absprechen, / Das Nazionalgepräge schöner Formen, das die unbedeutensten Weiber diese Volks oft so angenehm zu charakterisiren pflegt, möchte ein strenger Beurtheiler dieser ganz originellen Frau, in ihrem ganzen Thun und Wesen, in ihrer äussern Existenz überhaupt leicht unbarmherzig absprechen. [...] ihre Seele beherrscht die Züge ihres Gesichts in einer solchen Lebendigkeit des Ausdrucks, und ihre feurigen Augen wissen so gut bescheid, daß man den seinigen kaum traut, wenn man sie noch so aufmerksam betrachtet, und wenn man ihr eben so zuhört, ist man verloren./ist an keine Parteilichkeit mehr zu denken. " [Fett und Kursiv an Luise von Voss, 10. 4. 1799, ungedruckt, GSA 5/26,2; kursiv an Rahel Levin Varnhagen, 7.10.1798, ungedruckt, SV 38; normal formatiert an beide. Unterstreichungen von Brinckmann im Text.]

87 Gustav von Brinckmann an Rahel Levin Varnhagen, 7. 10. 1798, leicht modernisiert auch in: Wachtmeister 1871, S. 6.

88 Gustav von Brinckmann an Rahel Levin Varnhagen, 7. 10. 1798, modernisiert in: Wachtmeister 1871, S. 6.

89 „Ich habe nemlich ein halbes Projekt, Briefe aus Paris herauszugeben“, über „die sonderbare Wirkung welche die Revoluzion auf Sitte und Litteratur gehabt oder nicht gehabt“, Gustav von Brinckmann an Luise von Voss, 30. 1. 1799, ungedruckt, GSA 5/26,2. 
scheute, Themen für verschiedene Adressaten und Adressatinnen verschieden aufzubereiten und seinen Gedanken unterschiedlich Form zu verleihen.

Bisweilen lassen sich an der Diskussion einer Bekannten unterschiedliche Tonarten der Briefwechsel bei gleicher Wertung einer Person ablesen, so bei der Scheidung und möglichen Wiederverheiratung „der Veit“. Mit Lea Mendelssohn Bartholdy wurde der Fall pragmatisch spöttisch diskutiert - eine Heirat sei bei Schlegels „Hang zur Veränderlichkeit [...] wenig wahrscheinlich“90 -, und mit Rahel Levin Varnhagen in dem für diese Korrespondenz typischen, scheinbar lapidaren Tonfall abgehandelt: „[...] auch noch mit oder ohne Spreewasser etc. etc.!!!“91 Gegenüber Luise von Voss warb Brinckmann hingegen für Verständnis für „die Veit“: „[...] was eben nicht immer weise Masregeln bewirkt, ist eine gewisse jugendliche Inkonsequenz der Empfindungen und der Ideen [...]“.92 Dabei spricht aus dieser Charakterisierung als impulsive wenn nicht ,romantische ${ }^{6}$ Frau durchaus ein ernstes Interesse an der Person Dorothea Mendelssohn Veit Schlegels. Aus späteren Briefen wird deutlich, dass er die Selbstständigkeit und Intelligenz einer seiner „besten Freundinnen“ auch und besonders Luise von Voss gegenüber verteidigte, besonders aus Anlass der Darstellung in Schlegels Roman Lucinde [s. V.2]. Das Motiv Dorothea Mendelssohn Veit Schlegels, sich nicht taufen zu lassen, um sich das Sorgerecht für ihren Sohn zu erhalten, fand in den Korrespondenzen Brinckmanns mit den vier Frauen, wie im zuvor analysierten Dreiecksbriefwechsel der drei Männer, keine Berücksichtigung.

Ein ganz anders gelagertes Beispiel eines parallel verhandelten Charakters war Wilhelm von Burgsdorf.93 Die Kommentare über den märkischen Adligen betrafen sehr unterschiedliche Angelegenheiten. Die Persönlichkeit des Freun-

90 Lea Mendelssohn Bartholdy an Gustav von Brinckmann, 10.12. 1798, ungedruckt, BA M.

91 Gustav von Brinckmann an Rahel Levin Varnhagen, 7. 1. 1799, ungedruckt, SV 38.

Allerdings hatten die beiden sich über die gemeinsamen Freundin schon früher verständigt und konnten davon ausgehen, dass der/die andere die Scheidung auch nicht bedauern würde. Vgl. die Debatte 1794-1795 und bes. „Gottlob! so wird man doch wieder einen Menschen sehen; der allein denkt, handelt, fühlt; und den die Andern eigensinnig nennen. Wenn's ihr nur gut geht!“, Rahel Levin Varnhagen an Gustav von Brinckmann, 4. 9. 1795, in: GW I, S. $154 \mathrm{ff}$.

92 Gustav von Brinckmann an Luise von Voss, 30.1. 1799, ungedruckt, GSA 5/26,2.

93 Der Junker Wilhelm von Burgsdorf (1772-1822) war Rahel Levin Varnhagen spätestens seit 1795 über Brinckmann bekannt. 1796 begleitete er sie zur Kur nach Böhmen. Er war in Paris Mitglied der „deutschen Kolonie“ und täglicher Umgang von Brinckmann und den Humboldts. In Brinckmanns Briefen an Luise von Voss wurde er häufig erwähnt und ihr nach seiner Rückkehr ebenfalls als persönliche Bekanntschaft empfohlen. Auch Lea Mendelssohn Bartholdy gegenüber wird er ohne weiterführende Erklärung erwähnt, war ihr daher bereits Ende der 1790er-Jahre bekannt. 
des wurde zwar von allen und - per Text - sogar gemeinsam diskutiert: Als Brinckmann 1801 einen „Schattenriss“ Burgsdorfs verfasste, schickte er den Text sowohl an Rahel Levin Varnhagen als auch an Luise von Voss, letzterer mit dem Kommentar, dass „die Kleine“ den Text gelungen, aber nicht streng genug gefunden habe. ${ }^{94}$,Intimere‘ Angelegenheiten aber, wie die Liebesaffäre Burgsdorfs mit Caroline von Humboldt oder seine Finanzen kamen nur Rahel Levin Varnhagen gegenüber zur Sprache. Nur hier sind auch Billets finanziellen Inhalts überliefert. ${ }^{95}$ Das Interessante an dem Geldtransfer zwischen Burgsdorf, Brinckmann und Levin Varnhagen zeigt sich, wenn man Burgsdorfs eigene, wenig rezipierte Briefe hinzuzieht, in denen von einem unehelichen Sohn die Rede ist, den er in Berlin in Pension gegeben hatte. ${ }^{96}$ Dieser Teil der Burgsdorfschen Familiengeschichte wurde in der Literatur bisher vernachlässigt, wirft aber ein aufschlussreiches Licht auf das zeitgenössische Verständnis von Standes- und Geschlechterpflichten:97 Die Mittelspersonen zwischen Burgsdorf, der Pflegefamilie und seinem Sohn waren anscheinend Brinckmann und Levin Varnhagen, die sich um das Kind persönlich kümmerte. Vor Burgsdorfs eigener Familie, auch vor engeren aristokratischen Freunden wurde diese Affäre verborgen. ${ }^{98}$ Aussagekräftig ist die Episode auch als Beispiel dafür, wie um 1800, auch in Salonzusammenhängen, mit zweierlei Maß gemessen

94 Gustav von Brinckmann an Luise von Voss, 22. 10. 1801, ungedruckt, GSA 5/26,4. 95 Rahel Levin Varnhagen an Gustav von Brinckmann, 11. 1. 1798 und undatierte Billets zur selben Angelegenheit, ungedruckt, SV 38. Über die Liebe Burgsdorfs zu Caroline von Humboldt hatte Brinckmann 1795 geschrieben: „Übrigens müssen Sie wissen, daß B. förmlich in die Humb. verliebt ist, u. daß ein förmliches Verhältnis zwischen ihnen existiert.“ An Rahel Levin Varnhagen, 27. 8. 1795, ungedruckt, SV 38. Karl August Varnhagen löste das B. als Burgsdorf auf.

96 Der Sohn Wilhelm wurde zum Kantor am Französischen Dom in Pflege gegeben und hieß in den Briefen „der Kleine im Turm“. Die Mutter hatte Burgsdorf als Amme im Hause Cesar in Berlin untergebracht, in der Familie also, aus der Pauline Wiesel stammte. Vgl. Cohn 1907, S. 198.

97 Nur Günter de Bruyn erwähnt, dass Burgsdorf „viele Liebesaffairen [hatte], aus denen, den Gerüchten nach, vier uneheliche Kinder hervorgingen.“ de Bruyn 1999, S.107.

98 Zu dem Verhältnis Burgsdorfs zu seinem Sohn siehe die Briefe an Rahel Levin Varnhagen 1797 und 1798 in Cohn 1907. Nachdem er seine Freundin gebeten hatte, die Pockenimpfung für seinen Sohn in die Wege zu leiten schrieb er: „H[umboldt] will ich nicht darin melliren, er weiß nichts von dem kleinen Jungen im Turm, glaube ich." Wilhelm von Burgsdorf an Rahel Levin Varnhagen, 21. 4. 1797, in: Cohn 1907, S. 100. Caroline von Humboldt, Burgsdorfs damalige Geliebte, war allerdings eingeweiht. Vgl. Caroline von Humboldt an Rahel Levin Varnhagen, 1. 12. 1796, in: Cohn 1907, S.198. Von Burgsdorfs Familie war nur sein Vater informiert, der aber ließ mit den Zahlungen für das Kind auf sich warten, und Rahel Levin Varnhagen musste einspringen. 
wurde: ${ }^{99}$ Burgsdorfs befremdlich distanzierte Einstellung zu den Konsequenzen seiner Liebesgeschichten wurde nicht nur von ihm zu keiner Zeit entschuldigt, sie wurde auch, zumindest zu diesem Zeitpunkt, von keiner Seite nachhaltig thematisiert. Die Ehe- und Liebesgeschichte „der Veit“ hingegen wurde ausführlich besprochen und sollte zum Skandal werden.

\title{
1.4 „Toute la societé de Berlin est encore sous les armes“ - Der „jüdische Salon" im Geselligkeitsgewebe Berlins. Veränderungen um 1800
}

\author{
Ich vermisse noch oft Tante W. schöne Theestunden. \\ [...] Ich fand Sie, Tante Levy u ein par liebenswürdige Personen \\ (apropos- empfehlen Sie mich doch der schönen Tante, \\ wenn sie sich meiner noch erinnert). \\ Gustav von Brinckmann an Lea Mendelssohn Bartholdy, 1799
}

\begin{abstract}
Von den Veränderungen, die ich etwa gefunden habe [...]. Es ist hier wie überall gegangen: alle Verhältnisse sind loser geworden. [...] Zwar spricht man mehr von reell interessanten Dingen auch in der größten Gesellschaft, nur nicht gerade auf eine interessantere Weise.

Wilhelm von Humboldt an Gustav von Schlabrendorf, $1801^{100}$
\end{abstract}

Ein wesentliches Thema, das Brinckmann mit allen vier Frauen kontinuierlich diskutierte, war Geselligkeit. Dabei ging es ebenso darum, Bericht zu erstatten und stattgehabten Genuss oder Enttäuschungen zu teilen, wie um eine Bestimmung der idealen Umgangsform und die eher theoretisch diskutierte Frage, wie gesellige Bildung am besten zu erreichen sei. Brinckmanns Briefe bieten so nicht nur eine noch unausgelotete Quelle zur Berliner Geselligkeitsgeschichte. Die Geselligkeit kann zugleich als Parameter dienen, an dem sich ein (verändertes) Selbstverständnis Brinckmanns oder der Gesellschaft ablesen lässt.

Brinckmanns Briefe aus Paris hatten, da sie oft sehr nostalgisch waren, vor allem Aufschluss über die hinter ihm liegende Zeit an Berliner Teetischen und Anlass für Empfehlungen an alte Bekannte gegeben. Aller Verherrlichung „schöner“ oder „deutscher“ Teestündchen zum Trotz verlagerte sich aber, nach seiner Rückkehr nach Berlin im Juni 1801, der Schwerpunkt seines Umgangs,

99 Die feministische Forschung spricht in diesem Zusammenhang zu recht vom „Double Standard“. Es herrschten unterschiedliche Maßstäbe - für die Stände und für die Geschlechter. 100 Gustav von Brinckmann an Lea Mendelssohn Bartholdy, 9. 2. 1799, diese Stelle ungedruckt, BA M; Wilhelm von Humboldt an Gustav von Schlabrendorf, 13. 7. 1801, in: Theodor Kappstein (Hrsg.): Wilhelm von Humboldt im Verkehr mit seinen Freunden. Eine Auslese seiner Briefe, Berlin 1917, S.168. Das Zitat in der Überschrift: Gustav von Brinckmann an Luise von Voss, 30. 10. 1803, ungedruckt, GSA 5/26,6. 
beziehungsweise der seiner Berichte darüber. Könnte man für Brinckmanns Pariser Aufenthalt noch vermuten, dass Luise von Voss zur heimlichen Adressatin eines ,Tagebuchs-in-Briefen' geworden war, blieb die Besonderheit dieses Briefwechsels auch nach der Rückkehr aus Paris sichtbar.101 Wie während seines vorigen Berlinaufenthaltes an Rahel Levin Varnhagen erstattete er jetzt Luise von Voss detailliert Bericht:102 „Wollen Sie ein Bulletin unsrer Vergnügungen? Sonntags war Cour en robe; Montag nach der Oper ein großes Souper bei Chevalier DelBray [...]. Dienstags ein prächtiges Souper für den Hof u die ganze Stadt bei der Gräfin Hazfeld. Man rühmt es allgemein, als ebenso prächtig wie geschmackvoll [...].“103 In seinen Berichten erschienen nach 1801 erkennbar differenziertere Geselligkeitsformen und weitaus mehr Namen adliger Gastgebender wie von Alvensleben, Heinitz, Zinzendorf.

Es ist zu fragen, ob die veränderte Darstellung sich ändernde Strukturen der Berliner Geselligkeit widerspiegeln und/oder inwieweit hier eine neue Perspektive des Berichtenden zum Tragen kommt. Für Letzteres könnte seine veränderte berufliche Position sprechen, im Herbst 1803 avancierte Brinckmann vom Legationssekretär zum Geschäftsträger. Aber bereits unmittelbar nach der Rückkehr Brinckmanns 1801 hatte Friedrich Schlegel festgestellt, sein alter Freund sei „vornehm“ geworden,104 und Brinckmann selbst hatte Freunde von früher zu „Bekannten“ umgeschrieben: „Ich bin wieder in dem Zirkel meiner ehemaligen Bekannten, die mir durch Abwesenheit so interessant geworden, daß ich beinah alle für Freunde ansehen möchte. Das wird sich nun bald wieder geben, aber [...] auch jene Bekanntschaften sind doch wirklich hübsche Dekorazionen des Lebens, wie ich sie wünsche“. ${ }^{105}$ Möglicherweise hatte der Aufenthalt in der Weltstadt Paris oder im Reimarus-Sievekingschen Kreis in Hamburg ${ }^{106}$ seine Vorstellung von „guter Gesellschaft“ neu

101 Man schrieb sich mindestens posttäglich, zählte auch auf diese Regelmäßigkeit, lediglich Krankheit und politische Geschäfte wirkten sich ,verdünnend' auf die Briefdichte aus. Auch die Verheiratung Luises mit dem Diplomaten August Ernst von Voss (1779-1832) brachte zunächst keine Veränderung in den Briefwechsel, nur enthusiastische Grüße an den „verehrten Grafen“. Spätere abweichende politische Anschauungen der beiden Männer wurden angedeutet, scheinen aber keine Konsequenzen auf den Umgang gehabt zu haben. 102 Diese Berichterstattung macht den Briefwechsel Brinckmann-Voss zu einer reichen, noch auszuschöpfenden Quelle für die Geselligkeitsgeschichte Berlins im ersten Jahrzehnt des 19. Jahrhunderts. Im Vergleich wurde der Briefwechsel mit Levin Varnhagen seit 1797 merklich dünner, von Mendelssohn Bartholdy sind aus den ersten Jahren ihrer Ehe keine Briefe mehr überliefert, später weitaus formellere als die oben zitierten.

103 Gustav von Brinckmann an Karoline von Berg, 6. 1. 1803, ungedruckt, GSA 5/1.

104 Friedrich Schlegel an Rahel Levin Varnhagen, Dezember 1801, in: KFSA, Bd. 25, S. 319.

105 Gustav von Brinckmann an Luise von Voss, 22. 6. 1801, ungedruckt, GSA 5/26,4.

106 Nach seiner Abreise aus Frankreich war er 1800/1801 krankheitshalber mehrere Monate an Hamburg gebunden, wo im Salon der Frauen Reimarus und Sieveking verkehrte. Zurück in 
geprägt. ${ }^{107}$ Letztlich deuten das seinen Briefen ablesbare merkbar breitere Spektrum des gesellschaftlichen Angebots und die deutliche höhere Zahl an gastgebenden Personen aber vor allem darauf hin, dass sich die Geselligkeitsstruktur in Berlin um 1801 selbst geändert hatte. Auch die eingangs zitierte Beobachtung Humboldts spricht von organisatorischen Veränderungen. Das gesamte Geselligkeitsangebot war umfangreicher und luxuriöser geworden: Es gab „Theeassembleen oder Soupés beinah täglich, und bisweilen beides an einem Tag. Alle unsere eleganten Damen kehren zurück““.108 Von einem geselligen Vakuum, das nach Deborah Hertz um 1780 zur Entstehung der Salons weitgehend beigetragen habe, konnte ab 1800 nicht mehr die Rede sein. ${ }^{109}$ Tatsächlich sind die gesellig-gesellschaftlichen Angebote und Verpflichtungen nicht nur merkbar zahlreicher, sondern vor allem konturierter geworden als zehn Jahre zuvor, in dem unter III. analysierten Beispieljahr 1794/95. Erst um 1802, dann aber deutlich, lassen sich erste Ansätze für verschiedene ,Jours fixes' ausmachen: So konnte Brinckmann seiner auf ihrem Landgut weilenden Freundin Voss folgende Stadtneuigkeiten schreiben: „Baron Krüdener hat einen Freitag eingerichtet; Die traurigen Mittwochs der Frau von Saldern fan-

Berlin hielt er die Verbindung brieflich und leitete Briefstellen der Reimarus an seine Berliner Gastgeberinnen weiter. Wie unter II. dargelegt, sind die personellen Verbindungen zwischen Hamburger und Berliner Teetischen ein noch wenig bearbeitetes, aber lohnendes Forschungsfeld. Brinckmanns Korrespondenzen bestätigen, dass schon in den 1790er-Jahren die „Levy-Itzigs“, Sara und Salomon Levy, Freunde des Hauses Reimarus waren. Auf gute Kenntnis Berlins und ein gewisses Selbstbewusstsein der Hamburger Gastgeberinnen deutet folgendes Zitat: „[...] mögen Sie sich mit den Schlegeln herumtreiben, mit Gentz schwelgen, sich mit Schleiermacher excentrisiren, mit Fichte sogar Tobak rauchen, ich weiß, Sie kommen doch wieder an unseren Theetisch und denken an die guten Menschen die herumsitzen." Sophie Reimarus an Gustav von Brinckmann, 20. 4. 1802, zit. nach: Arndt Schreiber (Hrsg.): Wilhelm von Humboldt. Briefe an Christine Reinhardt-Reimarus, Heidelberg 1956, S. 166.

107 Zwei Konstanten in Brinckmanns Berichterstattung aus Paris deuten auf eine veränderte Sicht der Gesellschaft: Erstens hatte er geradezu Kontraste zwischen der deutschen und der französischen Gesellschaft ,gesammelt‘, insbesondere in der Geselligkeit. Zweitens nutzte er nach eigener Aussage seine Zeit in Paris als politische „Studienzeit“ - ein Anlass für lange Ausführungen zu den Vor- und Nachteilen der gesellschaftlichen Schichtung. Solche Überlegungen zum „Stand“ wurden in Berliner Briefen fortgesetzt und waren vermutlich nicht ohne Relevanz für seine Beurteilung der Mischung der Stände und Schichten in Berlin. [s. a. V.4] 108 Gustav von Brinckmann an Luise von Voss, 10. 11. 1803, ungedruckt, GSA 5/26,6. Zu den eleganten Damen zählte Brinckmann in diesem Brief neben der Herzogin von Kurland die Gräfin Hatzfeld, Gräfin Hardenberg und Gräfin Nathalie Stadion. Alle vier werden Luise von Voss gegenüber mehrfach als Gastgeberinnen genannt, ein Unterschied im Engagement dieser Damen, der das Haus der Herzogin von Kurland als ,Salon“ von anderen unterscheiden könnte, scheint in Brinckmanns Briefen nicht auf.

109 Auch nicht von einer Gemengelage nicht vereinbarer Interessen. Hertz 1990, bes. S. 105-107. 
gen wieder an“. ${ }^{110}$ Gleichermaßen wurde der Tod des Ministers von Heinitz als „ein wirklicher Verlust für die Gesellschaft, in Rücksicht seiner sehr ungenirten Freitage" betrachtet. ${ }^{111}$ Zugleich tauchten neue Begriffe auf, bzw. es scheinen einige Veranstaltungen jetzt erst einen Namen bekommen zu haben, zum Beispiel die „Theeassemblee“.112 Deutlich ambitionierter als „Teestündchen“ oder „Kränzchen“, und formeller als „Nachttee“ klingt auch „Literarischer Tee“ eine Veranstaltung der Gräfin Schlabrendorf, die allerdings, wie Brinckmann nicht ohne Schadenfreude bemerkte, auch scheiterte.113 Um 1804 scheint anspruchsvolle Geselligkeit ein erstrebenswertes Etikett in der „eleganten“ Gesellschaft geworden zu sein. Die Veranstaltungen waren so organisiert, dass ein aktiver Gast und Diplomat mehrere Teetische und Assembleen an einem Tag besuchen konnte und musste. ${ }^{114}$

Die „lärmende Assemblee“,115 als Geselligkeitstypus der „großen Welt“ oder „,vornehmen Gesellschaft“, 116 wurde in Brinckmanns Korrespondenz zum exemplarischen Gegenmodell des Gesprächs im kleinen Kreis, welches er sich

110 Gustav von Brinckmann an Luise von Voss, 13. 6. 1802, ungedruckt, GSA 5/26,5.

111 Gustav von Brinckmann an Luise von Voss, 16. 5. 1802, ungedruckt, GSA 5/26,5.

1121805 war die neue Begriffswut bereits in der Provinz angekommen, Brinckmann konnte aus Greifswald berichten, dass die Damen der Familie Armfeld „ein offenes Haus halten“ und Gräfin Piper habe eine „Theeassemble“. An Luise von Voss, 1. 12. 1805, ungedruckt, GSA $5 / 26,8$.

113 Gustav von Brinckmann an Luise von Voss, 20. 5. 1802, ungedruckt, GSA 5/26,5. Brinckmann, obzwar ein sehr engagierter Akteur des geselligen Geschehens dieser Zeit, distanzierte sich zunehmend vom Anspruch einiger Gastgeber und Gastgeberinnen und konnte so einen Grund für die schärferen Trennlinien benennen, die Konkurrenz unter den Organisatoren bzw. dass „der kleine gesellschaftliche Neid und die fade medisance unter den Weibern vielleicht nirgends so allgemein herrscht, wie alleweile in unserer hiesigen eleganten Welt." Gustav von Brinckmann an Luise von Voss, 31. 1. 1803, ungedruckt, GSA 5/26,6.

114 Der Trend zur Formalisierung der Gesellschaft hielt an. Bekannt ist die bereits zitierte Klage Rahel Levin Varnhagens über diese Erstarrung des Berliner geselligen Lebens nach 1819 und die „fade Begriffsverwirrung“. An Gustav von Brinckmann, 30. 11. 1819, in: GW II, S. $609 \mathrm{f}$.

115 Gustav von Brinckmann an Luise von Voss, 19. 10. 1801, ungedruckt, GSA 5/26,4. Hervorhebung H. L. L.

116 Die Assemblee, im zeitgenössischen Verständnis eine große gesellige Versammlung, erscheint zusammen mit dem Déjeuner und dem Souper als zunehmend gängige

Geselligkeitsform für größere Gästezahlen in Berlin nach 1800, veranstaltet in Häusern von Diplomaten, bei Hofe oder in adligen Palais. Vgl. die satirische Umschreibung von Nicolai, in der eine Dame „Assembleen hielt, wo in dem schön erleuchteten großen Saale, der wohlgeputzte benachbarte Adel, an zwanzig Spieltischen, mit dem ernsten Geschäft, die Zeit zu tödten, beschäftigt war." Friedrich Nicolai: Leben und Meinungen des Herrn Magisters Sebaldus Nothanker. Mit Kupferstichen von Dan. Chodowiecki gezeichnet und geätzet, 2 Bde., Berlin [u.a.] 1774-75, Bd.1, S. 172. 
von allen Gastgeberinnen erbat. ${ }^{117}$ Dieser Gegensatz war in den Jahren bis 1797 und Rahel Levin Varnhagen gegenüber noch nicht thematisiert worden, vermutlich, weil die wirklich „große Welt“ für den jungen Botschaftsassistenten noch nicht die entscheidende Rolle gespielt hatte, bzw. er nicht in ihr. Mit Rahel Levin Varnhagen hatte er sich stattdessen gegen „platte“ Aufklärer und langweilige Elegants verbündet. ${ }^{118}$ Wenn er 1802, in der kritischsten Phase ihrer Beziehung, über den Salon Levin Varnhagen zwar lobend schrieb, dass dort an „Einem Abend mehr Wiz, Verstand und Einfälle vergeudet wird, als in 3 unserer Asembleen“, ${ }^{119}$ wurde durch die Wortwahl „unser“ zugleich deutlich, dass Assemblée ein Modell der höfischen oder zumindest „grossen Welt“ war, zu der sich Brinckmann nach 1801 nun rechnete. ${ }^{120}$

Brinckmann, der in den untersuchten zehn Jahren gegenüber allen Korrespondentinnen nicht müde wurde zu beteuern, dass er das Einzelgespräch der großen Versammlung vorzöge, ließ diesen Beteuerungen zum Trotz nicht nach, diese zu besuchen. Im Gegenteil, Assembléen wurden ab 1801 zunehmend Teil seines Lebens. Mit Blick auf die Realität des Diplomatendaseins ist die Darstellung großer und kleiner Geselligkeit im Kontrast daher vermutlich primär als Stilisierung und oft als Kompliment an die Adressatin und Organisatorin der wahrhaft „geistreichen Gespräche“ zu lesen. Im Falle Luise von Voss’ passte

117 So pries er beispielsweise die „filosofischen Tees“ der von Voss und von Berg, und dankte dafür, dass sie inn als Menschen, nicht als „Weltmann“ empfangen. Gustav von Brinckmann an Karoline von Berg, 4. 2. 1798, GSA 5/1, auch in: Berg 2008, S. 120.

Hervorhebung im Original. So versicherte er Rahel Levin Varnhagen, sie möge nur Friederike Unzelmann zum Tee bitten, ,auf diesen Fall wird mich keine Assemblee beim Russischen, kein Soupé beim Englischen Gesandten abhalten, mich zu ihren niedlichen Füssen zu werfen.“ 24. 9. 1803, ungedruckt, SV 38. Vgl. ähnlich an Luise von Voss: „Freilich machten mich Ihre Theestündchen ein wenig gleichgültig gegen [...] die Assembléen der Engs. und die Vorlesungen der Gräfin Nathalie.“ 4. 11. 1801, ungedruckt, GSA 5/26,4.

118 So vermisste er sie bei der Diskussion eines wichtigen Buches, „weil ich immer verzweifelte, den feinen Weltleuten begreiflich zu machen, daß es noch etwas weit schöneres als Lebensart und Eleganz gäbe“, oder er fürchtete, er sei „so deutlich, platt u vernünftig geworden, dass man mich zum Aufklären brauchen könnte“. Gustav von Brinckmann an Rahel Levin Varnhagen, 20.5. 1794 und 30. 7. 1795, ungedruckt, SV 38.

119 Gustav von Brinckmann an Luise von Voss, 10. 10. 1802, ungedruckt, GSA 5/26,5. Großschreibung im Original.

120 Noch deutlicher wird die Entwicklung im Vergleich zu seinem ersten Berliner Aufenthalt 1789, als er sich von den oberen Kreisen noch explizit distanziert hatte: Den besten Umgang suchte er da „im Mittelstande, wo vielleicht im ganzen genommen noch mehr Aufklärung und feine Bildung anzutreffen ist, [...] als in der höhren Sfäre, wo der tägliche Strudel von Visiten, Assembleen und Bällen jeden Genuß einer vernünftigen Unterhaltung, oder einer seligen Einsamkeit unmöglich macht." Gustav von Brinckmann an Friedrich Schleiermacher, 4. 12. 1789, in: Meisner / Schmidt 1912, S. 17 f. 
er sich möglicherweise der ihr eigenen Vorstellung von Dezenz an, die anscheinend mit der Schaustellung bei großen Festen nichts anfangen konnte und an Brinckmann einmal schrieb: „[...] man mag nun sagen was man will ich finde diese genre an fetes zum Geburtstag der Königin - indecent“..121

\section{Wechselnde Vermittlerrollen und Verbindungen zum Hof}

Grundsätzlich ist auch nach 1800 zunächst noch auffällig, wie viele Überschneidungen der geselligen und gesellschaftlichen Kreise es gab - sodass Brinckmann, wie auch Gentz oder die Brüder Schlegel, gleichermaßen bei Luise von Voss wie Rahel Levin Varnhagen verkehrten. ${ }^{122}$ Die späte Empfangszeit der Letzteren konnte sie zum Abschluss eines gesellschaftsreichen Tages machen. ${ }^{123}$ Wurde Brinckmann mit Recht als Habitué zweier Gesellschaftskreise bezeichnet, waren es genau genommen noch mehr Szenerien: Beispielsweise traf er bei Caroline von Humboldt Burgsdorf, und „nachher soupirte ich mit Burgsdorf, Frl Arnstein, ihrer Cousine, Schlegels, Tiek, Burg. und Bernhardi bei Sanders“.124 Den Abend dieses Tages verbrachte er, wie einem Billet vom Folgetag zu entnehmen ist, in Gesellschaft des Grafen von Berg bei Sara Levy. ${ }^{125}$ Damit verkehrte er nicht nur beim Adel und in jüdischen Häusern, sondern auch bei verschiedenen Gastgebern des nichtjüdischen Mittelstands. Anders formuliert standen jüdische und nichtjüdische Kreise, keineswegs immer so benannt, Besuchern gleichzeitig offen und wurden von denselben Männern aufgesucht, manchmal in so schnellem Wechsel, dass es sogar die Beteiligten verwirrte: „Wie hat sich denn das Hagensche Souper auf einmal in ein Arnsteinsches verwandelt? Und bin ich bei dem letzten? Oder wie steht das alles.“, lautete eine typische Frage von Friedrich von Gentz an seinen ,Geselligkeitsmanager‘ Brinckmann. ${ }^{126}$

121 Luise von Voss an Gustav von Brinckmann, 8. 3. 1804, ungedruckt, BA, V.

122 Vgl. „Da die beiden Centauren [Schlegels] erst gestern Mittag bei Ihnen assen, so wird Ihnen der Eindruck von beiden noch lebendig sein." Gustav von Brinckmann an Luise von Voss, 9. 1. 1802, ungedruckt, GSA 5/26,5. Dies ist für die Datierung eines „Salons“ bei Luise von Voss bemerkenswert, da ihre gesellige Tätigkeit meistens auf nach 1806 bestimmt wurde. 123 Ein Bericht Brinckmanns über einen Besuch bei einer Gräfin endete mit dem Kommentar: „Später machte ich gestern Abend die Entdeckung daß die Baronesse Hagen den ersten Thee auf dem continent, und höchst wahrscheinlich die lezte Zierpuppe von Tochter besitzt - Noch später assistirte ich mit Humbold einem Soupé bei der kleinen Levin, wo ich zu meiner grossen Freude den vom Lande zurückgekehrten Burgsdorff entdeckte.“ Gustav von Brinckmann an Luise von Voss, 3. 9. 1801, ungedruckt, GSA 5/26,4.

124 Gustav von Brinckmann an Luise von Voss, 9. 1. 1802, ungedruckt, GSA 5/26,5.

125 Gustav von Brinckmann an Luise von Voss, 10. 1. 1802, ungedruckt, GSA 5/26,5.

126 Friedrich von Gentz an Gustav von Brinckmann, 1. 1. 1802, in: Wittichen 1910, S. 84. 
Auch das Bild des Habitués, der dem Salon neue Gäste bringt, erhält durch die hier vorgenommene Parallellektüre einige neue Facetten. Wohl ist Gustav von Brinckmann in der Literatur zu Recht als Mann bezeichnet worden, der Gäste einführte und ,anbrachte،, beispielsweise Friedrich Schlegel zu Rahel Levin Varnhagen. In welch selbstbewusstem und zugleich schmeichelndem Ton solch eine Anfrage aber formuliert werden konnte, zeigt ein begleitendes Billet von Hitzel Fließ Boye Sparre, die sich betont als deutsche[!] Literaturinteressierte mit Brinckmann gruppierte:

Nun auch ein Wörtlein, aber diesmal deutsch, recht bieder, treuherziges Deutsch, weil wir doch nun einmal deutsche sind [...]. Eine neue Bekanntschaft, wie die eines Schlegel, muß mich erfreuen, denn auch ich hoffe, dass Sie diesmal Ihre Doktorin nicht im Stiche lassen werden, [...], kurz, mein lieber Brinckmann, ich muß den interessanten Mann auch durch Ihre Macht anscheinen und bewundern. ${ }^{127}$

Und Henriette Herz dankte noch 1804 überraschend beiläufig für die Vermittlung eines Kontakts: „Schleiermacher sagte mir etwas von einem baldigen Zusammentreffen mit der Fr. v. Berg, ich bitte es so zu arrrangiren, dass es nicht am nächsten Montag geschehe sonst muß ich mir die Freude versagen. Vergessen Sie die Literattur Zeitungen nicht? [...]““.128

Gegenüber dem Haus Berg-Voss trat Brinckmann dann als Gebetener, aber auch als Bittender auf. Frau von Berg hatte ihm Empfehlungsschreiben, etwa nach Weimar oder an Friedrich Jacobi mitgegeben - wie sie auch für Marianne Meyer Eybenberg einen empfehlenden Brief an Goethe schrieb.129 Vergleichbar nutzte nicht nur der Diplomat das Haus Berg-Voss als Verbindung zum Hof, als es darum ging für eine verarmte Freundin in Paris eine Pension zu erhalten. ${ }^{130}$

127 Hitzel Fließ Boye Sparre und Rahel Levin Varnhagen an Gustav von Brinckmann, 2. 8. 1797, diese Stelle ungedruckt, SV 38. Rahel Levin Varnhagen zeigte sich schließlich doch froh, Schlegel woanders und zufällig getroffen zu haben, denn „sonst sah's immer aus, als sollten Sie mir den bringen, die andern Leute sind doch so." An Gustav von Brinckmann, 31. 8. 1797, in: GW I, S. 170.

128 Henriette Herz an Gustav von Brinckmann, 15. 9. 1804, ungedruckt, BA H. Vgl. Johann Gottlieb Fichte an dens.: „Frau von Berg, deren Bekanntschaft ich Ihrer Güte verdanke, erkundigte sich bei mir, ob ich wohl für ein gewisses Publikum lesen würde.“ 23. [?]. 1804, so zitiert nach: BA F.

129 Berg 2008, S. 218 f. Mit Faksimile.

130 Vgl. die ausführlichen Erörterungen im Briefwechsel mit Luise von Voss über das Schicksal der Elise Leuchsenring und die Diskussion, wie ihr von welcher Prinzessin Unterstützung zu schaffen sei. GSA 5/26,4-6. 
Auch Marianne Meyer Eybenberg wollte sich zur Unterstützung derselben Freundin ihrer guten Beziehungen zu einer Prinzessin bedienen. ${ }^{131}$

An dieser Stelle muss einmal betont werden, weil es in der Literatur noch nicht detailliert erforscht ist, dass es verschiedene gesellschaftliche Kontakte jüdischer Salonfrauen zum Hofe gab - auch abgesehen von der bekannten Freundschaft Rahel Levin Varnhagens zum ,enfant terrible‘ des Hofes, Prinz Louis Ferdinand. Nicht nur konnte Friederike Liman im Badeort einem Mitglied des Königshauses vorgestellt werden. Fanny von Arnstein wurde mit ihrer Tochter Henriette 1798 bei Hofe empfangen. Dies geschah zu „gegenseitiger großer Zufriedenheit“, wie ihre Cousine Lea Mendelssohn Bartholdy stolz feststellte:

Wissen Sie auch, dass T. Arnstein u Jette unsre schöne Königin liebliche Prinzeß Ludwig, u. schätzenswerthe Prinzeß v. Oranien gesprochen haben? Ja wohl! U das in Charlottenburg, zu gegenseitiger großer Zufriedenheit. Auch dort war die Wundercousine, wie es klugen Leuten zukommt, völlig ungenirt $\mathrm{u}$ frei, $\mathrm{u}$ dies gefiel der Prinzeßin v. Oranien vorzüglich, so wie Jette hingegen von dem einnehmenden Betragen $u$ der allerliebsten Lebhaftigkeit der Ludwig ganz entzückt war. ${ }^{132}$

Die gegenseitige Zufriedenheit ist bedeutsam im Vergleich zu dem sich wenig später abzeichnenden zumindest einseitigen Unbehagen an ständeübergreifender Begegnung.

Die Rolle von gebendem Gast und gastgebender Person konnten auch um 1800 wechseln. Schließlich trat der Salongast Brinckmann selbst als Gastgeber und Arrangeur gemischter Geselligkeit auf. Einem Tee bei ihm war es zu verdanken, dass die Gräfin von Voss einen Großteil seiner alten Freundinnen persönlich kennenlernte. Über diesen Tee sandte er an ihre Mutter

das Verzeichnis der dabei befindlichen Personen, die, so verschieden sie auch sein mögen, doch in mancher Rücksicht alle interessant waren. Frau v. Engeström, Mad. [?]ron, Frau v. Arnstein mit ihrer schönen Tochter, eine äusserst geistreiche Msl Salomon, eine Cousine der Frh Arnstein, [...]; Madam Levy, Mad. Unzelmann, und die immer als eine Macht für sich anzusehende Gräfin Voß. Von Männern nur H. v. Engeström, Grf Voß, Gentz, der Banquier Levy , u. ich-.133

131 Sie wurde aber in diesem Vorhaben von Brinckmann gehindert, der es für angeratener hielt, den indirekten Weg über Frau von Voss zu gehen, da „der Prinzessin in diesen Tagen in Pottsdam höchst wahrscheinlich Marianens Ankunft und Negoziazion ein wenig ungelegen gewesen wäre“. Gustav von Brinckmann an Luise von Voss, 13. 10. 1801, ungedruckt, GSA 5/ 26,5. Die Prinzessinnen, die hier in Frage kommen, waren Prinzessin Luise, die Prinzessin Ferdinand oder die Prinzessin Auguste, vgl. Brinckmanns Erörterungen an Luise von Voss, 19. 10. 1798, ungedruckt, GSA 5/26,1.

132 Lea Mendelssohn Bartholdy an Gustav von Brinckmann, 24. 7. 1798, ungedruckt. Dieses Ereignis wird von Hilde Spiel in ihrer Biografie Fanny von Arnsteins nicht erwähnt.

133 Gustav von Brinckmann an Karoline von Berg, 12. 10. 1801, ungedruckt, GSA 5/26,4. Die geistreiche „Msl Salomon“ ist Lea Mendelssohn Bartholdy. 
Das Zusammentreffen hatte Brinckmann auf Wunsch einer jüdischen Freundin arrangiert:

Henriette Mendelsson hatte mir ihren Wunsch geäussert, dass die Grfin u. Frl. Arnstein sich irgendwo begegnen möchten, $u$. bequemer, als bei mir konnte dies nicht geschehen. Alle Anwesenden hatten gewünscht einmal mit der Unzelmann in Gesellschaft zu sein; also sehen Sie mir meine Frauenzimmerwahl nur nicht, als eine unvorbereitete Macedoine an. Ich würde mich nie unterstanden haben zu einer Geselschaft mit der Gräfin Voss irgendein Frauenzimmer zu bitten, ohne sie erst darüber zu befragen.134

Aufschlussreich ist die Art, in der Brinckmann der Mutter der Gräfin einerseits geradezu stolz über sein geglücktes Impromptu und die Mischung von Personen jüdischer und aristokratischer Herkunft berichtet, sie andererseits darüber beruhigen zu müssen glaubte, dass letztlich die Wünsche der Gräfin ausschlaggebend waren und dass die Mischung keine unvorbereitete war.

\section{Landsitze und Häuser der Diplomatie als Orte gemischter Geselligkeit}

Groß Giewitz und Bahrensdorf bei Beeskow: Die Landsitze der Frauen von Berg und von Voss werden hier als gesellige Treffpunkte nicht analysiert, nur erwähnt, da sie für die jüdischen Beteiligten der Salongesellschaft in den Jahren um 1800 nicht zum Kommunikationsort wurden. Zwar wurden einige Gäste der jüdischen Salonièren dorthin geladen, oder beispielsweise von Brinckmann dorthin vermittelt, der Friederike Unzelmann nach Giewitz brachte - ein Besuch der jüdischen Salonfrauen auf den Gutshöfen der genannten Aristokratinnen selbst lässt sich jedoch nicht nachweisen. Zugleich sei damit nachdrücklich auf den Forschungsbedarf und die neueren Forschungsansätze zu den Landsitzen aristokratischer Salonièren hingewiesen, die in der Forschung zurecht zunehmend als Knotenpunkte im geselligen Netz wiederentdeckt und als „Musenhöfe“ 135 diskutiert werden. Der Begriff „Musenhof“ bedarf zwar, auf

134 Gustav von Brinckmann an Karoline von Berg, 12. 10. 1801, ungedruckt, GSA 5/1. Macedoine bedeutet, in Übertragung vom französischen Begriff für „Obstsalat“, eine willkürliche Mischung an Gästen.

135 Aus Sicht der Salonforschung ist eine wissenschaftlich vergleichende Auseinandersetzung mit beiden Begriffen „Salon“ und „Musenhof“ neu und notwendig. Der Begriff „Musenhof“ wird in der Literatur- und Kulturgeschichtsforschung überwiegend mit dem Hof und der Regentschaft Anna Amalias von Sachsen-Weimar-Eisenach verbunden. Längst nicht alle Arbeiten enthalten eine solch kritische Auseinandersetzung mit dem Begriff wie der Sammelband von Joachim Berger (Hrsg.): Der Musenhof Anna Amalias: Geselligkeit, Mäzenatentum und Kunstliebhaberei im klassischen Weimar, Köln 2001. Eine irreführende Assoziation hat Theodore Ziolkowski, wenn er die Hinterhofwohnung Dorothea Mendelssohn Veit Schlegels in der Berliner Ziegelstraße als ,in einem sehr präzisen Sinn zum Musenhof der Berliner Romantik“ erklärt. Ziolkowski 2006, S.37. Viel zu erwarten ist von einem neuen Forschungsprojekt zur „Neuständischen Geselligkeit“, das sich den Vergleich der städtischen 
märkische und mecklenburgische Landsitze angewandt ebenso wie im Falle der Weimarer Herzogin, noch genauerer Definition. Allerdings suggeriert er zurecht, dass man an oder auf den Hof „gezogen“, also eingeladen werden musste. Das Auswahlprinzip war sicherlich ein anderes als in der Stadt mit ,vorbeikommenden' Gästen eines offenen Hauses.Eine grundsätzliche Frage an die „Musenhof“-Forschung wäre, welche gesellschaftlichen oder individuellen Voraussetzungen dazu gehörten, Personen jüdischen Hintergrunds einzuladen - wie es im Falle des Aufklärers und Salongastes Salomon Maimons geschah, der auf dem Gut des Grafen Kalckreuth lebte und arbeitete. ${ }^{136}$

Ein ganz anderer Landsitz, der zu ständeübergreifenden Begegnungen führte, aber in der Literatur bisher kaum diskutiert wurde, wurde von Lea Mendelssohn Bartholdy Brinckmann gegenüber als ehemaliger Treffpunkt in Erinnerung gerufen, die so genannte Bartholdische Meierei. ${ }^{137}$ Die prachtvolle landschaftliche Anlage der Familie Itzig lag außerhalb Berlins, südöstlich des Schlesischen Tors. Lea Mendelssohn Bartholdy nannte sie einen „hübschen Vereinigungsort“, zu dem sie Personen ihres Interesses lud.138 Ein Billet Sara Levys deutet darauf hin, dass auch andere Salonfrauen der Familie Itzig ihre Gäste „zu den Bewohnern der Meyerey vor dem Schlesischen Thore führen“ konnten. ${ }^{139}$ Im Briefwechsel mit Brinckmann am vor allem der Berliner Aufenthalt von Stéphanie-Félicité de Genlis zur Sprache. ${ }^{140}$ Die exilierte ehemalige Prinzen-

Geselligkeit Berlins mit der ländlichen in Brandenburg um 1800 vorgenommen hat. Vgl. Reinhard Blänkner: Salons und Musenhöfe - Neuständische Geselligkeit in Berlin und in der Mark Brandenburg um 1800. Ein Forschungsumriss, in: ders. / de Bruyn 2010, S.11-34. Zum „Musenhof“ der Luise von Voss auf Gut Giewitz s. Hannah Lotte Lund: ,Eine Menge umgänglicher Bekannte von meinem Gehege - Salongeselligkeit zwischen Berlin und Brandenburg um 1800. Knotenpunkte im kommunikativen Netz, in demselben Band, S. 4974. In diesem Falle war es Brinckmann selbst, der Giewitz zu einem „Musenhof“ erhob. Wohl nannte er fast alle seiner Korrespondentinnen zu irgendeinem Zeitpunkt seine Muse, nach Giewitz aber wollte er wie „nach Ferrara zurückkehren“, also an den Musenhof der Lukrezia Borgia. Gustav von Brinckmann an Luise von Voss, 28. 11. 1805, ungedruckt, GSA 5/26,8. 136 Eine Frage, der am Beispiel der Familie von Voss noch nachzugehen wäre, ist, inwieweit sich das nationalpolitische Engagement des Grafen auf dem Gut deutlicher als in Berlin Bahn zu brechen vermochte. Vgl. den Bericht von Gustav von Brinckmann an Karoline von Berg, 19. 10. 1805, GSA 5/1.

137 Zur Geschichte und Bebauung des Grundstück s. Elke von Nieding: Versteckt in der Geschichte - Bartholdys Meierei, in: Mendelssohn Studien 15 (2007), S.107-119.

138 Lea Mendelssohn Bartholdy an Garlieb Merkel, 26. 8. 1799, zit. nach: Hensel 1924, Bd. 1, S. 101.

139 Sara Levy an Gustav von Brinckmann, 16. 8. 1801, ungedruckt, BA L.

140 Stéphanie-Félicité Ducrest de Saint-Aubin (1746-1830), später Comtesse de Genlis, Dame der Gesellschaft und Bestsellerautorin, lebte 1798 im Exil in Berlin. Als ehemalige Erzieherin und Gesellschafterin am französischen Hof kann sie nur beschränkt als Salonière gelten, wurde aber von ihren Zeitgenossen als Frau wahrgenommen, die das Talent besaß, 
erzieherin und Autorin lebte in unmittelbarer Nähe dieses Itzigschen Sommeraufenthalts, was zu einem relativ ungezwungenen Kontakt geführt habe. ${ }^{141}$

Sie lebt hier äußerst eingezogen $u$ sparsam, hat aber ächt französische gute Laune $u$ Frohsinn, um das herrlich zu finden. Denken denn auch Sie schlecht über ihren Charakter wie die ganze Welt? Geistreich, witzig, talentvoll, interessant $u$ angenehm ist sie, man kann nicht mehr u keiner versteht besser die Kunst, einem ganze Stunden mit süßer Beredsamkeit wegzuschwazzen. ${ }^{142}$

Die Bekanntschaft der Familie Itzig und anderer Mitglieder der Salongesellschaft mit Madame de Genlis könnte symbolisch stehen für den Umstand, dass politisch instabile Verhältnisse einerseits, und räumliche Nähe andererseits, zu Kontakten führten, die ein Jahrzehnt vorher oder später nahezu undenkbar waren.

Die Diskussion von Katalysatoren standesübergreifender Geselligkeit führt, zurück in der Hauptstadt, zu zwei weiteren Merkmalen des geselligen Gewebes nach 1800: die Rolle von Gastgebern aus und in diplomatischen Häusern für gemischte Geselligkeit und ein sich abzeichnender Wandel in der Wertung eben dieser Mischungsversuche. Brinckmanns Briefe sprachen regelmäßig von Zusammentreffen in den Häusern des spanischen und des englischen Gesandten, sowie natürlich besonders ausführlich von Einladungen in die Räume seines Dienstherren, des schwedischen Gesandten Engeström, bzw. seine eigenen. Wie seinen Berichten an Luise von Voss und Karoline von Berg zu entnehmen ist, mischte er dabei nicht zufällig, sondern absichtsvoll Gelehrte und Hofleute oder Freundinnen mit aristokratischem, jüdischem und Bühnenhintergrund. Das (neue) gesellschaftliche Engagement der Diplomaten wurde bestätigt von Wilhelm von Humboldt, der 1801 nach seiner Rückkehr aus Paris seine Heimatstadt sehr verändert fand und an Schlabrendorf schrieb: „Sie, der Sie so lange abwesend sind, würden die größeste Veränderung in Absicht der auswärtigen Gesandten antreffen. In Ihrer Zeit konnte man sie nur mit Vorsicht sehen. Jetzt macht fast niemand ein Haus als sie“. .43

An Brinckmanns Schilderung dieser Zusammentreffen wird dabei eine sich ändernde (Selbst-)Wahrnehmung ablesbar: Während er bis 1801 für die Freund-

an jedem ihrer Lebensorte einen Kreis gebildeter Personen an sich zu ziehen. Die Bekanntschaft der internationalen Berühmtheit und ,Starautorin' des 18. Jahrhunderts wurde während ihrer Exilzeit in Berlin und später auf Besuchsreisen in Paris geradezu gesucht. 141 Auch andere Frauen der Salongesellschaft traten zu ihr in Kontakt. Sie verkehrte bei der Herzogin von Kurland und schrieb für das Liebhabertheater der Familie Cohen bzw. Sara Meyer Grotthus Stücke, mit der sie lange Jahre danach noch brieflich in Verbindung blieb. 142 Lea Salomon Bartholdy an Gustav von Brinckmann, 10. 12. 1798, ungedruckt, BA M. 143 Wilhelm von Humboldt and Gustav von Schlabrendorf, 13. 7. 1801, in: Kappstein 1917, S. 169 . 
schaft mit jüdischen Salonièren warb, ohne dass die Herkunft überhaupt thematisiert wurde [vgl. V.3], schien Ende des Jahres 1801 das Zusammentreffen von Juden und Nichtjuden bereits als riskant empfunden $\mathrm{zu}$ werden. Brinckmann beschrieb, wie sich seine engagierte und wohl etwas naive Dienstherrin in die Bredouille brachte, als sie für Fanny von Arnstein und ihre Tochter Henriette einen Empfang veranstalten wollte. Das Unterfangen löste schon im Vorfeld einen Skandal aus:

Es wurde zum Theil en l'honneur de Madame d'Arnstein gegeben und sollte daher aus Furcht vor den - Christen eigentlich aus einer ziemlich eingeschränkten Anzahl Personen bestehen. Unglücklicher Weise war vorigen Freitag eine grosse Assemblée bei O’Farils, wo Fr.v. Engs. doch der Versuchung nicht widerstehen konnte, mündlich noch sehr Viele zu bitten, und so hielten sich alle unsre gewöhnlichen Sonntagskinder, die heut weggelassen waren, für äusserst beleidigt [...], ob sie sich auch nicht zu viel bieten liessen?144

Wie Brinckmann weiter berichtete, zeigten sich dann aber viele bemüht, das Beste aus der Situation $\mathrm{zu}$ machen, vor allem, indem sie die Herkunft der Ehrengäste geflissentlich übersahen:

Frau von Arnstein hätte noch durchgehen mögen, als unleugbare Baronne d'Empire, eben so wie ihre Tochter, zu deren Entschuldigung Baron Stjerneld unaufhörlich anführte: sie habe noch gar keine Religion [...]. Stadion hielt sich an das Solide, die Milionen; die französische Gesandtschaft an das Vergängliche die Schönheit, und so wurde die niedliche Henriette, doch eigentlich nicht wie eine Jüdin im Christenhause behandelt.

Brinckmann selbst beteiligte sich an der dann folgenden ,Verschleierungstaktik':

Beinah übler wäre es der Baronesse Boye gegangen, wenn mir die Engs. nicht befohlen hätte ihr gleich eine Spielpartie [...] zu schaffen, mit ausdrücklicher Verschweigung ihrer Nazionaleigenthümlichkeit. - Als aber Madam Levy, und der Banquier Levy, beide jüdischer Religion, und kaum bürgerlich geschweige adlich, in den Salon traten - glaubte ich in der That daß Gentzen der Schlag rühren sollte, und er lispelte nur ganz ängstlich: „Das würde unmöglich gut gehen.“ Ich versicherte ihm indeß: Er möchte nur für sein Spiel sorgen; ich wollte schon meiner Seits diese schlechten Karten mit hinlänglicher Feinheit ausspielen. [...] Ich unterhielt mich ebenso vernünftig wie angenehm mit Mad. Levy, die übrigens gar nicht verlassen war, da mehr wie die Hälfte von der Ges. männlichen Gesellschaft ihr Haus frequentiren. [...] $]^{145}$

144 Dies und das folgende Zitat Gustav von Brinckmann an Karoline von Berg, 19. 10. 1801, ungedruckt, GSA 5/1. „O'Farils“ ist ebenfalls ein diplomatisches Haus.

145 Gustav von Brinckmann an Karoline von Berg, 19. 10. 1801, ungedruckt, GSA 5/1. Streichung im Original. Fanny von Arnstein war gemeinsam mit ihrem Gatten Nathan von Arnstein in den Freiherrenstand erhoben worden. „Baronesse Boye“ meint Hitzel Fließ Boye Sparre. „Madame und Bankier Levy“ sind die Salonière Sara Levy, Schwester Fanny von Arnsteins und ihr Gatte Salomon Levy. Beide blieben lebenslang ungetauft. 
Abschließend gab Brinckmann seiner Freude Ausdruck, dass letztendlich der gute Geschmack in der Gesellschaft die Oberhand gewonnen hätte, wozu er das Erscheinungsbild der Frauen von Arnstein ebenso wie das mischende Engagement seiner Gastgeberin zählte.

Bemerkenswert sind an dieser Schilderung drei Elemente: Erstens die Tatsache, dass eine jüdische Herkunft offizielles Thema am Teetisch wurde, bzw. dass sie als „Nazionaleigenthümlichkeit“ nicht mehr irrelevant war, sondern bedacht und am besten „verschwiegen“ werden musste. Zweitens fällt die unterschiedliche Sicht der Freunde Friedrich von Gentz und Gustav von Brinckmann auf die Situation auf, und dass es Brinckmann 1801 noch als ein Zeichen von Gewandtheit galt, sich über gesellschaftliche Herkunft und damit verbundene Vorurteile hinwegzusetzen. Drittens fällt das fragile Gleichgewicht der Gesellschaft ins Auge, die Tatsache, dass auf ein und derselben Gesellschaft, im Wortessinne im selben Raum, auf der einen Seite die Gastgeberin die jüdische Herkunft einiger Gäste zu verschweigen müssen glaubte, auf der anderen eine andere jüdische Salonière aber, die als solche bekannt war, von nichtjüdischen Freunden sichtlich umlagert wurde. Wobei wiederum zu fragen wäre, was an Sara und Salomon Levy als „jüdisch“ erkennbar gewesen sein soll. Interessant ist, dass Brinckmann sich gewissermaßen selber ins Wort fiel, insofern die Hälfte nur der „männlichen“ Gesellschaft bei Levys verkehre, was den Befund aus Kapitel III bestätigt, dass Frauen christlicher bürgerlicher Herkunft jüdische Häuser selten besuchten. Der Bericht deutet in summa auf eine veränderte Wahrnehmung in der Berliner Gesellschaft um 1800. Wie unter V.3 dargestellt, sollte Brinckmanns Haltung von diesem Stimmungsumschwung in der Gesellschaft nicht lange unbeeinflusst bleiben.

\title{
Gastgeberinnen zwischen Konkurrenz und Gruß-Freundschaft
}

\author{
Weder Luise von Berg, noch ihre reitende Mutter / \\ Noch Henrietten die ich Nymphe der Donau genannt / [...] \\ Keine von allen, ich schwör es, lad ich zum herrlichen Thee / [...] \\ und verspreche Du sollst Göttin des Festes mir sein. \\ „Brief Brinckmanns“ an eine jüdische Gastgeberin, Parodie von Ludwig Robert 146
}

Es stellt sich letztlich die Frage, wie die Lieblingsgastgeberinnen des Diplomaten zueinander standen, auch, ob er sie einander bekanntmachte. Dabei ist auffallend, dass trotz der guten Überlieferung nicht genau festzustellen ist, wie es zu einem Kennenlernen zwischen von Voss und Levin Varnhagen kam, das

146 Robert 1876, S. 139. 
zwischen 1801 und 1802 stattgefunden haben muss. ${ }^{147}$ Jedenfalls waren die Frauen sich über die Bedeutung der jeweiligen anderen im Leben des gemeinsamen Gastes Brinckmann durchaus bewusst. Die Nichtaristokratinnen nahmen die Konkurrenz mit einem ironisch-scherzhaften Ton: Rahel Levin Varnhagen sprach von „Ihrer Berg“ und „Ihrer Voss“, während Lea Mendelssohn Bartholdy spottend fragte, ob ihn wirkliche Zahnschmerzen abhielten zu kommen, oder „niedliche Ursachen, als die Unzelmann, oder sublime Ursachen, als Gräfin Voß, oder frivole Ursachen, als Mad d'Engstroem“?148 Rahel Levin Varnhagens Bruder Ludwig Robert spottete über Brinckmanns Geselligkeitsmanagement in oben zitiertem gefälschtem Brief, in dem er den Diplomaten als von der Qual der Wahl gekennzeichnet portraitierte, und dabei Gastgeberinnen jüdischer, bürgerlicher und aristokratischer Herkunft nebeneinander stellte. ${ }^{149}$

Ein Unterschied wurde merkbar, als es ums Heiraten ging. Bezeichnend ist der Aphorismus Rahel Levin Varnhagens: „Ich bin aber schon längst mit ihm [Graf Voss] ausgesöhnt, seit ich weiß daß ihn Luise liebt, ich glaubte, sie hätte

147 Direkte Briefwechsel zwischen Rahel Levin Varnhagen und Luise von Voss sind nicht überliefert. Dennoch scheint es zu einigen Begegnungen in Gesellschaft bzw. am dritten Ort gekommen zu sein. Noch 1801 aber schickte Brinckmann eine von ihm verfasste Charakteristik Rahel Levin Varnhagens an Luise von Voss mit den Worten: „Das Original hat Ihnen nie uninteressant geschienen, und so schenken Sie wol auch der Kopie einige Augenblicke“, was darauf schließen lässt, dass die Frauen einander in Gesellschaft begegnet waren oder Brinckmann so lebendig von Rahel Levin Varnhagen erzählt hatte, dass Luise von Voss sie fast im Original kennen konnte. Gustav von Brinckmann an Luise von Voss, 22. 10. 1801, ungedruckt, GSA 5/26,4. Auf eine persönliche Bekanntschaft bereits 1802 deutet der Umstand, dass Brinckmann, als er einmal Klatsch über Schlegel und Goethe verbreitete, die Gräfin explizit bat, nicht einmal mit der kleinen Levin darüber zu reden. 14. 10. 1802, ungedruckt, GSA 5/26,5. Es ist davon auszugehen, dass Rahel Levin Varnhagen Lea Mendelssohn Bartholdy sowohl aus dem Haus Itzig wie über ihren Mann Abraham geläufig kannte, mit dem sie langjährig befreundet war. Nach 1819 scheint es zum lockerem, regelmäßigen gesellschaftlichen Umgang gekommen zu sein. Ein Briefwechsel der Frauen untereinander ist nicht überliefert, wie Lea Mendelssohn Bartholdy rückblickend meinte, schrieb sie „nie einen Brief, zuweilen nur billete an Rahel“. An Henriette Arnstein Pereira, 27. 5. 1836, in: Mendelssohn Bartholdy 2010, Bd. 1, S. 371.

148 Lea Mendelsohn Bartholdy an Gustav von Brinckmann, 10. 2. 1802, ungedruckt, BA M. Madame Engström war die Gattin des Vorgesetzten von Brinckmann. Es ist nicht restlos zu beweisen, aber wahrscheinlich, dass sich Grüße in den Briefen an Gustav von Brinckmann auf Levin Varnhagen beziehen: „Wenn Sie die Kleine sehen, grüßen Sie herzlich - Voss thut ein gleiches für Sie.“ Luise von Voss an Gustav von Brinckmann, 17. 9. 1804, ungedruckt, BA V. 149 Neben den zitierten Luise und Karoline von Berg sowie Henriette Arnstein Pereira werden in der Elegie noch Friederike Unzelmann, Henriette Herz, Sophie Sander sowie Brinckmanns Hausherrin Engström genannt, schließlich natürlich die adressierte Hitzel Fließ Boye Sparre. Da das Gedicht Luise von Berg mit ihrem Mädchennamen nennt, ist es spätestens 1800/01 entstanden. 
ihn nur geheirathet“". ${ }^{150}$ Diesem solidarischen Ton stand faktisch allerdings eine ,trennende Gemeinsamkeit‘ entgegen: Karl Graf Finck von Finckenstein, der mehrere Jahre als Verlobter Rahel Levin Varnhagens auftrat, wurde während dieser Zeit auch als Kandidat für die Hand Luises gehandelt. Auf diese Gerüchte hin sprach Burgsdorf Brinckmann gegenüber von einer „großen Nachricht“. Er gab seiner Verwunderung Ausdruck, dass sein Vetter, der doch die „älteste und größte Familie“ [gemeint die jüdische] erobert habe, doch ein standesgemäßes Familienbedürfnis habe. ${ }^{151}$ Als Rahel Levin Varnhagen davon erfuhr, riet sie Karl, Luise zu heiraten, um der Farce ein Ende zu machen. Sie fasste den Unterschied zwischen sich und der Aristokratin aus der Perspektive der Gesellschaft deutlich zusammen: „Sie ist jung, hübsch, liebenswürdig, reich; alles vereinigt sich für sie; ihr Glück wäre das Deinige, die Zufriedenheit beider Familien. Ich habe nichts dem entgegenzusetzen, was man nennen könnte; und ich schweige“. ${ }^{152}$

Im Gegensatz zu ihrem unterschiedlichen Wert auf dem Heiratsmarkt galten die Salons beider Frauen, besonders was die Vernetzung in literarisch interessierten Kreisen betraf, Beteiligten als gleichwertig. Als beispielsweise Burgsdorf Unterschriften für August Wilhelm Schlegels Vorlesungen sammeln wollte, hielt er die Geselligkeiten bei Frau von Berg, Rahel Levin Varnhagen und Sara Meyer Grotthus für gleichermaßen geeignet. ${ }^{153}$ Wirkliche Vergleiche der Geselligkeiten sind kaum zu finden. ${ }^{154}$ Noch 1803 konnte Gentz eine Reihung aufmachen: „Empfehlen Sie mich der Levi, der Frau v. Berg, der Gräfin Voß, und allen, die

150 Rahel Levin Varnhagen an Gustav von Brinckmann, 17. 11. 1801, hier nach SV 38, auch in: GW I, S. 249.

151 Wilhelm von Burgsdorf an Gustav von Brinckmann 21. 4. 1797, in: Cohn 1907, S. 96. Da die tatsächliche Konkurrenz, von Karl August Varnhagen erstmalig und relativ dramatisierend dargestellt, nur mit Andeutungen belegbar ist, ist der vorsichtigen Auslegung de Bruyns zuzustimmen, dass es weniger darauf ankommt, „inwieweit Klatsch Tatsachen wiedergibt“, als darauf, wie ihre ,Freunde“ mit diesem Gerücht umgehen: „Der Heiratsplan, den Karl angeblich hat, wird hier in einer Weise kommentiert, die man von zwei vertrauten Freunden Rahels nicht erwartet. Ihr Glück, ihr Unglück interessiert die beiden nicht; die Freude an der Neuigkeit deckt jede Anteilnahme zu.“ de Bruyn 1985, S. 42. Vgl. ähnlich Cohn 1907, S. 206. 152 Rahel Levin Varnhagen an Karl Finck von Finckenstein, 4. 9. 1799, in: de Bruyn 1998, S. $281 \mathrm{f}$.

153 Wilhelm von Burgsdorf an Rahel Levin Varnhagen, 15. 10. 1801, in: Cohn 1907, S. 183. 154 Das erste und einzige Mal, dass Brinckmann die Geselligkeit Rahel Levin Varnhagens dem maßvollen Umgang mit Luise von Voss gegenüberstellte, geschah nach einem Dinner, das ihm als solches „unästhetisch leichtfertig“ war. Gustav von Brinckmann an Luise von Voss, 4. 11. 1801, ungedruckt, GSA 5/26,4. Im selben Brief stellt er die „Theestündchen“ der Luise von Voss allerdings auch anderen leeren aristokratischen Gesellschaften gegenüber, sodass das eigentlich Irritierende hier der „Ton“ der Gesellschaft, nicht ein spezifisch ,jüdisches‘ Element war. 
Sie lieben“. ${ }^{155}$ Eine einzige hierarchisierende Bewertung der Salons der Rahel Levin Varnhagen und Luise von Voss ließ sich bisher finden, bei Wilhelm von Humboldt, der Brinckmann vorschlug:

Ein kühnes Rendezvous wüßte ich wohl, ich halte es nur für zu kühn. Das wäre bei der Gräfin Voß. Sie hat mir gestern wieder unendlich gefallen, - ach! Gott! und wie ziehe ich sie allen Gräfinnen vor, die man erst mit Jüdinnen vergleichen muß, um sie erträglich zu finden. [...] Da das Projekt zur Gräfin V. wohl gewiß auch Ihnen zu kühn vorkommt, so sinke ich wieder zu Israel herab, und schlage Ihnen die Levin vor. ${ }^{156}$

Der Unterschied in der gesellschaftlichen Herkuft zwischen beiden Frauen relativierte sich allerdings mit der Zeit. In späteren Jahren scheint es zu einigen entspannteren gesellschaftlichen Begegnungen zwischen den beiden Frauen gekommen zu sein. 1813, noch vor der Ehe mit Varnhagen, berichtete Rahel Levin Varnhagen beiläufig, dass sie mit Luise von Voss bei Friedrich Schleiermacher Tee getrunken und sich ausführlich unterhalten habe. Und in den 1820er Jahren wurde sie geradezu Brinckmanns Berichterstatterin aus dem Hause Berg-Voss. ${ }^{157}$

Nach dem Abschied von Berlin hatte sich Brinckmann sich anscheinend darauf besonnen, was ihn nach eigener Aussage mit Levin Varnhagen verbunden hatte, die Welt ernsthaft studieren zu wollen, ohne sich aber vom Ernst der darin vorhandenen Strukturen oder Niederlagen anstecken zu lassen, sondern diesen mit Witz oder Ironie zu begegnen. 1808 ermutigte er sie, mit einem ihrer eigenen Zitate: „Wir wollen (Auch wieder nach Ihnen) selbst das Unglück wie ein Kunstwerk betrachten u. ehren! [...] Und so leben Sie wohl, wie eine Kunstkennerin"!158 Problematisch hatte dies Konstrukt einer ,Kunstbetrachtung“, einer gewollten Distanzhaltung in Momenten werden müssen, in denen einer von beiden sich in den verspotteten gesellschaftlichen Strukturen positionieren musste und nicht mehr allein beobachtend sein konnte, etwa als Diplomat einer Nation im Krieg oder als Jüdin auf der Suche nach einem passenden Ehemann.

155 Friedrich von Gentz an Gustav von Brinckmann, 25. 8. 1803, in: Wittichen 1910, S. 150.

156 Wilhelm von Humboldt an Gustav von Brinckmann, undatiertes Billet, in: Leitzmann 1939, S. 181.

157 Ein Bericht liest sich fast medizinisch und nicht übermäßig respektvoll: „Die Gräfin Voß ist wohl; ihre Tochter zum zweitenmal im Kindbett. Die Gräfin noch immer nicht begreifend, warum Sie nicht antworten, ich sehe sie manchmal bei Bekantinnen; Frau von Berg hin und her reisend [...]. Kurz, obgleich alt, die alte. Gräfin Voß wohnt in der Kochstraße; das Haus hat einen Garten; der Mann eine Perücke: die zweite Tochter rührend hübsch: etwas schwacher Brust.“ Rahel Levin Varnhagen an Gustav von Brinckmann, 24. 4. 1824, dies ungedruckt, SV 38. Über den Tee bei Schleiermacher: An Gustav von Brinckmann, 11. 1. 1813, in: GW II, S.77 f. 158 Gustav von Brinckmann an Rahel Levin Varnhagen, 27.1. 1808, ungedruckt, SV 38. 
Aus der Perspektive Schwedens, oder der des Alters, konnte Brinckmann anscheinend das wiederfinden, was ihn von Anfang an angezogen hatte, eine geistreiche Frau.

\title{
2 „Freigeistige Amazonen“ oder Ausnahmefrauen? - Zur Diskussion von Geschlechterstereotypen im Briefwechsel
}

\author{
Auch sind ja die Weiber eigentlich wahre Poesieen der Schöpfung, \\ [...] als blosse Impromtpus oft umso verführerischer. Die Männer sind alle Prosa, \\ [...], so bleiben die Meisten auch Leider! dem Zeitungsstyl näher. \\ Gustav von Brinckmann an Rahel Levin Varnhagen, 1799
}

\begin{abstract}
Dass mir diese sanfte Weiblichkeit (die eigentlich nur Weichlichkeit heißen sollte) nie genügen würde. Unsere Weiblichkeit enthält und erfordert vielleicht den größten Kraftaufwand, [...] - der Mann kann sich mit Tugenden begnügen, das Weib braucht Tugend (wie Schiller sehr schön sagt) [...] wenn sie irgendetwas wehrt seyn will.

Luise von Voss an Gustav von Brinckmann, 1804159
\end{abstract}

Das Vorhaben, die in diesen Korrespondenzen verhandelten Geschlechterbilder zu untersuchen, ist nicht nur von der disziplinären Verortung der Arbeit, sondern vor allem von den untersuchten Schreibenden selbst angeregt: Nicht nur gestaltete Brinckmann in beinahe jedem seiner Briefe mit umfänglichen Komplimenten Ideale der Weiblichkeit mit Worten. Immer wieder gaben ihm und seinen Brieffreundinnen auch Begegnungen mit realen Personen, wie Germaine de Staël oder literarischen Figuren, wie Schlegels Lucinde, Anlass zu theoretischen Reflexionen über die Geschlechter - seien sie abstrakt formuliert, wie die oben zitierte Kritik Luises von Voss' am Tugendbegriff, oder als Verallgemeinerung, wie bei Brinckmann, der oft pauschal von den oder allen Frauen sprach. Auf eine Analyse der Weiblichkeitskonzeption Gustav von Brinckmanns [V.2.1] und seines Konzepts der Ausnahmefrauen [V.2.2] folgt daher eine Darstellung der Lucinde-Rezeption bei den hier untersuchten Schreibenden und in der Berliner Salongesellschaft [V.2.3]. Zum zeitgenössi-

159 Gustav von Brinckmann an Rahel Levin Varnhagen, 10. 10. 1799 ungedruckt, SV 38; Luise von Voss an Gustav von Brinckmann, 8. 3. 1804, ungedruckt, BA V. Das Zitat geht weiter: , - ihre Bestimmung vollenden, in ihrem Kreise wirken und schaffen will, so muss sie Kraft innere eigene Seelen Kraft haben - und wo die so ganz fehlt, da sind nur die Weiber wie Kinder, aber das sichere beruhigende Gefühl von Liebe u Freundschaft können sie mir nicht mehr geben -“. Ebd. Der Begriff aus der Titelzeile „freigeistige Amazone“ ist eine Zusammenziehung aus einem weiter unten zitierten Brief Brickmanns an Luise von Voss, 18. 12. 1799, ungedruckt, GSA 5/26,2. 
schen Diskurs über die Geschlechter gehörte neben der Debatte über literarische Geschlechterbilder auch immer die Auseinandersetzung über die Rollenbzw. Sphärenaufteilung im realen Leben. Abschließend wird daher die Einstellung der fünf Schreibenden zu Frauen in der Öffentlichkeit befragt, am Beispiel der Autorschaft von Frauen [V.2.4]. Dass hier der Schwerpunkt erneut auf einer Weiblichkeitskonzeption und einer männlichen Perspektive zu ruhen scheint, liegt daran, dass nur von Brinckmann so viel Textmaterial vorliegt, dass ein Gesamteindruck herausgefiltert werden kann. Von Lea Mendelssohn Bartholdy und Luise von Voss sind auf der Grundlage des gesichteten Materials bemerkenswerte Interventionen festzuhalten, aber kein konsistentes Bild. Im Falle Rahel Levin Varnhagens schließlich gibt es, wie erwähnt, bereits so viele und gegensätzliche Interpretationen auf gemischter Zitatenbasis, dass an dieser Stelle die Analyse bewusst auf die Position beschränkt wird, die sie Brinckmann gegenüber einnahm. Es geht also im Folgenden um das Nachzeichnen der Standpunkte, die die Schreibenden mit ihrer Korrespondenz in der zeitgenössischen Geschlechterdebatte bezogen haben oder hätten.

\subsection{Zur Weiblichkeitskonzeption Gustav von Brinckmanns}

Es fällt auf, daß Gustav von Brinckmann in seinen Komplimenten an die hier vorgestellten Frauen ihr Äußeres, ihre Schönheit fast gar nicht thematisierte. Äußerungen, die über einen verbalen Handkuss hinausgingen, fielen selten, und fast nie nahm er in direkten Äußerungen auf den Körper Bezug. ${ }^{160}$ Das ist insofern relevant, als Brinckmann nach 1805 eine ,neu empfundene‘ Fremdheit seiner jüdischen Freundinnen in deren Äußeren erkennen wollte, welches er vorher weder positiv noch negativ kommentiert hatte. [s. V.3].

Zentrale und durchweg positiv besetzte Begriffe waren bei Brinckmann „Liebenswürdigkeit“, „Grazie“ und „Geist“, Eigenschaften, die sich vor allem im Umgang manifestieren. ${ }^{161}$ Wie oben angedeutet, bewegte sich Brinckmann mit seiner öffentlichen Bewunderung für intelligente Frauen außerhalb des Zeitgeistes, insofern er Frauen auch zu intellektuellen Betätigungen verhalf

160 In Kommentaren über Dritte gab es diese zwar gelegentlich - so wurden etwa mehrfach Caroline von Humboldts Augen betont oder daß Madame de Staël keine schönen Züge habe - aber auch dies geschah in einer Weise, die einem Außenstehenden keinen gültigen Eindruck vermitteln würde.

161 Bezeichnend für seine dichotomische Denkungsart ist die Formulierung an Rahel Levin Varnhagen aus Paris: „Es mag also zum Theil meine Schuld sein, daß ich noch keinen interessanten Mann, und kaum eine liebenswürdige Frau entdeckt.“ Gustav von Brinckmann an Rahel Levin Varnhagen, 7. 10. 1798, in: Wachtmeister 1871, S. 5. 
und sie zum Schreiben anregte. Mit seiner Vorliebe für Dichotomien hingegen erwies er sich als Denker der Epoche und rückte mit seinen Formulierungen und Gegensatzpaaren in die Nähe Friedrich von Schillers, etwa in einem Distichon, das er 1799 Luise von Voss beilegte:

\author{
Bestimmung \\ Groß wird jeder durch seiner Natur erfüllte Bestimmung: \\ Thaten veredlen den Mann, schöne Gefühle das Weib. ${ }^{162}$
}

Seinem Freund Wilhelm von Humboldt schien er die Begrifflichkeit für einen anderen Vers entliehen zu haben:

\author{
Die Geschlechter: \\ Beiden Geschlechtern verlieh die Natur verschiedene Stärke: \\ ihrer zerstörenden Macht gleichet der männliche Trotz; \\ wie die belebende Kraft der unsterblichen, still und unmerklich, \\ unwiderstehlich und sanft wirket der weibliche Sinn. ${ }^{163}$
}

Die einander entgegengesetzten Kräfte als Bewegungskräfte der Natur entsprechen Humboldts männlichem und weiblichem „Prinzip“, die ebenfalls von der Natur als notwendig verschiedene (Zeugungs-)Kräfte eingerichtet wurden. Wie Schiller kleidete auch Brinckmann diesen Humboldtschen Gedanken in klare und zugleich verbrämte Bilder des männlichen Trotzes und der „unwiderstehlichen" weiblichen Sanftheit.

In Versform goss Brinckmann seine Ansichten zur Geschlechterfrage nur selten, aber die Unterschiede zwischen den Geschlechtern bzw. die Notwendigkeit solcher Unterschiede wurde er nicht müde zu betonen, spielerisch einzuarbeiten, auch $\mathrm{zu}$ theoretisieren. ${ }^{164}$ Selbstironisch sprach er einmal sogar von einem „Fragment meiner Theorie der Weiblichkeit“, das er dann an mindestens zwei Leserinnen gleichzeitig schickte. ${ }^{165}$ Tatsächlich liest sich seine „Theorie“ eher wie ein Plädoyer gegen die Aufhebung der Schranken, gegen zuviel Gleichheitsbestrebung:

162 Gustav von Brinckmann an Luise von Voss; 10. 4. 1799, ungedruckt, GSA 5/26,2.

163 Gustav von Brinckmann an Luise von Voss; 10. 4. 1799, ungedruckt, GSA 5/26,2.

164 Oft kam er in einem Brief von verschiedenen Anlässen immer wieder auf dieses Thema zurück. So kam er beispielsweise von den „Schranken der Geschlechter“ darauf, dass „die Weiber [...] im Ganzen mehr Zartheit des innern Sinnes besizen als wir“, und darauf, dass die Staël abstäche „gegen ihr eigenes Geschlecht. Das unsrige lebt mehr in der Politik.“ Gustav von Brinckmann an Luise von Voss, 18. 12. 1799, ungedruckt, GSA 5/26,2. 165 Brinckmann zitiert dabei seinen eigenen, nicht überlieferten Brief an Henriette Mendelssohn in einem Brief an Luise von Voss, 29. 10. 1801, ungedruckt, GSA 5/26,4. 
Und am Ende, meine Freundin! wer gewinnt wol bei dieser Ueberkultur des Zeitalters, bei diesem Verwischen der Grenzlinien zwischen den Geschlechtern [...] Ihr holden und liebenswürdigen Kezerinnen? Ich fürchte weder wir noch Ihr! Keine Helden Kraft des Genies ersezt den aufgelösten Zauber jener sittsamen Anmut, die allein das eiserne Schicksal versöhnt, und für deren Verlust wir Euch doch früher, oder später verantwortlich machen. [...] vermögt Ihr wol eigenmächtig den Götterspruch zu entkräften, der Eure Höhere Würde nun Einmal an die Bedingung des Duldens geknüpft hat?166

Während Brinckmann einerseits hier mit Schillers Dichotomie von weiblicher Anmut und männlicher Würde spielte, kommt andererseits deutlich zum Ausdruck, dass er durch den Zugewinn an Autonomie auf Seiten des weiblichen Geschlechts eingestandenermaßen den Verlust an Lebensqualität für das männliche fürchtete. ${ }^{167}$

In dem Bestreben, aus der Polarität Galanterie herauszuschlagen, erwies sich Brinckmann als Vertreter der klassischen Geschlechterideologie, bei der eine, oft mythische, Überhöhung des Weiblichen den Ausschluss der Frauen aus wesentlichen Gesellschaftsbereichen verbrämte. Man kann durchaus von den mehrfach thematisierten „Sfären“ als grundlegendem Denkmodell Brinckmanns sprechen. ${ }^{168} \mathrm{Zu}$ der Einstellung, dass man einerseits denkende Frauen nicht genügend würdige, dass aber andererseits die Wirkung weiblicher Personen im privaten Schreiben und Umgang läge, passen auch die Literaturempfehlungen, die Brinckmann in seine Briefe flocht. Er stellte sich in eine Reihe mit- und empfahl Klopstock, Kant oder Rousseau. ${ }^{169}$ Andererseits muss er auch die für ihre Liberalität berühmten Briefe der Madame Sévigné gelobt haben, denn Luise von Voss antwortete 1804 zweifelnd: „Die Briefe der Sévigné habe

166 Gustav von Brinckmann an Luise von Voss, 29. 10. 1801, ungedruckt, GSA 5/26,4. Hervorhebung im Original.

167 In seiner ästhetisch-philosophischen Schrift „Über Anmut und Würde“ (1793) thematisierte Schiller die Anmut als eine vor allem weibliche Schönheit im Zusammenhang mit einer spezifisch weiblichen „biegsamen“ (Charakter-)Bildung und Würde als Ideal, das eher bei Männern erwartet würde. Interessant ist hier einerseits, dass Anmut und Grazie bei Zeitgenossen oft synonym verwendet wurden, dass aber Brinckmann auch von einer „hohen Würde“ der Weiber sprach, Würde also anders wertete bzw. definierte als Schiller.

168 Die Rede ist auch von „Schranken“ und „Grenzlinien“ zwischen den Geschlechtern. Alles nach Gustav von Brinckmann an Luise von Voss, 18. 12. 1799, ungedruckt, GSA 5/26,2. 169 So heißt es an Luise von Voss, er betrachte wie Klopstock eine „denkende Freundin“ als Geschenk des Himmels, verehre das weibliche Geschlecht, „aber Rousseau und Jean Paul vergöttern es nicht weniger.“ 10.4. 1799, ungedruckt, GSA 5/26,2. Eine wesentliche Aufgabe sah Brinckmann, wie Kant, in der Kultivierung des Mannes: „Es scheint mir Undankbarkeit und Beleidigung gegen die Würde des Geschlechtes zu sein, in dem Umgang mit Frauen nur Vergnügen und Unterhaltung zu suchen. Da sie so fähig und von Natur bestimmt sind, unseren stürmenden Geist [...] das einzige harmonische Glück zu gewähren, das nur sie bisweilen dem eisernen Schicksal noch abzuschmeicheln vermögen." Ebd. 
ich nicht, will sie aber anschaffen, denn was sie mir drüber sagen macht mich sehr begierig sie wieder zu lesen. Auch ich habe sie im 12ten Jahr mit wenig Nutzen und wenig Interesse gelesen“. ${ }^{170}$

\section{2 „Amazones d'esprit“}

Ein deutliches Beispiel für Brinckmanns ambivalente Haltung gegenüber politisch und gesellschaftlich aktiven Frauen war Germaine de Staël. Sowohl ihres markanten Äußerens als auch ihrer Initiativen in Politik und Literatur wegen wurde ihr von vielen Zeitgenossen die „Weiblichkeit“ abgesprochen bzw. das Etikett „unweiblich“ oft gewissermaßen als „Buße‘ für ihr selbstständig gestaltetes Leben auferlegt. Lea Mendelssohn Bartholdy fasste die in Berlin umgehenden Gerüchte „über eine so merkwürdige $u$ so verschieden geschilderte Person, wie die Baronne Staël“ so zusammen: „Was ich mir aus manchen Beschreibungen abstrahirt, ist: dass sie bei einem seltnen Grad von Verstand $\mathrm{u}$ jeder höhren Geisteskraft so wenig Weiblichkeit $\mathrm{u}$ Liebreiz verbinde, dass man sie erstaunenswerth, aber nicht anziehend finden könne“. ${ }^{171}$ Brinckmann griff in seiner Charakteristik der Staël genau diesen Punkt auf, indem er sie als Phänomen zwischen allen Sphären, nicht nur der männlichen und weiblichen, sondern auch zwischen der deutschen versus der französischen, der bürgerlichen versus der adligen begriff und aus der Not bzw. aus einer eigentlich männlich codierten Leidenschaft bei der Staël eine weibliche Tugend machte, so „dass ihr in einem gewissen Sinn zwar die feinere Weiblichkeit abgesprochen werden kan, in mancher Rücksicht hat sie aber davon sehr viel, $u$ so gar die Hauptzüge ihre Charakters sind ächt weiblich. Diese beweist schon ihr schönes Bedürfnis einer aufopfernden Liebe, wobei sie gewöhnlich dem sie bezaubernden Gegenstand alle egoistischen Rücksichten völlig aufopfert“. ${ }^{172}$

Hier scheint ein Widerspruch auf zwischen der unverminderten Begeisterung für die „einzige Staël“ und seinen eher vehementen Äußerungen zu grenzüberschreitenden Frauen im allgemeinen, den „Amazonen“. Mehrfach finden sich in den Korrespondenzen negative Kommentare zu der „moralischen

170 Luise von Voss an Gustav von Brinckmann, 5. 8. 1804, ungedruckt, BA V. Marie de Sévigné (1626-1696) war eine hochgebildete und früh verwitwete französische Aristokratin, die ihre Unabhängigkeit genoss und darüber schrieb. Die Briefe an ihre Tochter, die Leben und Skandale bei Hofe beschreiben ebenso wie sie aufgeklärte Erziehungsratschläge und Literaturstellen enthalten, dokumentieren das Leben einer sehr eigenständigen Frau.

171 Lea Mendelssohn Bartholdy an Gustav von Brinckmann, 18. 12. 1798, ungedruckt, BA M. 172 Gustav von Brinckmann an Lea Mendelssohn Bartholdy, 9. 2. 1799, diese Stelle in: Wachtmeister 1871, S. 10. 
Amazone“, „Amazone d'esprit“ oder den „politischen Amazonen“, zu denen er Madame de Staël, sicher eine der am meisten ,verunsichernden' Frauen des Jahrhunderts, aber nicht zählte. ${ }^{173}$ Dieser Widerspruch löst sich nur, wenn man Brinckmann ein Konzept einzelner ,Ausnahmefrauen“ zugesteht, die „einzig“ waren und bleiben sollten. Ein Blick auf den jeweiligen Anlass seiner ,Warnungen' gibt Hinweise darauf, was Brinckmann für verwerflich hielt: $\mathrm{Zu}$ einer „moralischen Amazone“, fürchtete er beispielsweise, würde Dorothea Mendelssohn Veit Schlegel in den Händen ihres Partners Schlegel werden, weil sie schon vorher männliche Züge gehabt habe, die er noch herausfordere. ${ }^{174}$ Und als „Amazone des Geistes“ bezeichnete er die gelehrte Gräfin Nathalie Stadion, der er an anderer Stelle vorwarf, „Vorlesungen“ zu halten statt eines Salons. ${ }^{175}$

Im Bild der Amazone, der weiblichen Kriegerin, ist eine Überschreitung der Geschlechtergrenzen bzw. eine Mischung der Rollen implizit. In Brinckmanns Fall, wie bei einigen seiner Korrespondenzpartnerinnen, bezog sich dies allerdings nicht auf politisches Streben, sondern meistens auf ein ,unweibliches‘ Übermaß an Bildung: „Die Moralische Amazone ist doch kein Held, und vorurtheilsfreie Ausbildung des sanften Geschlechts, ist, bei allen Grazien!, etwas weit edleres, als weibliche Freigeisterei“!176

Einerseits wurde in allen hier untersuchten Korrespondenzen, und nicht nur von Seiten Brinckmanns, vor einem Übermaß an Gelehrsamkeit bei Frauen gewarnt, andererseits scheint aber die Lektüre von Klassikern wie Homer, wie bei Luise von Voss, oder das Anfertigen von Übersetzungen aus dem Mittelfranzösischen, wie im Falle Dorothea Mendelssohn Veit Schlegels, nicht zu diesem Übermaß gezählt zu haben. Dass Brinckmann dieser Art von Betätigung positiv gegenüberstand, war den Frauen bekannt. Er wurde von ihnen offen um Unterstützung gebeten. ${ }^{177}$ Auch Lea Mendelssohn Bartholdy beschrieb, wie sie als

173 „Moralische Amazone“: Gustav von Brinckmann an Luise von Voss, 18. 12. 1799, ungedruckt, GSA 5/26,2; „Amazone d'esprit“: Ders. an Luise von Voss, 3. 9. 1801, ungedruckt, GSA 5/26,4; „politische Amazonen“: ders. an Lea Mendelssohn Bartholdy, 9. 2. 1799, diese Stelle ungedruckt, BA M.

174 Gustav von Brinckmann an Luise von Voss, 18. 12. 1799, ungedruckt, GSA 5/26,2. Er begründete seine Befürchtung: „[...] von jeher mangelte es ihrem Innern jenes glücklichen Gleichgewichts streitender Kräfte [...] Sie, wo möglich, zu verweiblichen, nicht sie noch rücksichtsloser empor zu reissen in eine unbestimmte Sfäre, war die Pflicht ihrer Freunde, und ich zweifle, daß ihr Schlegel diesen Dienst erwiesen habe.“

175 Gustav von Brinckmann an Luise von Voss, 4. 11. 1801, ungedruckt, GSA 5/26,4

176 Gustav von Brinckmann an Luise von Voss, 18. 12. 1799, ungedruckt, GSA 5/26,2.

177 So bat Dorothea Mendelssohn Veit Schlegel Brinckmann zur Verbesserung ihrer finanziellen Situation, „daß Sie mir eine Übersetzung zu machen, verschaffen können. [...] Außer im mathematischen und physikalischen Fach mag es übrigens seyn, was es will, nur freilich nicht, wie es will, denn von der Übersetzung eines schlechten Buches bekomme ich einen kleinen Schauer.“ Juli 1799, in: KFSA, Bd. 24, S. 303. 
junges Mädchen im Reimarus-Sievekingschen Zirkel zunächst davon abgeschreckt worden sei, dass die Tochter des Hauses Oden rezitierte: „Ich gestehe, dass sie mir etwas pedantisch schien, $u$ dass ich's ein wenig gegen die bescheidene Weiblichkeit gesündigt hielt, Klopstockische Oden auswendig in Gesellschaft herzusagen: eben[?] so schreckte mich armes schüchternes Ding ihr ewiges Politisieren zurück.“ In der Zwischenzeit habe er, Brinckmann, aber wesentlich dazu beigetragen, ihr Urteil zu besänftigen, es „hat sich [...] jeder Gesichtspunkt so sehr verrückt, $u$ bei dem politischen $u$ litterarischen ton der allgemein im Reimaruschen Kreise herrschte, ists mir so begreiflich, dass auch sie[?] annahm, dass es höchst unbillig wäre, sie deßwegen $\mathrm{zu}$ tadeln“. ${ }^{178}$

Hier bestätigt Lea Mendelssohn Bartholdy das für das späte 18. Jahrhundert vielfach konstatierte ,Öffentlichkeitsverbot‘: Weniger die Gelehrsamkeit, also Kenntnis der Oden, als das öffentliche „Hersagen“ war die eigentliche „Sünde“ gegen die Weiblichkeit. Vergleichbar schrieb Henriette Mendelssohn an Brinckmann über die bekannte Gelehrte Dorothea Schlözer, sie sei zwar sehr klug, aber keine Amazone, weil sie ihre Kenntnisse nicht öffentlich anwandte:

[...] bei dieser umfassenden gründlichen Gelehrsamkeit, diese höchste Simplizität, diese Lebenslust, diese Leidenschaftlichkeit! Selbst ihr Mangel an weiblicher Grazie, den sie aber auf keine Weise, weder zu verbergen noch absichtlich wie sonst wohl amazonen, wie etwa die Gräfin Schlabrendorf thut, zu zeigen sucht, hat etwas pikantes ohne von ihren früheren männlich angestrengten $u$ ernsthaften Beschäftigungen für weibliche Bestimmung verdorben zu sein, liebt und erzieht sie ihre Kinder einfach und gut. ${ }^{179}$

Der Abscheu vor zur Schau gestellter Bildung scheint ein geschlechtsübergreifender gewesen $\mathrm{zu}$ sein und wurde auch bei Männern angeprangert. Man

178 Lea Mendelssohn Bartholdy an Gustav von Brinckmann, 10. 12. 1798, ungedruckt, BA M. 179 Henriette Mendelssohn an Gustav von Brinckmann, 15. 6. 1804, ungedruckt, BA M. Dorothea Schlözer (1770-1825), Tochter eines Göttinger Geschichtsprofessors, promovierte mit 17 Jahren als zweite Frau in Deutschland und wurde damit zum Exempel der Auffassung ihres Vaters von einer möglichen gleichwertigen Erziehung für Frauen und Männer. International gefeiert heiratete sie den reichen Lübecker Senator Mattheus Rodde und erzog neben eigenen noch Kinder aus dessen erster Ehe. Wie ihre Biografin schreibt, kann Henriette Mendelssohn mit ihrer Wertung dieses Frauenlebens als typisch gelten, denn mit der Ehe holte sich Dorothea Rodde „die öffentliche Bestätigung dafür, eine ganz normale, gesunde, schutzbedürftige, eben echte Frau zu sein. [...] Nun erst, so meinen vor allem die Frauen ihres großen Freundeskreises, hätte sie den einzig richtigen Weg eingeschlagen, der dem weiblichen Geschlecht wahre Vollkommenheit verheißt.“ Renate Feyl: Dorothea Schlözer, in: dies.: Der lautlose Aufbruch. Frauen in der Wissenschaft, Berlin 1981, S. 70-80, hier S. 77. Die erwähnte Gräfin Schlabrendorf hingegen wurde oft mit dem Beiwort „männlich“ versehen, mit Hinweisen auf ihre als exzentrisch geltende Kleidung und die Tatsache, dass sie im Herrensattel ritt, oder wegen ihrer selbstständigen Lebensführung. 
machte in diesem Kreis zudem einen Unterschied zwischen bloß erlernter Bildung und echtem Interesse bzw. angeborenem Witz. Rahel Levin Varnhagen schätzte Brinckmann besonders für ihre Originalität. Luise von Voss gegenüber nannte er sie mehrfach „eine so reiche Natur, und eine so originale Ausbildung, daß sie demjenigen, der das Schauspiel der Ideen nun einmal über alles liebt, durchaus sehr gefallen muß“. ${ }^{180}$ Levin Varnhagen selbst machte er regelmäßig Komplimente wie das folgende: „Den meisten der übrigen, wäre ein geistreiches Mädchen überhaupt hinlänglich gewesen; mir war Ihre Eigenthümlichkeit zum Bedürfniß geworden“. ${ }^{181}$ Damit ist ein weiterer Begriff aus Brinckmanns Weiblichkeitsrepertoire genannt: er suchte und fand fast immer „das Eigenthümliche“ an einer Frau, was seine besondere Affinität zu den Frauen de Staël und Levin Varnhagen sowie zu Mendelssohn Veit Schlegel erklärt.

„Grazie“ einerseits und Originalität andererseits - modern möglicherweise als "Charakter“ zu bezeichnen - markierten damit das Spannungsfeld des Brinckmannschen Ideals. Als die vielgepriesene Originalität Levin Varnhagens 1805 für ihn unangenehme Konsequenzen hatte, namentlich der Ton in ihrem Kreis sich änderte, zog er sich daraus zurück. Da erst, in der negativen Beurteilung, kam es zu einer auffallenden Verknüpfung ihres „unweiblichen“ und „jüdischen“ Stils. ${ }^{182}$ Ebenso konnte Brinckmann an der Originalität von Schlegels Lucinde zwar die gattungspoetische „Frechheit“ schätzen, fühlte sich aber dennoch in seinem Geschmackssinn getroffen. So war ihm ,jener allgemeine Wurf genialischer Frechheit nicht eigentlich anstössig - aber das Absichtliche der Undelikatesse verräth weniger die üppige Fülle einer jugendlichen Einbil-

180 Gustav von Brinckmann an Luise von Voss, 10. 10. 1802, diese Stelle ungedruckt, GSA $5 / 26,5$. Dieses Kompliment ist bemerkenswert, weil es in demselben Brief fällt, in dem Rahel Levin Varnhagens Sofa plötzlich als „Judensofa“ bezeichnet wurde, vgl. V.3. Diese Schmähung und gleichzeitige Wertschätzung gingen für Brinckmann anscheinend zusammen.

181 Gustav von Brinckmann an Rahel Levin Varnhagen, 7. 10. 1798, SV 38, ohne Betonung auch in: Wachtmeister 1871, S.5.

182 Er fand, der Umgang in ihrer Gesellschaft, vor allem „aber der Ton hat sich jedenfalls geändert - und es ist Einmal richtig, daß die lumpichsten Männer diesen in einem gewissen Sinn doch nicht so verderben können, wie Weiber aus der nehmlichen Klasse.“ Und gerade damit würden die beteiligten Frauen „die Würde der Weiblichkeit auf eine recht gotteslästerliche Weise entweihen. Es ist in meinen Augen eine wahre Sünde wider den heiligen Geist der Grazien - die nicht verziehen werden soll. Jenen Fluch muß ich nun freilich auch, wiewohl ungern, über die Levin aussprechen." Gustav von Brinckmann an Luise von Voss, 28. 4. 1805, diese Stelle ungedrukt, GSA 5/26,8. Dies ist eben der Brief, in dem er auch erstmals ausführlich über das „Jüdische“ bzw. „Egyptische“ in seiner Freundin räsonierte. Die hier geknüpfte Verbindung zwischen einem Mangel an Weiblichkeit und der Zunahme jüdischen ,Wesens ist kennzeichnend für Brinckmanns Haltung um diese Zeit. 
dungskraft, als das berechnete Spiel einer emporgekünstelten Sinnlichkeit“. ${ }^{183}$ Brinckmann unterstellte Schlegel damit bei dieser Veröffentlichung, die er unästhetisch fand, Berechnung. Vor allem aber ,verhöhnte' das Buch nach Brinckmanns Meinung - und hier unterschied er sich von vielen Geschlechtertheoretikern der Zeit inklusive dem Verfasser der Lucinde - die Situation der Frau, einer individuellen Freundin und des weiblichen Geschlechts allgemein. Von der Lucinde und „der Veit“ auf die allgemeinen gesellschaftlichen Verhältnisse kommend, konstatierte Brinckmann unversehens die zeitgenössische Ungleichheit der Geschlechter, und die erhöhte Abhängigkeit der Frau: „Als wären die Verhältnisse eines Weibes und eines Mannes ja die nämlichen. Als wäre es nicht himmelschreiende Ungerechtigkeit hiebei von einer schimärischen Gleichheit der Anopferungen zu träumen“. ${ }^{184}$

„Schimärische Gleichheit“: Diese Formulierung ist bedeutsam, da der Begriff „schimär“, unwirklich, von Brinckmann in unterschiedlichen Wertungen verwendet wurde. ${ }^{185}$ Als Brinckmann die „schimärische Gleichheit der Stände“ ablehnte, tat er es im behaglichen Rückblick auf schön verbrachte Tage in Weimar und das wohltuende Interesse kulturfördernder Aristokraten, deren Einflussmöglichkeiten Brinckmann bewahrt wissen wollte. Hier wird der Begriff Schimäre im Sinne von ,Hirngespinst“ verwandt, namentlich der niederen Stände und Schichten. Mit dem Blick auf Lucinde und besonders auf die Biografie seiner Freundin Dorothea begriff er aber den gesellschaftlichen Unterschied der Geschlechter und ihrer „Anopferungen“ als prekäre Situation und eine Gleichheit der Geschlechter als ,Trugbild‘, sodass ein Buch, das den Geschlechtsunterschied scheinbar aufhob, ihm gefährlich erschien, weil die hier beschriebene Gleichheit schimärisch bleiben musste, ein nicht einlösbares Versprechen.

\subsection{Lucinde versus Dorothea - Die Rezeption der Lucinde im Briefwechsel und in der Berliner Salongesellschaft}

Es gehört zu den Zeichen des letzten Hyper-Tollhäusischen Decenniums des 18ten Jahrhunderts, daß ein solches Werkchen von jemand geschrieben, von jemand gedruckt, und von jemand gelesen werden konnte. Was will noch aus diesem Kindlein werden?

Christoph Martin Wieland, 1799

183 Gustav von Brinckmann an Luise von Voss, 20. 12. 1799, ungedruckt, GSA 5/26,2.

184 Gustav von Brinckmann an Luise von Voss, 3. 3. 1800, ungedruckt, GSA 5/26,3.

185 Seine Aussage „Ich hasse die schimäre Gleichheit der Stände" fiel in Hanau, auf der Weimar nachfolgenden Reisestation. Gustav von Brinckmann an Luise von Voss, 25. 2. 1798, ungedruckt, GSA 5/26,1 [s. a. V.4]. 
Ein erotisch-redseliges-universelles Wirrsal.

Peter Hacks, $19766^{186}$

Friedrich Schlegels Roman Lucinde ist bei der Frage nach der Wechselwirkung zwischen Salongeschehen und Geschlechterdiskussion als wohl prägnantestes Beispiel personeller und diskursiver Überschneidung besonders relevant, da der Roman im unmittelbaren Umfeld der Salons entstand. ${ }^{187}$ Der Fragment gebliebene Roman - ein geplanter zweiter Teil ist nie erschienen - erzählt in verschiedenen Textformen und aus unterschiedlicher Perspektive die Liebesund Lebensgeschichte/n von Julius, der schließlich in Lucinde die Frau seines Lebens findet und die mit ihr sowohl geistiger wie sinnlicher Hinsicht gefundene Erfüllung ausgiebig besingt. ${ }^{188}$ Die bisweilen schwülstig anmutende Sprache des Romans und eine Rezeptionsgeschichte, die unter dem Primat der „Unanständigkeit“"189 stand, täuschen darüber hinweg, dass der eigentliche

186 Christoph Martin Wieland an Carl August Böttiger, 16. 6. 1799, in: Wielands Briefwechsel, hrsg. von der Berlin-Brandenburgischen Akademie der Wissenschaften durch Siegfried Scheibe, Bd. 14 (Juli 1797-Juni 1799). Erster Teil: Text, bearbeitet von Angela Goldlack, Berlin 2000, S.504. Wieland hatte sich das Buch zwei Tage vorher erbeten mit der Formulierung, wenn Schlegels neues Werk auf „komische Art toll“ wäre und nur das Zwerchfell, nicht die Galle bewegte, möge Böttiger es ihm schicken. Ebd., S. 502; Peter Hacks: Der Meineiddichter [1976], in: ders.: Die Maßgaben der Kunst I (Hacks Werke 13), Berlin 2003, S. 258-272, hier S. 267. Hacks' Verrisse Friedrich Schlegels sind auch darauf zurückzuführen, dass Schlegel zur Symbolfigur einer literaturwissenschaftlichen Wende in der DDR wurde, die Hacks bekämpfte.

187 Zur Vorgeschichte bzw. Rekonstruktion der Schlegelschen Aufenthaltes in Berliner Salons, wenn auch zum Teil mit veralteter Wertung, vgl. Hans Eichner: Lucinde, in: KFSA, Bd. 5 (1962), S. XVII-LXIX. Die vielzitierte Schilderung der Liebesbeziehung durch ihre Freundin Henriette Herz ist eine Ausarbeitung des Journalisten J. Fürst. Das

Originalmanuskript enthält zwar Hinweise auf die unglückliche erste Ehe mit Simon Veit, bricht aber ab, bevor es zur Schilderung des Jahres 1797 kommt. Herz 2000, S. 101-154, bes. S. $130 \mathrm{f}$.

188 „Besingen“ ist eine zutreffende Umschreibung für einige der zahlreichen Gattungen, die in den Roman bewusst eingewoben wurden, vor allem für die nachstehend zitierte „Dithyrambische Fantasie über die schönste Situazion“, den Rollentausch. Dass der zweite Teil nie vollendet wurde, ist hinsichtlich der Geschlechtertheorie bedauerlich, weil Schlegel beabsichtigte, ein weibliches Pendant zu konzipieren: „Das Gegenstück im zweyten [Teil] sollten Weibliche Ansichten [seyn], vielseitige Briefe von Frauen und Mädchen verschiedner Art über die gute und schlechte Gesellschaft.“ Friedrich Schlegel an Caroline Schlegel Schelling, Spätmärz 1799, in: KFSA, Bd. 24, S. 252.

189 Als beispielhafte und häufig zitierte Kritik sei auf die von Wilhelm Dilthey hingewiesen, der 1870 zusammenfasste: „Ich beabsichtige nicht zu beweisen, daß der Roman Friedrich Schlegels sowohl unsittlich als auch dichterisch formlos und verwerflich ist. Diese Einsicht bedarf keiner Begründung mehr“, und der dennoch ein Kapitel über seinen „Ekel“ davor 
Inhalt den zeitgenössischen Standard an Darstellungsformen des Erotischen keineswegs übertraf. 190 Die Lucinde offenbarte de facto von ihrer weiblichen Heldin nicht viel mehr, als ein zeitgenössisches Reisekostüm für Frauen es getan hätte. „Skandalös“ war möglicherweise die durch den Rollentausch im Leser evozierte Fantasie von einer im Bett aktiven Frau. ${ }^{191}$

„Wenn wir die Rollen tauschen und mit kindischer Lust wetteifern, wer den andern täuschender nachäffen kann, ob dir die schonende Heftigkeit des Mannes besser gelingt oder mit die anziehende Hingebung des Weibes. [...] Ich sehe hier eine wunderbare sinnreich bedeutende Allegorie auf die Vollendung des Männlichen und Weiblichen zur vollen ganzen Menschheit. Es liegt viel darin, und was darin liegt, steht gewiß nicht so schnell auf wie ich, wenn ich dir unterliege. 192

Während der Roman als Kunstwerk heute als rehabilitiert betrachtet werden kann, muss der emanzipatorische Gehalt bzw. das im Roman entwickelte Geschlechterbild nach wie vor als umstritten gelten. Es ist erstaunlich, aber wahr, dass noch Ende der 1990er-Jahre für die Einsicht gestritten werden

schrieb. Wilhelm Dilthey: Leben Schleiermachers. 1. Band. Auf Grund des Textes der 1. Auflage von 1870 und der Zusätze aus dem Nachlass herausgegeben von Martin Redeker, Göttingen 1991, S. 496 u. 516. Für eine prägnante Darstellung der Etappen der LucindeRezeption vgl. Karl Konrad Polheim: Kleine Bibliographie, in: Friedrich Schlegel, Lucinde. Ein Roman. Studienausgabe. Kritisch herausgegeben und mit Begriffs-Repertitorium und Nachwort versehen von Karl Konrad Polheim, Stuttgart 1999, S. 213-215. Die immer noch gültige Wirkungsgeschichte des „Unanständigen“ findet sich bei Ludwig Marcuse: Obszön. Geschichte einer Entrüstung, Zürich 1984, S.58-106. In einer der jüngsten Arbeiten wird der Roman als Verbindung zwischen Philosophie und Literatur diskutiert: Veli-Matti Saarinen: The Daybreak and Nightfall of Literature. Friedrich Schlegel's Idea of Romantic Literature: Between Productive Fantasy and Reflection, (German Language and Literature, 1956), Frankfurt/M. 2007.

190 Zeitgenössische Bücher über die „Galanterien“ in großen Städten beschrieben mit einigem Genuss und wesentlich mehr Details „Ausschweifungen“ aller Stände, wie „ein Quatro in der Gartengrotte“ oder Besuche in „Knabentabagien“. Vgl. die Erinnerungen des Offiziers in: Friedel 1987, S. 51 ff. bzw. $144 \mathrm{ff}$. Ludwig Marcuse nennt daher in seinem Versuch, die Ursachen für „150 Jahre deutscher Entrüstung“ über Schlegels Roman zu finden, drei andere mögliche Motive: die unverhohlene Erwähnung des Genusses der körperlichen Liebe ohne klassizistische Metaphern, die angenommene „Indiskretion“ in Bezug auf Schlegels eigene Erfahrung und schließlich die Freude an der Anarchie, vor allem im Geschlechterverhältnis. Vgl. Marcuse 1984.

191 Weibliche sexuelle Initiative wurde im öffentlichen Diskurs Ende des 18. Jahrhunderts nur Prostituierten zugestanden; nicht von ungefähr war ein Großteil der zeitgenössischen geschlechtertheoretischen Texte auf die Passivität der Frau ausgerichtet: „Im unverdorbenen Weibe äussert sich kein Geschlechtstrieb, und wohnt kein Geschlechtstrieb, sondern nur Liebe.“ Fichte 1970, S. 100.

192 Schlegel 1999, S. 19. 
musste, dass ein Text, der Frauen eigenes sexuelles Interesse zugesteht, nicht automatisch als ein Markstein der Frauenemanzipation zu werten ist. ${ }^{193}$

Im Zusammenhang dieser Arbeit ist erstens die Frage interessant, was die ebenso oft als moralisch lax wie literarisch gebildet gekennzeichnete Salongesellschaft am Roman primär diskutierte: die Darstellung des Erotischen, das Liebeskonzept oder den gattungspoetischen Anspruch einer neuen Form des Romans? Zweitens ist zu fragen, inwieweit das Diktum, der Skandal hänge mit der hauptsächlich biografischen Lesart des Textes durch Zeitgenossen zusammen, für die Salongesellschaft zutraf, die durch vielfältige persönliche Bindungen mit der Beziehungsgeschichte Veit-Schlegel gut vertraut war. Drittens geht es um die Wahrnehmung des Textes als zentrales Dokument der Geschlechtscharakterdebatte. Während Wilhelm von Humboldts in Kapitel IV besprochene Horen-Aufsätze als Grundlagentext des polaren Geschlechterbildes betrachtet werden, galt Friedrich Schlegel lange als Vertreter eines progressiveren Modells: „Nur sanfte Männlichkeit, nur selbständige Weiblichkeit sei die rechte, die wahre und schöne“. ${ }^{194}$ Wurde der Text von den Korrespondenten als Herausforderung Humboldts und emanzipatorisch wahrgenommen?

\section{Wenn „Götterbuben aus der Schule schwatzen“ - Lucinde in Berlin}

Friedrich Schlegel war im Sommer 1797 nach Berlin gekommen und bald zum Stammgast in verschiedenen literarischen Kreisen geworden. Er hatte vermutlich im Haus der Henriette Herz Ende August 1797 deren Freundin Dorothea

193 Entgegen der traditionellen Deutung des Romans als Moralreform oder Schlegels „Evangelium der Liebe“ (Eichner 1962, S. XXIX) haben neuere Arbeiten darauf aufmerksam gemacht, dass die neuen Rollen der Frau als Gespielin und Gesellschafterin noch keine Gleichheit implizieren. Symptomatisch bringt ein Sammelband zum Berliner Salon 1997 zwei gegensätzliche Interpretationen des Frauen- und Geschlechterbildes in der „Lucinde“: Hans Eichner geht davon aus, dass Friedrich Schlegel mit der Überwindung „der Trennung von Seelenfreundin einerseits und Eheweib und Bettgenossin andererseits“ „gewiß einen Platz in der Geschichte der Frauenemanzipation verdient" habe. Hans Eichner: Das Bild der Frau in der Frühromantik. Theorie und Wirklichkeit, in: Schultz 1997, S.1-19. Der Aufsatz ist sonst nur wegen seiner reaktionären Ansichten bemerkenswert. Ihm gegenüber steht die umfassende Analyse von Barbara Becker-Cantarino: „Feminismus“ und „Emanzipation“? Zum Geschlechterdiskurs der deutschen Romantik am Beispiel der Lucinde und ihrer Rezeption, in: Schultz 1997, S. 21-44. Vgl. das einfache, aber zutreffende Statement von Ludwig Marcuse: „Die Romantiker waren keine Frauenrechtler. Sie hatten nur ihre Freude an der Selbstständigkeit des anderen Geschlechts.“ Marcuse 1984, S. 88.

194 Friedrich Schlegel, Über die Philosophie. An Dorothea, 1799, zit. nach: Pohlheim 1999, S. 205. 
kennengelernt, 195 die anschließende Liebes- und Scheidungsgeschichte spaltete bekanntlich die Salongesellschaft. Henriette Herz unterstützte ihre Jugendfreundin, Markus Herz brach den Kontakt zu dieser ab. Friedrich Schleiermacher wurde in dieser Zeit zu ihrem Berater in praktischen wie philosophischen Fragen. Auch Gustav von Brinckmann wurde in sehr offenen Briefen auf das Thema angesprochen und gebeten, „von allen Motiven die man mir unterschieben wird, glauben Sie nichts, als was ich Ihnen hierüber geschrieben“. ${ }^{196}$ Ende 1798 zog „die Veit“ aus dem Haus ihres Gatten aus und Anfang 1799 wurde die Scheidung ausgesprochen. Die Entstehung des Romans fiel genau in diese Umbruchsphase. ${ }^{197}$ Lucinde kursierte im Manuskript unter den Romantikern, aber auch in Berlin und machte schon vor dem Erscheinen Furore. ${ }^{198}$ Das Buch erschien, als sich die Wogen betreffs der Scheidung gerade etwas geglättet hatten, und löste einen Skandal aus, der möglicherweise durch antijüdische Ressentiments noch angefacht wurde. ${ }^{199}$ Während Schlegel die Lucinde zu die-

195 Der Beginn ihrer Partnerschaft ist umstritten. Die Schlegelforschung datiert den Beginn des Liebesverhältnisses auf September aufgrund von Andeutungen in einem Brief an Novalis. Raymond Immerwahr, Einleitung, in: KFSA, Bd. 24, S. XIX-LIII, hier S. XXVIII. Das Zitat aus der Überschrift nach einem Ausspruch Dorothea Mendelssohn Veit Schlegels: „Sie findet aus Gelegenheit der Luc.[inde], daß die Götterbuben aus der Schule schwatzen.“ Friedrich Schlegel und Henriette Mendelssohn an August Wilhelm Schlegel, Anfang Februar 1799, in: KFSA, Bd. 24, S. 227. „Götterbuben“ soll die Bezeichnung Wielands für die Brüder Schlegel gewesen sein. Vgl. Caroline Schlegel Schelling an Friedrich Schlegel, 14.-15. 10. 1798, in: KFSA, Bd. 24, S. 177.

196 Dorothea Mendelssohn Veit Schlegel an Gustav von Brinckmann, 2. 2. 1799, in: KFSA, Bd. 24, S. 224. Dieser vielzitierte Brief ist Ausweis einer sehr selbstbewussten Frau, von der es nach einer Schilderung ihrer ärmlichen Verhältnisse ironisch heißt: „[...] da haben Sie in wenigen Worten alles was ich nun besitze - aber wie soll ich Ihnen alles herrechnen, was ich los geworden bin?" Ebd. S. 223. Hervorhebung im Original.

197 Ende Oktober 1798 hatte Friedrich Schlegel seinem Freund Novalis von dem Plan berichtet, „einen leichtfertigen Roman Lucinde leicht zu fertigen“. Anfang Februar 1799 sandte er einen ersten Teil an August Wilhelm und Caroline Schlegel zur Begutachtung, der dann unter den Romantikern kursierte. Friedrich Schlegel an Novalis, 20. 10. 1798, in: KFSA, Bd. 24, S. 183.

198 Schon die Ankündigung des Romans machte die Salongesellschaft neugierig. Am 19. 1. 1799 wurde die „Lucinde“ in der Allgemeinen Literatur-Zeitung für die Ostermesse angekündigt. Vgl. Eichner 1962, S. XIX. Am selben Tag fragte Marianne Meyer Eybenberg in einem Brief an Goethe indirekt danach: „Jetzt schreibt er einen Roman, der Lucinde heisst, und wovon der erste Theil zu Ostern erscheinen soll; das ist alles. was ich davon weiß.“ in: GJB XIV, 1893, S. 37. Auch Gustav Brinckmann wurde kontaktiert, er schrieb: „Ein Roman von Schlegel kan leicht etwas sehr interessantes werden, aber schwerlich wird es seinem Titel entsprechen.“ An Luise von Voss, 30.1.1799, ungedruckt, GSA 5/26,2.

199 Vgl. die Zusammenfassung bei Eichner 1962, S. L ff., wonach die Kritiken oft nicht weniger schwülstig zu Werke gingen als sie dem Verfasser zu sein unterstellten. Der Aufruhr machte „Lucinde“ aber nicht zu einem Bestseller, im Gegenteil. Gegenschriften wie „Drei 
sem Zeitpunkt vor allem als entpersonalisierte Religion der Liebe gedeutet wissen wollte, ${ }^{200}$ interessierten sich die bösesten Gegenschriften nur für die angenommene Verletzung der Intimsphäre, allen voran Daniel Jenischs Satireschrift Diogenes Laterne. ${ }^{201}$ Neben anderen antijüdischen Witzen enthielt diese Schrift ein erfundenes, aber als echt angepriesenes „Billet=doux der geschiedenen Madam Veit, jüdischer Nazion, nunmehr halbverehelichten Friedrich Schlegel, ${ }^{\star}$ ) an Herren Friedrich Schlegel über seinen Roman Lucinde." Dabei zog Jenisch in seinem gefälschten Text, der die Schreiberin als „lenden-nackte Spartanerin“ nannte, diese wesentlich weiter aus, als Schlegel es getan hatte. ${ }^{202}$

Briefe an ein humanes Freudenmädchen über die Lucinde von Schlegel“, Berlin 1800, waren bald verbreiteter als die „Lucinde“ selbst. Ebd. Die Gerüchte über die „Unanständigkeit“ des Textes in der Berliner literarischen Szene waren anscheinend befördert durch Verleger, besonders die Verlegergattin Helene Unger, die für antijüdische Ressentiments bekannt war. „Die Kätzin [Unger] unterläßt nicht schon jetzt alles, was sie mit ihrem giftigen Athem erreichen kann, davon mitzutheilen, man spricht schon jetzt von der Unanständigkeit der Lucinde, und das kömt von ihr her.“ Dorothea Mendelssohn Veit Schlegel an Friedrich Schleiermacher, 8. 4. 1799, in: KFSA, Bd.24, S. 266. Hervorhebung im Original.

200 Schlegel selbst sprach 1800 rückblickend spöttisch von der „Gefahr, übermütig zu werden, weil das Gesindel mich so sehr verabscheut“. Friedrich Schlegel, Notizen, zit. nach: Eichner 1962, S. LI. Seine Ablehnung der Eheschließung als einer „verhassten Ceremonie“ wird meist als modern und antibürgerlich gedeutet. Dass es seiner Freundin nicht so leicht fiel und fallen konnte, als geschiedene jüdische Frau mit einem jüngeren, umstrittenen Mann zusammen zu leben, scheint bei seinen Überlegungen keine Rolle gespielt zu haben.

Stattdessen problematisierte er gegenüber seiner Schwägerin, der Altersunterschied führe irgendwann doch dazu, dass er eine Geliebte bräuche, daher wolle er lieber nicht heiraten, denn „wenn es ihr nicht länger anständig ist, meine Frau in diesem Sinne zu seyn, dann bin ich noch sehr jung." Beide Zitate: Friedrich Schlegel an Caroline Schlegel Schelling, 28. 11. 1798, in: KFSA, Bd. 24, S. 202. Wenn auch hier das spezielle (ehemalige Liebes-)Verhältnis zur Adressatin in Betracht gezogen werden muss, lässt sich Schlegel eine gewisse Ignoranz gegenüber der Situation seiner Frau nicht absprechen.

201 [Daniel Jenisch]: Diogenes Laterne. Ein satyrisches Taschenbuch auf das Jahr 1800, Leipzig 1799.

202 Jenisch 1799, S. 374. An das * war die Fußnote geknüpft: „Madame Veit, welche Herr Friedrich Schlegel in Berlin kennen lernte, und die deshalb von ihrem bisherigen Ehemanne, nach eilfjähriger Ehe, geschieden ward. Das Gelächter über den Roman Lucinde, verbunden mit dieser Geschichte, war in Berlin allgemein.“; „Spartanerin“: Ebd., S. 375. Vgl. auch die ,falsche“ Anzeige im selben Heft: „Demonstrativer Beweis, daß Fichte und Schlegel die größesten Männer des achtzehnten Jahrhunderts sind. Diese Schrift des Charitépredigers Schleyermacher, welche derselbe in der litterarischen Gesellschaft, unter dem lauten Beyfall aller darin befindlichen Judenweiber, vorgelesen, empfehlen wir dem Publikum zum voraus.“ S. 366. Bemerkenswert ist eine Notiz Karl August Varnhagens, auf seinem Exemplar: „Diogenes Laterne. Leipzig 1799. Warum ich solches Zeug aufbewahre? Als Zeichen jener Zeit, damit man sehe, wie es damals herging, und daß dergleichen nicht bloß heute geschieht, wie so oft ungerecht behauptet wird.“ Undatierter Klebezettel, SV 96. 
In das hochgradig ambivalente Bild der literarisch-personellen Verflechtungen im Umfeld dieses Werkes gehört der Umstand, dass Dorothea Mendelssohn Veit Schlegel zu eben der Zeit, als die Kritik oft in antijüdischen Sentenzen über sie herfiel, einen für seine antijüdische Haltung bekannten Mann zum Freund gewann. Johann Gottlieb Fichte, seit Juli 1799 in Berlin und in engem Kontakt zu Friedrich Schlegel, war nicht nur begeistert von dessen Werk, sondern ein eingestandener Bewunderer seiner Freundin, die ihn häufig zu Gast hatte: „Meine Philosophen laufen unaufhörlich die Stube auf und ab“ und „und wir leben sehr gut, froh und lehrreich zusammen“, hieß es in Briefen nach Jena. ${ }^{203}$ Fichte selbst machte das Paradox explizit: „Das Lob einer Jüdin mag in meinem Munde besonders klingen; aber diese Frau hat mir den Glauben, daß aus der Nation nichts gutes kommen könne, benommen“. ${ }^{204}$ Fichte war auch einer der wenigen Freunde, der ihre Gründe, sich nicht gleich taufen zu lassen, ernst nahm.

\section{Kein Skandal im Salon}

Saarinens Befund, dass Schlegels Schreibprozess an der Lucinde ein einsamer gewesen sei, kann so nicht bestätigt werden. ${ }^{205}$ Friedrich Schleiermacher schrieb bekanntlich beinahe parallel und in enger Absprache mit Schlegel seine Reden über die Religion. ${ }^{206}$ Henriette Herz stand während des jeweiligen Schreibprozesses mit beiden in engem Kontakt und wurde ,Testpublikum'. Schlegel selbst las ihr aus dem Manuskript vor, wobei sie den Roman aber sehr „weltlich“ nahm, wie er ironisch feststellte. ${ }^{207}$ Nicht nur Dorothea, auch ihre Schwester Henriette Mendelssohn schrieb, was kaum bekannt ist, das Manu-

203 Friedrich Schlegel, Dorothea Mendelssohn Veit Schlegel und Friedrich Schleiermacher an Caroline Schlegel Schelling, Juli 1799, in: KFSA, Bd. 24, S. 299.

204 Johann Gottlieb Fichte an Marie Johanne Fichte, 13. 9. 1799, in: FGA III,4, S. 78 f. Er ging soweit, „die Veit“, die sehr interessant, gütig und sanftmütig sei, seiner Frau als Freundin zu empfehlen und zu sagen, er habe sie „von Herzen“ lieb. Ebd., S. 78. Vgl. auch den Brief vom 2. 8. 1799 , in: ebd., S. 27.

205 Saarinen 2007, S. 98.

206 Friedrich Schleiermacher: Über die Religion. Reden an die Gebildeten unter ihren Verächtern, Berlin 1799. Zur Wechselbeziehung dieser zwei Werke und ihrer Autoren s. Theodore Ziolkowski: Vorboten der Moderne. Eine Kulturgeschichte der Frühromantik. Stuttgart 2006: „So wird kreuz und quer gelesen und kopiert und kommentiert [...] und Dorotheas Berliner Wohnung ist die ,geistige Zentrale‘. Ebd., S. 38. Eine zweite ,Zentrale‘ war möglicherweise die Wohnung von Henriette Herz.

207 „Die Herz hat neulich einen Theil davon mit vieler Theilnahme angehört. Indessen nimmt sie sie zu weltlich. Daran bist Du mit Deiner Religion schuld.“ Friedrich Schlegel an Friedrich Schleiermacher, Mitte April 1799, in: KFSA, Bd. 24, S. 268. 
skript ab und berichtete Freunden davon: „Denken Sie nur ich bin jezt beschäftigt einen Roman von Friedrich Schlegel! für den Druck abzuschreiben, er heißt Lucinde und ist ein gar wunderlich wunderbares Erzeugnis"!208 Auch Rahel Levin Varnhagen muss Lucinde im Manuskript gekannt haben, da Schlegel bereits im Ende Januar ihren Rat kolportierte: „Die Levy meint, ich soll mich auf dem Titel nicht nennen, übrigens aber nichts schonen. Das lässt sich hören, besonders das lezte“. ${ }^{209}$ Berührungsängste mit Thema und Darstellung hat es in der Berliner Salongesellschaft anscheinend nicht gegeben. Im Vergleich zur in Kapitel IV dargestellten Rezeption der Horen in den Berliner Salons fiel der Umgang mit Schlegels Lucinde durchaus pragmatischer, aber auch weniger ehrfurchtsvoll aus, „weltlich“ eben. Zugleich ist kaum eine wirklich begeisterte Rezension auszumachen. Während Henriette Herz' Reaktion noch auf eine weitgehend positive Aufnahme deutet, soll ihr Mann seine Abneigung in deutliche Worte gefasst haben: „,Der eine Theil ist eine gemeine prosaische Schweinigelei, der zweite eine poetische und der dritte Unsinn““..210 Die Briefe der untersuchten Korrespondenten bestätigen die bekannte Annahme, dass von Schlegels Berliner Freunden und Bekannten nur Fichte die Lucinde wirklich geschätzt habe, der es „eines der grösten Genie Producte“ nannte und mehrfach las. ${ }^{211}$ Der Einzige aus dem Umkreis Schlegels, der öffentlich, mit Vertraute[n] Briefen über Friedrich Schlegels Lucinde, für das Buch und seinen Autor eintrat, war Friedrich Schleiermacher, der auch schon in der Scheidungsphase dem Paar beigestanden hatte. ${ }^{212}$

208 Henriette Mendelssohn an Gustav von Brinckmann, 5. 2. 1799, ungedruckt, BA M. 209 Friedrich Schlegel an August Wilhelm Schlegel, 29. 1. 1799, in: KFSA, Bd. 24, S. 223. 210 So kolportierte Johann Daniel Sander an Karl August von Böttiger, 22. 6. 1799, in: Maurach 1990, Bd.3, S.35. Nicht nur die Liebesgeschichte Schlegels mit „der Veit“, auch die Lucinde selbst scheint das Haus Herz in der Rezeption gespalten zu haben. Wenn dem klatschenden Verleger Sander zu glauben ist, hat Herz eine bald kursierende Satire Kotzebues auf Schlegel nicht nur genossen, sondern „allenthalben zum besten gegeben“. Das implizierte, wie Sander ergänzte, „eine gewisse Kränkung für seine Frau, die einstweilen noch zu dem Anhange der Schlegel gehört!“ Johann Daniel Sander an Carl August Böttiger, 29. 10. 1799, in: Maurauch 1990, Bd.3, S.51. Gemeint ist August von Kotzebue: Der hyperboräische Esel, oder: Die heutige Bildung. Ein drastisches Drama und philosophische Lustspiel für Jünglinge, Leipzig 1799. Das Drama enthält den Part eines jungen Galans, der nur aus Zitaten Friedrich Schlegels zusammengeschrieben ist.

211 Johann Gottlieb Fichte an Marie Johanne Fichte, 8. 9. 1799, in: FGA III,4, S. 67.

212 In seinen 1800 anonym erschienenen Buch verteidigte er das darin aufscheinende höchste Ideal der Liebe auch gegen ästhetische Mängel, konnte allerdings weder die Kritiker unter den Zeitgenossen noch unter den Nachlebenden überzeugen. Stattdessen wurde es oft zum Anlass genommen, an Schleiermachers literarischer Objektivität zu zweifeln. „Zweifellos hat Schleiermacher Schlegels Buch freundlicher beurteilt als die Tendenz es verdiente.“ Friedrich Wilhelm Kantzenbach: Friedrich Daniel Ernst Schleiermacher. Mit Selbstzeugnissen und Bilddokumenten, Reinbek 1995, S. 74 f. 
„VII. Du sollst keine Ehe schließen, die gebrochen werden müsste.“- Friedrich Kantzenbachs These, dass Schleiermacher auch seine Ideen zu einem Katechismus der Vernunft für edle Frauen vor dem Hintergrund der Abwendung seiner Freundin von Veit hin zu Schlegel verfasst habe, lässt sich zwar nicht wirklich beweisen. Dennoch ist wichtig festzuhalten, dass mit dem Katechismus einer der wirklich progressiven Texte der Geschlechterdebatte im Zusammenhang mit personellen Entwicklungen in den Salons entstand. ${ }^{213}$ Und nachweisen lässt sich, dass die Autoren Schlegel und Schleiermacher in ihren Werken Formulierungen mit Blick auf die Salonfrauen änderten. ${ }^{214}$

In den hier untersuchten Briefen fand sich keine Verteidigung von Schlegels Liebeskonzeption aus weiblicher Hand. Allerdings ist auffallend, dass sowohl Rahel Levin Varnhagen als auch Henriette Mendelssohn auch keine Einwände gegen die Veröffentlichung des Romans erhoben, sondern sein Erscheinen im Wortessinne durch Rat - Schlegel möge „nichts schonen“ -, bzw. Tat, Abschreiben, beförderten, und das, obwohl sie die Lebenssituation ihrer Freundin und Schwester aus eigener Anschauung kannten. Henriette Mendelssohns ebenso knappe wie prägnante Kritik betraf die Form, nicht den Inhalt des Romans: „Henr.[iette] hat auch bis zu den Lehrjahren gemeynt, es sey kein Roman, sondern Romanextract, woraus nun jeder selbst welche machen könne“. ${ }^{215}$ Vermutlich wurden diese Frauen von dem Grad, bis zu welchem der Roman autobiografisch gelesen wurde, bestimmt aber von dem Ausmaß der damit verbundenen Häme, überrascht.

Ebenso streitbar wie die immer noch anhängige Deutung ihrer Biografie als „aufopfernder Muse“ Friedrich Schlegels ist die Interpretation, die die Rolle Dorothea Mendelssohn Veit Schlegels zur Entstehungszeit der Lucinde erfährt. ${ }^{216}$ Dass sie die Veröffentlichung der Lucinde nicht verhindert hat, muss keineswegs blinde Verehrung ihres neuen Partners bedeuten, wie auch einige

213 Kantzenbach 1995, S.72 f. Allerdings distanzierte sich der Prediger später von seiner Umformulierung kanonischer Texte unter der Fahne der Gleichberechtigung, die 1798 anonym im „Athenäum“ erschien, deutlich und lehnte beispielsweise Scheidung kategorisch $\mathrm{ab}$.

214 So schlug Schlegel Schleiermacher vor, „der Veit zum Possen“ den Begriff Willkür in seine Gebote mitaufzunehmen, was auch geschah: „V. Ehre die Eigentümlichkeiten und die Willkür Deiner Kinder." Bezeichnend ist, dass er dies in einem Gemeinschaftsbrief mit Dorothea schrieb: Friedrich Schlegel und Dorothea Mendelssohn Veit Schlegel an Friedrich Schleiermacher, 27. 3. 1798, in: KFSA, Bd. 24, S. 117.

215 Friedrich Schlegel an Caroline Schlegel, Spätmärz 1799, in: KFSA, Bd. 24, S. 253. Der Ausspruch ist auch belegt durch einen Brief Henriette Mendelssohns an Gustav von Brinckmann, der Text käme ihr vor wie ein „Fläschgen“, „einen Roman kann sich jeder nach Belieben daraus machen“, 5. 2. 1799, ungedruckt, BA M.

216 So formuliert noch Barbara Becker-Cantarino 2000, S. 125. 
feministische Interpretationen noch nahelegen, sondern kann auch eine genuine Begeisterung für das literarische Experiment beinhalten. ${ }^{217}$ Vor allem spricht die unmittelbare Aufnahme eines eigenen Romanprojektes noch im selben Jahr für ein bemerkenswertes Selbstbewusstsein einer sich ausprobierenden Schriftstellerin an der Seite eines umstrittenen Schriftstellers. Auch ihr Florentin wurde von Mitgliedern der Berliner Salongesellschaft im Manuskript gelesen, wurde von Zeitgenossen der Lucinde verglichen und schnitt dabei oft besser ab als der Roman ihres Partners. ${ }^{218}$

Auffallend ist die pragmatische Herangehensweise der Berliner Salongesellschaft an den Text auch im Vergleich mit der brieflichen Diskussion zweier junger gebildeter Leserinnen aus ihrem weiteren Umfeld im November 1799. Sophie Brentano, Brieffreundin von Henriette Arnstein Pereira, fragte diese im Tonfall etwa eines mutigen Schulmädchens: „Kennst Du auch (.wir sind ja alte, erfahrne Personen.) das Werk einer dieser Schlegel: Luzinde? - Ist es dir nicht bekannt, so will ich es nicht empfohlen haben; aber wenn du es gelesen hast, so laß mich dein Urtheil darüber hören.[...] Plauder also ein wenig mit mir über die neue, kühne Theorie dieser verwegenen Männer“"'219 Sie enthielt folgende klare Antwort, die über den Ruf, der dem Roman im wahrsten Sinne vorauseilte, einiges aussagt: „Die Luzinde Liebe habe ich nicht gelesen, und werde sie auch nicht lesen. Ich bin nicht prude und lache über eine unheilige Idee wie $\mathrm{Du}$ dich wohl erinnern wirst, aber ich lese dergleichen Sachen nicht gern, ich mag meine Einbildungskraft nicht verunreinigen“. ${ }^{220}$ Hingegen verband Rahel Levin Varnhagen noch 1802 eine Einladung zum Mittagessen an Friedrich von Gentz mit dem Vorschlag, über die Lucinde „ordentlich disputi-

217 Darin wäre sie ihrer Schwägerin durchaus wieder vergleichbar. Bekannt in diesem Zusammenhang ist die Aussage Caroline Schlegel Schellings: „Wenn ich seine Geliebte wäre, so hätte es nicht gedruckt werden dürfen. “ Weniger oft zitiert wird allerdings die dann folgende Überzeugung, dass Persönliches hinter dem Kunstwerk zurückzustehen habe: „Dies ist alles indeß keine Verdammniß. Es giebt Dinge, die nicht zu verdammen, nicht zu tadeln, nicht wegzuwünschen, nicht zu ändern sind, und was Friedrich thut, gehört gemeinhinglich dazu.“ Caroline Schlegel Schelling an Novalis, 20. 2. 1799, in: Sigrid Damm (Hrsg.): Begegnung mit Caroline. Briefe von Caroline Schlegel-Schelling, Leipzig 1989, S. 217. 218 „Und das [Lesen des „Florentin“] konnte, da Jette und ich ihn zusammen lesen wollten, nur an einem ruhigen Abend geschehen, wo Herz abwesend war." Friedrich Schleiermacher an Dorothea Mendelssohn Veit Schlegel, 6.12. 1800, zit. nach: Dorothea Schlegel: Florentin, hrsg. von Wolfgang Nehring, Stuttgart 1993, S. 269. Jette meint Henriette Herz.

219 Sophie Brentano an Henriette Arnstein, 4. 11. 1799, in: Karen Schenck zu Schweinsberg (Hrsg.): Meyne Seele ist bey Euch geblieben. Briefe Sophie Brentanos an Henriette von Arnstein. Weinheim 1985, S. 88

220 Henriette Arnstein Pereira an Sophie Brentano, 10.1. 1800, in: Schenck zu Schweinsberg 1985, S. 97. 
ren“ zu wollen. Der Eingeladene antwortete jedoch, vermutlich scherzhaft, sie sollte niemandem sagen, dass sie das Buch gelesen habe.221

Brinckmann selbst, guter Freund „der Veit“ und guter Kenner Schlegels, machte eine bemerkenswerte Wandlung in seiner Meinung durch. Er hatte die Lucinde zunächst nicht biografisch gelesen und sprach in seiner ersten Kritik im Brief an Luise von Voss nur vom gattungspoetischen Anspruch, dem ,genialischen Wurf“ und den ästhetischen Mängeln des Werkes. Erst im Folgejahr, aufgewühlt durch die Polemik Jenischs, die Dorothea Mendelssohn Veit Schlegel im Wortessinne in Unterwäsche darstellte, wurde er wütend auf Schlegel, der diese Entblößung provoziert oder doch in Kauf genommen habe. Brinckmann wurde deutlich, und er machte deutlich, dass so eine Veröffentlichung durchaus geschlechtsspezifisch unterschiedliche Folgen für die beiden Protagonisten haben würde:

\begin{abstract}
Was verliert denn der Mann bei diesem ganzen Narrenspiel revoluzionärer Sentimentalunabhängigkeit! in einigen Jahren bespotet er dieselbe vielleicht selbst als einen Geniestreich; Er steht alsdan noch da in ganzer Kraft und Blüte neue Romane zu dichten, oder seinen poetischen Lebens- zum Geschichtstyl zu veredlen - aber Sie ist alsdan entheiligt, verblüht, mit sich selbst und der Welt gleich unversöhnlich verzürnt, kurz sie endigt ein unruhiges Leben, als Opfer einer filosofischen Albernheit.222
\end{abstract}

Bedeutsam ist dabei, dass er die vorgebliche moralische Entrüstung der Berliner Gesellschaft ebenso unsittlich fand wie Schlegels Text selbst: „Gegen die Erbärmlichen, die ihn und die V. gleich heftig, und schonungslos antasten, nehme ich ewig ihre Partie, den die Bosheit jener Farisäer ist wahrl. um kein Haar moralischer.“

Während sich die Weimarer Dichter fast alle über das Machwerk der „Unnatur“223 Lucinde erhoben, herrschte in Berlin nach Ansicht von Beteiligten

221 Angeregt wurde dieser Vorschlag vermutlich durch die Vorlesungen des Bruders, August Wilhelm Schlegel, die Levin Varnhagen und einige ihrer Gäste 1802 besuchten. Die Konversation findet sich in ungedruckten Vorlesungsmitschriften Rahel Levin Varnhagens.

S. 107. Renate Buzzo-Márgari: Schriftliche Konversation im Hörsaal: „Rahels und Anderer Bemerkungen in A. W. Schlegels Vorlesungen zu Berlin 1802“, in: Hahn / Isselstein 1987, S. 104-127, hier S.107. Ob die Deutung des Hefts als „einmaliges Dokument der authentischen Salonkonversation“ in ihrer Absolutheit gilt, ist zu fragen. Der Ton deckt sich jedoch mit der ironischen Annäherungsweise in den Briefwechseln zum Thema. Ebd., S. 106. 222 Dies und das folgende Zitat: Gustav von Brinckmann an Luise von Voss, 3. 3. 1800, ungedruckt, GSA 5/26,3.

223 Vgl. Schillers Rezension an Goethe, in der er - jahrzehntelange Debatten vorwegnehmend - das Buch als „Gipfel moderner Unform und Unnatur“ bezeichnete. Friedrich von Schiller an Johann Wolfgang von Goethe, 19. 7. 1799, in: Beetz 2005, Bd.1, S.723. Goethe antwortete, wie meist, wenn es Schlegel betraf, ausweichend, er werde sich der „wunderlichen Schleglischen Produktion“ bei Gelegenheit annehmen, 20. 7. 1799, Ebd., S. 724 . 
„Parteigeist“. Friedrich Schleiermacher fasste die Empörung und ihre Ursache hellsichtig zusammen im „Verdruss, dass sie für die Verletzungen ihrer Dezenz nicht die Valuta in barem Sinnenkitzel erhalten haben“, sprich, dass der Band nicht so pornografisch war wie erhofft.224 So wurde die „Frechheit“, die gattungspoetische und personelle Herausforderung der Lucinde durchaus erkannt und unterschiedlich gewürdigt, ihr Verfasser aber in Salonkreisen keineswegs als Verteidiger einer „vollendeten Menschheit“ betrachtet.

\section{„Behüte uns der Himmel vor solchen Beschützern“}

Bemerkenswert ist für den zeitgenössischen Diskurs über die Geschlechter, mit welchen anderen Texten Schlegels Roman gemeinsam verhandelt, mit welchen er gleichzeitig in den Salons diskutiert wurde. Auf Lea Mendelssohn Bartholdys Frage nach Lucinde empfahl Brinckmann ihr Kant, dessen 1798 erschienene Anthropologie in pragmatischer Absicht er gerade las. ${ }^{225}$ An dieser Schrift ist im klaren Gegensatz zur Lucinde neben der frauenfeindlichen Haltung besonders das sie begleitende Desinteresse des Publikums auffällig.226 Das mag am wissenschaftlichen Charakter und Anspruch des Buches liegen, das von Kant auch zur Begründung der wissenschaftlichen Disziplin gedacht war, es nimmt aber, insbesondere beim hier interessierenden Schwerpunkt, wunder, da „Kants Äußerungen zur Frau und zu den Juden geschmacklos und unter aller Kritik“ genannt werden können. ${ }^{227}$

224 Friedrich Schleiermacher an Gustav von Brinckmann, 4. 1. 1800, in: Kantzenbach 1995, S. 74.

225 Zitiert wird hier nach der Ausgabe: Immanuel Kant: Anthropologie in pragmatischer Hinsicht, in: ders.: Werke in sechs Bänden, hrsg. von Wilhelm Weischedel, Bd VI: Schriften zur Anthropologie, Geschichtsphilosophie, Politik und Pädagogik, Darmstadt 2005, S. 395-690.

226 Obwohl die „Anthropologie“ mit 2.000 Exemplaren in erster Ausgabe alle früheren Werke Kants übertraf und 1800 in zweiter Auflage erschien, entwickelte sich keine wirkliche öffentliche Auseinandersetzung um das Werk. Informationen nach: Reinhardt Brandt: Kritischer Kommentar zu Kants Anthropologie in pragmatischer Hinsicht (1798) (KantForschungen, Bd.10), Hamburg 1999, S. 7 f. Schleiermachers negative Renzension im „Athenäum“ 1799 habe nur die Interesselosigkeit des Publikums verstärkt. Ebd. Das Zitat in der Überschrift nach: Lea Mendelssohn Bartholdy an Gustav von Brinckmann, 15. 4. 1799, ungedruckt, BA M.

227 Brandt 1999, S. 19. Vgl. beispielsweise: „Die unter uns lebenden Palästinenser sind durch ihren Wuchergeist seit ihrem Exil, auch was die größte Menge betrifft, in den nicht ungegründeten Ruf des Betruges gekommen.“ Kant 2005, S.517 f. Fn. Kant begründet im Folgenden die Kraft dieses „Wuchergeistes“ mit der geopolitischen Lage Israels, das für Karawanenhandel sehr vorteilhaft gelegen sei. S.518. Fn. 
Kant definierte im Abschnitt „Charakter des Geschlechts“ als Voraussetzung des Friedens in jeder Zweierbeziehung die Unterwerfung eines Partners, „denn in der Gleichheit der Ansprüche zweier, die einander nicht entbehren können, bewirkt die Selbstliebe lauter Zank“.228 Dass nun der weibliche Teil der schwächere sein solle, sah Kant in der Weisheit der Natur begründet, die der Frau mit der Fähigkeit des Gebärens zugleich die Furcht um das Kind mitgegeben habe und Sehnsucht nach männlichem Schutz. ${ }^{229}$ Der Abschnitt „zerstreute Anmerkungen“, auf den Brinckmann sich bei seiner Empfehlung berief, bündelte ebenso prägnante wie deutlich misogyne Aphorismen und solche, die der in der Lucinde dargestellten weiblichen Initiative explizit widersprachen: „Das Weib ist weigernd, der Mann bewerbend“, und: „Die Natur will daß das Weib gesucht werde“.230

In einem langen Brief an Lea Mendelssohn Bartholdy bemerkte Brinckmann zunächst: „Es ist sehr leicht, gegen Ihr Geschlecht Satiren zu machen wiewol die meisten auch zieml. platt sind - aber ich bin überzeugt, dass es eben so leicht wäre, dieses ganze weiche Geschlecht tugendhaft, sitsam u liebenswürdig zu machen, wenn wir es je redlich drauf anlegten“. ${ }^{231}$ Dieses ambivalente Zitat, in dem er sowohl ein Ausbildungspotential der Frauen wie eine erzieherische Aufgabe der Männer postulierte, leitete ihn über zu der Literaturempfehlung, die er einleitete: „Freuen Sie sich, der größte Filosof des Jahrhunderts, Kant selbst nimmt sich der Weiber in seiner neuen Anthropologie sehr hübsch an. Er sagt sie sind zum Herrschen, die Männer zum Regieren bestimmt, $u$ es ist ein eben so feiner wie wahrer Unterschied“.232

Während Brinckmann der galanten Verkleidung des Double Standards hier noch etwas abgewinnen konnte, wehrte sich Lea Mendelssohn Bartholdy nachdrücklich gegen solche Zuschreibungen - und zwar gleichermaßen gegen die Brinckmanns wie die Kants: „Sie sind überzeugt, dass ich den Kant nicht lese, $\mathrm{u}$ wollen mir deshalb weiß machen, dass dieser größte aller Philosophen in seinem neusten Werke die Weiber in Schutz nimmt? Behüte uns der Himmel vor solche Beschützer!“ Sie deutete zugleich an, dass das Werk in ihrem Zirkel

228 Kant 2005, S. 648.

229 Bemerkenswert ist die zweite Aufgabe, die „Cultur der Gesellschaft und Verfeinerung derselben durch die Weiblichkeit“; die Sittsamkeit der Frau solle den Mann zähmen. Kant 2005, S. 651.

230 Kant 2005, S. 652.

231 Gustav von Brinckmann an Lea Mendelssohn Bartholdy, 2. 2. 1799, diese Stelle ungedruckt, BA $M$.

232 Gustav von Brinckmann an Lea Mendelssohn Bartholdy, 2. 2. 1799, diese Stelle ungedruckt, BA M. Das Originalzitat lautet: „Das Weib soll herrschen und der Mann regieren; denn die Neigung herrscht und der Verstand regiert.“ Kant 2005, S. 657. 
Kreise gezogen hatte, und ironisch aufgenommen worden war: „Ein recht boshafter Mann hat mir die witzigen, aber ganz entsetzlichen Bemerkungen über die armen Frauen vorgelesen: das ist ja barbarisch“. ${ }^{233}$ Damit gab sie zu erkennen, dass sie wusste, dass sich Brinckmann aus Kants „Zerstreuten Bemerkungen“ über die Geschlechterfrage die ,mildeste“ ausgesucht hatte. Deutlich verwahrte sie sich gegen die Mythologisierungstendenz, die gesellschaftliche Ungleichheiten verbrämen sollte: Behüte uns der Himmel vor solchen Beschützern. Ganz ähnlich hatte sich Rahel Levin Varnhagen einmal gegen eine Überhöhung Brinckmanns mit den Worten gewehrt: „[...] daß Sie sich so sehr schwach gegen mich stellen, mich so hoch über sich setzen, dadurch machen Sie mich zum Idole, und sich zum lebenden Menschen“. 234

Brinckmann jedoch ließ nicht locker. Anstatt auf die Argumentation seiner Korrespondentin einzugehen, wählte er eine andere vorgeblich galante Äußerung, um sie von Kants guter Absicht zu überzeugen. Zugleich unterstellte er Lea Mendelssohn Bartholdy, sie habe sich in ihrer Rezeption nur von den Vorurteilen der Männer leiten lassen. Brinckmann formulierte ironisch, aber deutlich, dass man bei einigen Männern den „grauen Star stechen“ lassen müsse, namentlich bei solchen, die

Ihnen aus dem Kant vorlesen, um zu Beweisen, dass der große Mann die Weiber verachtet. Weil in seiner Anthropologie einige Plattitüden über sie vorkommen! [...] der einzige Saz; „das Weib sei im Häuslichen Leben zum Herrscher, der Mann zum Regiren bestimmt“ muß Sie überzeugen, dass er die Würde Ihres Geschlechts kennt und sie selbst die zartesten Umrisse seiner Natur kennt. ${ }^{235}$

Die Diskussion wurde nicht fortgesetzt, möglicherweise deshalb, weil Lea Mendelssohn Bartholdy sich weder überzeugen lassen noch weiter streiten wollte. In anderen Briefwechseln der Salongesellschaft aus dieser Zeit wurde Kants Anthropologie kaum erwähnt. ${ }^{236}$ Bezeichnend für die Haltung der Beteiligten ist vielleicht der ironisch-distanzierte Ton Schleiermachers, der sich als einer der wenigen öffentlich dazu äußerte und von einer „Sammlung an Trivialitäten“ sprach. ${ }^{237}$ Auch zu Kants, wenngleich nur in Fußnoten steckenden, antijü-

233 Lea Mendelssohn Bartholdy an Gustav von Brinckmann, 15. 4. 1799, ungedruckt, BA M. 234 Rahel Levin Varnhagen an Gustav von Brinckmann, 5. 2. 1795, SV 38, auch in: GW I, S. 128. Brinckmann zitierte diesen Brief ausführlich in seinem Nachruf. Brinckmann 1876, S. 241.

235 Gustav von Brinckmann an Lea Mendelssohn Bartholdy, 17. 5. 1799, ungedruckt, BA M. 236 Ludwig Robert bemerkte, dass David Veit seine Vorlesung daran orientierte. An Rahel Levin Varnhagen, 11. 10. 1801, in: ERLV II, S. 52.

237 [Friedrich Schleiermacher]: Anthropologie v. Imm. Kant, Königsb. 98, in: Athenäum. Eine Zeitschrift, hrsg. von August Wilhelm Schlegel und Friedrich Schlegel, Reprographischer Nachdruck, 3 Bde., Darmstadt 1992, Bd. II/2 [1799], S. 303-306, hier S. 303. Dass Schleiermacher zu seinen Kritikpunkten neben der mangelnden Textstruktur auch „die 
dischen Bemerkungen in der Anthropologie lassen sich in den hier untersuchten Korrespondenzen keine Kommentare finden. ${ }^{238}$

\section{4 „Meine Freunde sind mein Publikum“ - Über die Autorschaft von Frauen und die große versus die kleine Öffentlichkeit}

Auf die Disparität zwischen den Erwartungen männlicher Salongäste an ihre Gastgeberin als bloß privatim tätiger Muse und der tatsächlichen Zahl von Salonièren, die selbst als Autorin an die Öffentlichkeit traten, hat die kritische Salonforschung in den letzten zehn Jahren vermehrt hingewiesen.239 Die hier vorgenommene Parallellektüre liefert in diesem Zusammenhang einen interessanten Hinweis auf das damit verbundene Verständnis von Öffentlichkeit einiger Salonbeteiligter.

Als der Briefwechsel zwischen Mendelssohn Bartholdy und Brinckmann wieder einsetzte, war „Weiblichkeit“ wieder Thema, in Form einer neuen gemeinsam gelesene Lektüre. Lea Mendelssohn Bartholdy fragte: „Was sagen Sie denn zu den Schwestern von Lesbos? Ich habe ganz die sanfte, weibliche Seele, den reinen, hohen Geist, die liebliche Einbildungskraft, den feinen ästhetischen Sinn Ihrer Amalie darin erkannt“.240 Mit „Ihrer Amalie“ spielte sie auf die mehrfach geäußerte Begeisterung Brinckmanns für Amalie von

Behantlung des weiblichen Geschlechtes als eine Abart“ zählte, wurde in den hier untersuchten Korrespondenzen nicht weiter verfolgt. Ebd., S. 306. Die Haltung ließe sich zumindest für den Kreis um Friedrich Schlegel als allgemein annehmen, da er Schleiermacher um die Rezension gebeten hatte: „Übernähmst Du wohl für die Notizen Kants Anthropol[ogie] und Garvens letzte Schriften? - Du weißt die Idee davon. -“ Friedrich Schlegel und Dorothea Mendelssohn Veit Schlegel an Friedrich Schleiermacher, 14. 4. 1799, in: KFSA, Bd. 24, S. 267.

238 Anmerkungen zu Juden finden sich bemerkenswerterweise unter dem Stichwort „von den Gemütsschwächen im Erkenntnisvermögen“, so beim Stichwort „Betrug“ die oben zitierte zum „Wuchergeist.“ Diese Bemerkung steht nicht isoliert, auch andere Quellen aus dieser Zeit überliefern antijüdische Äußerungen Kants. Vgl. den viel zitierten Tagebucheintrag des Theologen Johann Friedrich Abegg von einem Mittagessen bei Kant am 14. 6. 1798: „Die Rede war von der jüdischen Gesellschaft, von den Juden: ,Es wird nichts daraus kommen; so lange die Juden Juden sind, sich beschneiden lassen, werden sie nie in der bürgerlichen Gesellschaft mehr nützlich als schädlich werden. Jetzo sind sie die Vampyre der Gesellschaft'، Johann Friedrich Abegg: Reisetagebuch von 1798, hrsg. von Walter und Jolanda Abegg in Zusammenarbeit mit Zwi Batscha, Frankfurt/M. 1987, S. 190.

239 Vgl. z. B. Kinkshofer 2001 und Lund 2007. Das Zitat aus der Überschrift: Gustav von Brinckmann an Luise von Voss, 27. 5. 1800, ungedruckt, GSA 5/26,3.

240 Lea Mendelssohn Bartholdy an Gustav von Brinckmann, 16. 12. 1799, ungedruckt, BA M. 
Imhof ${ }^{241}$ an und betonte ihr grundsätzliches Interesse an weiblicher Autorschaft: „Der holde Zauber weiblicher Grazie besellt es ganz [...]; Ich liebe es nun einmal, das die Produkte der Dichterinnen ihren eignen Stempel tragen, $\mathrm{u}$ die Kraft $\mathrm{u}$ Energie die viele in dem reizenden Gedicht vermissen wollen, muß doch wohl mehr das Charakteristische des Apoll als der jüngsten Muse sein“. ${ }^{242}$ Brinckmann scheint diese Einstellung zum „weiblichen Schreiben“ geteilt zu haben, denn gegenüber Luise von Voss lobte er das Gedicht als „Abdruck einer ungewöhnlich zarten und schönen Seele“ mit dem Argument, ein Mann hätte dem Text mehr „Energie“ aber nicht so „milde Beleuchtung“ gegeben. ${ }^{243}$

Allerdings wurde weibliche Autorschaft im Umfeld der Salons am selben Beispiel auch durchaus kritisch beurteilt. Mit gerade gegenteiligem Argument äußerte sich Henriette Arnstein Pereira: Die Schwestern von Lesbos fände sie nicht gut, denn, wenn eine Frau dichtete, also „wenn ein Mädchen aus ihrer Sphäre tritt, wenn sie die Augen der Welt auf sich zieht, wenn sie es wagt mit Männern um den hohen Preis zu ringen, so muß sie etwas großes geben, so muß sie würdig seyn, neben Männern zu stehen“, und das könne Amalie von Imhof noch nicht. ${ }^{244}$

Wenn die Bedingungen weiblicher Autorschaft so deutlich diskutiert wurden, und manche Frauen ebenso wie viele männliche Leser und Autoren über die „Einhaltung der Weiblichkeitsnormen wach[t]en“, ist interessant zu fragen, wie ein Dichterdiplomat sich dazu verhielt, der das Schreiben von Frauen förderte und zugleich an der Wahrung der Weiblichkeit interessiert war. ${ }^{245}$ Aus Brinckmanns fördernder und fordernder Haltung weiblichen Intellektuellen gegenüber, und aus seiner Bewunderung für einige Autorinnen, wäre zu fol-

241 Die Dichterin Amalie von Imhof, verheiratete von Helvig (1776-1831) hatte Brinckmann während seines kurzen Weimaraufenthaltes 1797 kennengelernt. Sie gehörte zu Schillers Kreis bewährter Autorinnen, veröffentlichte 1797-1800 Gedichte in seinen Zeitschriften und wurde später unter anderem mit Übersetzungen aus dem Schwedischen bekannt. Ihr Epos „Schwestern von Lesbos“ erschien im „Musen-Almanach auf das Jahr 1800“.

242 Lea Mendelssohn Bartholdy an Gustav von Brinckmann, 6. 12. 1799, ungedruckt, BA M. 243 Gustav von Brinckmann an Luise von Voss, 26. 12. 1799, ungedruckt, GSA 5/26,2. 244 Henriette Arnstein Pereira an Sophie von Brentano, 10.1. 1800, in: Schenck zu Schweinsberg 1985, S. 97.

245 Sigrun Schmid: Der „selbstverschuldeten Unmündigkeit“ entkommen. Perspektiven bürgerlicher Frauenliteratur. Dargestellt an Romanbeispielen Sophie von La Roches, Therese Hubers, Friederike Helene Ungers, Caroline Auguste Fischers, Johanna Schopenhauers und Sophie Bernhardis, Würzburg 1999, S. 321. Schmid nennt Imhofs Werk und Arnsteins Kommentar ein typisches Beispiel für die „Voreingenommenheit gegenüber weiblicher Autorschaft“ um 1800 auch unter Frauen. Ebd., S. 319. Umso interessanter sind die von Lea Mendelssohn Bartholdy angeführten Argumente pro weiblicher Autorschaft. 
gern, dass er auch seine Erfahrungen als Dichter oder seine Kontakte zu Verlegern zu Gunsten seiner Freundinnen ins Spiel gebracht hätte. Tatsächlich hat er gute Texte ,aus Frauenhand', wie etwa in Briefen enthaltene oder beigelegte Charakteristiken von Personen oder Rezensionen, als solche gewürdigt. ${ }^{246}$ Doch scheint es, wenn man die Debatte um die ,richtige 'Veröffentlichung „Rahels“ ansieht, für Brinckmann einen wesentlichen Unterschied zwischen dem Schreiben und dem Veröffentlichen seiner Freundinnen gegeben zu haben. ${ }^{247}$ Derselbe Mann, der nicht ohne Stolz im Zirkel seiner Bekannten kolportierte, dass die jüngste Schlegel-Veröffentlichung in Wahrheit nicht von Friedrich, sondern von Dorothea angefertigt worden sei, ${ }^{248}$ erwies sich, als es schließlich darum ging, Rahel Levin Varnhagens Briefe zu veröffentlichen, als einer der größten Gegner des Projektes. Er scheute dabei nicht vor übertriebenen Vergleichen, um an das Verantwortungsgefühl ihres Ehemannes zu appellieren, ihrer „beider Rahel“ den Status einer „Selbstdenkerin“ oder „Sibylle“, sogar eines „Sokrates“ zu belassen, die ihre Wirkung mündlich entfalteten. ${ }^{249}$ Er ging soweit, nicht nur zu behaupten, Levin Varnhagen sei nicht nur keine Schriftstellerin gewesen, sondern sie habe es auch nicht sein wollen. Diese Behauptung widersprach nicht nur ihren Veröffentlichungen zu Lebzeiten, sondern auch zahlreichen anderslautenden Aussagen in ihren Briefen an Brinckmann, was diesen nicht davon abhielt, sie wiederholt und schon zu ihren Lebzeiten zu kolportieren. Seine inhaltliche Begeisterung zusammen mit seiner stilistischen Kritik - „in diesem Sinn schreibt sie schlechter als irgendeine Pensions-Mamsell“ - führten dazu, dass er, wie zuvor David Veit, Rahel Levin Varnhagens Briefe weiterreichte, auch an Luise von Voss, sie aber zuvor für die aristokratische Leserin ,redigiert‘ hatte: „Geändert habe ich nichts, aber nachgeholfen hie und da, und unverzeihliche Eigenheiten getilgt“.250

Aus der Parallellektüre ergeben sich zwei interessante Auseinandersetzungen, in denen es zugleich um Rahel Levin Varnhagens Art der Gesellschaft

246 Beispielsweise ist eine längere Rezension von der Hand Luise von Voss', betreffend de Staëls „Corinne“, in seinem Nachlass überliefert. Der Text muss ihm so gut gefallen haben, dass er ihn in Schönschrift abschrieb. Eine weitere Verwendung ist bisher nicht nachweisbar. Ambitionen, mit eigenen Werken an die Öffentlichkeit zu treten, scheint Luise von Voss nicht besessen zu haben, die Möglichkeit wird nicht einmal erwähnt.

247 Vgl. zu dieser Debatte, die heute noch aktuelle Fragen vorwegnimmt Isselstein, 2001, S. 187-207.

248 „Haben Sie vielleicht die Geschichte der Jungfrau von Orleans, herausgegeben von Fr. Schlegel, angekündigt gesehen, Es ist aber nicht von ihm sondern von der Veit geschrieben." Gustav von Brinckmann an Luise von Voss, 3. 6. 1802, ungedruckt, GSA 5/ 26,5.

249 Vgl. Brinckmann 1876, passim.

250 Gustav von Brinckmann an Luise von Voss, 20.1. 1808, ungedruckt, GSA 5/26,11. 
wie um das Veröffentlichen ging, und in denen die Ansichten zu anonymen Veröffentlichungen fast unversöhnlich aufeinander prallten. 1804 gab Brinckmann seiner Freundin ein Manuskript zur Korrektur, das in nicht mehr zu rekonstruierender Zusammenarbeit entstanden war, und sie meldete per Billet: „Ich habe schon beinah das Buch fertig: manchmal hatt' ich nur kein Bleistift; aber bei nichts Gravem hat es mir gefehlt. Adieu! Eine recht schöne kurze Antwort! R. L.“251 Als Brinckmann sich Ende des Jahres 1804 für sein wochenlanges Fernbleiben entschuldigte und das tröstende PS anfügte „Übrigens lass ich unser Buch drucken“ ${ }^{252}$ wehrte Rahel Levin Varnhagen sich deutlich: „Daß unser Buch erscheint daraus mach ich mir nichts! Wenn die Welt nicht weiß, daß es unser ist. Unbekannt hab ich manches vollbracht. Und es kränkt mich endlich, daß mir die Sprache fehlt! Wenigstens bildet sich jetzt eine schmerzhaft in meinem Herzen für die, die sich meine Freunde nennen wollen." Auch ließ sie sich so nicht über sein Fernbleiben hinwegtrösten: „Hier ist endlich Einmal die Wahrheit! ich mag Sie nicht wie einen „Verwundeten“ behandlen! [...] Sie sind psychologisch mit dem kleinen Kreise fertig, und lassen sich nur soviel incomodiren, als es Ihre Geschäftspflicht Ihnen auflegt; dabey haben Sie die Wonne autor zu sein und mit Ihren Gedanken in geordnete Kenntniße graben und leuchten zu können“..253

Nicht nur erkannte und benannte Levin Varnhagen genau, dass Brinckmann aus persönlichen Gründen nicht mehr regelmäßig zu ihr käme, weil er „psychologisch mit dem kleinen Kreis fertig“ sei. Sondern sie wehrte sich auch deutlich gegen die Rolle der bloßen Muse. Das Buch nütze ihr nichts, wenn die Welt nicht um ihre Autorschaft wisse und ihr somit die Sprache genommen sei. Brinckmann war von ihrer Reaktion so getroffen, dass er am selben Tag noch seine Motive darlegte: „Nein, liebe Kleine! Ihre Ansicht war doch diesmal so durchaus falsch daß sie mich beinah frappirt hat, [...] die Bemerkung: ,Sie sind mit dem kleinen Kreise psychologisch fertig.' Im Gegentheil mit Personen, wie Sie, werde ich nie fertig; aber freil. mit Ihrem grossen Zirkel sehr bald“.254 Auf die Angelegenheit des Buches ging Brinckmann aber nicht mehr ein.

251 Rahel Levin Varnhagen an Gustav von Brinckmann, 6. 5. 1804, ungedruckt, SV 38. Möglicherweise handelt es sich um den Band Carl Gustav von Brinckmann: Gedichte. 1. Bändchen, Berlin 1804.

252 Gustav von Brinckmann an Rahel Levin Varnhagen, 10. 2. 1805, ungedruckt, SV 38. Sie antwortete am selben Tag, worauf auch Brinckmann noch mal am selben Tag ein Billet schickte, was zusätzlich auf ein gewisses Aufgebrachtsein schließen lässt.

253 Rahel Levin Varnhagen an Gustav von Brinckmann, 10. 2. 1805, in: Hahn 1998, S. 199.

254 Gustav von Brinckmann an Rahel Levin Varnhagen, 10. 2. 1805, in: Hahn 1998, S. 199 f. Mit einem Rest von Galanterie fuhr er fort, ihre Gäste wisse er „nun einmal so auswendig, daß ihre Unterhaltung mich ermüdet wie das Lesen in Campes Kinderbibliothek. Bei Ihnen ist das anders. Sie brauchen solche Menschen zum Ballspielen, um ihrem Geist Mozion zu 
Die berechtigte Frage, ob sich Brinckmann, ähnlich wie Goethe in seiner Ablehnung von Sara Meyer Grotthus' Autorschaft, sich entweder lästige Aufgaben oder Konkurrenz vom Leibe halten wollte, muss dennoch verneint werden. Brinckmanns Ablehnung, Briefe zu veröffentlichen - und möglicherweise auch die Aversion, Gedanken von Freundinnen zu veröffentlichen - hing, wie er betonte, mit seinem speziellen Konzept von Öffentlichkeit zusammen. Allzu textgetreue Veröffentlichung erschien ihm, wie vielen seiner Bekannten, unsittlich. Er traf diesen Unterschied auch für sich selbst, „daß ich zum öffentlichen Schriftsteller weder Beruf noch Talent genug besitze und habe mich also darauf beschränkt nur ein handschriftlicher Verfasser zu sein, zur Unterhaltung meiner Freunde und meiner selbst“. 255

Einen vergleichbaren Unterschied machte er für musikalische Vorführungen oder solche des Witzes, die vor ausgewählten Freunden oder der Allgemeinheit jeweils anders zuzurichten seien: „Meine Freunde sind mein Publikum, u. in einem kleinen häuslichen Zirkel mag einer ja wol ganz artig das Klavier spielen, ohne dadurch berechtigt $\mathrm{zu}$ werden, sich öffentlich hören $\mathrm{zu}$ lassen“. ${ }^{256}$ Typisch für Brinckmann war daher, dass er die Lucinde im Manuskript rezensierte und dies an verschiedene Freunde und Leser schickte, unter anderem an Schleiermacher, mit dessen veröffentlichter Rezension er sich sogar verglich: „Ich habe endlich die Luzinde nicht blos gelesen, sondern sogar, wiewol nur im Manuscript rezensirt, und unser Urtheil scheint viel gemeinschaftliche Berührungspunkte zu haben“.257

Wieviel Wert Brinckmann darauf legte, dass seine Privatbriefe nur einem ausgesuchten Kreis von Lesern unter die Augen kamen, zeigte sich bei einer zweiten Auseinandersetzung über das Veröffentlichen von Briefen. Rahel Levin Varnhagen hatte eine witzige Stelle aus Brinckmanns Briefen Friedrich Schlegel zur Kenntnis gebracht, der sie seinem Bruder zum Druck im Athenäum weiterleitete. So las Brinckmann in Paris sein eigenes Zitat unvermutet, wenngleich anonym, in der Zeitung. ${ }^{258}$ Seine Verstimmung wurde nicht dadurch

machen, wenn er zu faul ist, was anders zu thun. Ich bin schon zu steif, um mich zu bücken, und zu zerstreut um etwas aufzufangen." Ebd.

255 Gustav von Brinckmann an Karl August Varnhagen, Januar 1839, zit. nach: Isselstein 2001, S. 195. Es ist davon auszugehen, dass der Verlust vom gesprochenen zum geschriebenen Wort Thema in den Salons bzw. zwischen Levin Varnhagen und Brinckmann gewesen sein muss, da in ihren Tagebüchern sich ähnliche Ansichten finden.

256 Gustav von Brinckmann an Luise von Voss, 27. 5. 1800, ungedruckt, GSA 5/26,3.

257 Gustav von Brinckmann an Friedrich Schleiermacher, 29. 1. 1800, in: Meisner / Schmidt 1912, S. 22.

258 [Gustav von Brinckmann:] Aus einem Briefe von Paris über Kotzebues Menschenhaß und Reue, in: Schlegel / Schlegel 1992, Bd. II/2 [1799], S. 321. 
gemildert, dass Schlegel auf lakonische Art schrieb: „Übrigens bin ich Ihnen vielen Dank schuldig für Ihren Beytrag zum Athenäum“. 259 Brinckmann fasste seine Erregung zusammen in einer ausführlichen „Nachschrift vom 10. Oktober 1799 ! die zuerst gelesen werden muß“:

Ich bin böse auf Sie, liebste Levin, und das hätte ich bei einem Haare vergesen, ich habe seit langer Zeit ein Hühnchen mit Ihnen zu pflücken, oder eigentlich einen ganzen Auerhahn zu rupfen. Wie in aller Welt können Sie Schlegeln zum Druck etwas aus meinen Briefen mittheilen? Es ist, ohne allen Scherz, nicht hübsch. Ich könnte vielleicht so gut wie ein anderer Briefe zum Druck schreiben, aber ich muß es vorher wissen, und ich hasse ganz herzlich diese Wuth, jeden augenblicklichen Einfall, jeden freundschaftlichen Scherz in Buchhändlerwaare zu verwandeln. ${ }^{260}$

Obwohl die Formulierung, dass er nichts gegen Veröffentlichung habe, es aber vorher wissen wolle, in erster Linie auf verletzte Eitelkeit schließen lässt, ist wesentlich, dass Brinckmann den Vorfall zum Anlass nahm, mehreren seiner Freunde den Unterschied zwischen dem gesprochenen Witz und dem für den Druck geschriebenen zu erläutern. ${ }^{261}$ Gegen die Veröffentlichung seiner Briefe im kleineren Kreis, etwa dem Salon Levin, hatte er dabei explizit nichts einzuwenden. Abgesehen davon, dass sich hier das zeittypische Legitimationsmuster der Geschlechter umdrehte - ein männlicher Autor verteidigte sich, dass sein geistiges Eigentum wider seinen Willen - und in diesem Fall von einer Frau - veröffentlicht worden sei -, ist der Vorfall ist hier vor allem aus dem Grund interessant, da er den Salon und seine Gastgeberin als ,kleine‘ eigene Öffentlichkeit oder Zwischeninstanz zur ,wirklichen' Veröffentlichung belegt.

Langfristig problematisch hätte dieses Verständnis von Öffentlichkeit allerdings dadurch werden können, dass Brinckmann das Dilemma zwischen Sprache und Schrift für seine Freundinnen anders löste als für sich: er veröffentlichte Privatdrucke für Freunde, Rahel Levin Varnhagen gestand er lediglich die Rolle der Muse zu, indem er idealisierend in seinem Nachruf behauptete: „Sie konnte die besten von uns Buchstabenmenschen, ja selbst den wirklichen Künstler begeistern, sie selbst konnte, und wollte kaum eine Quartseite so

259 Friedrich Schlegel an Gustav von Brinckmann, Juli 1799, in: KFSA, Bd. 24, S. 304.

260 Gustav von Brinckmann an Rahel Levin Varnhagen, 10. 10. 1799, ungedruckt, SV 38.

261 Sprachwitz ließ sich nach Brinckmanns Auffassung nicht drucken. „Im Gegentheil: Es ist etwas ganz anderes Witzig sein und Witz haben. Das letztere kann der Fall des Schriftstellers sein, ohne daß er in Gesellschaft witzig ist. Er mag also drucken lassen; Der Witz hingegen der sich durch Sein und Thun und Sprache und Blick des Menschen offenbart [...]. Das witzigste Ihrer Unterhaltung zum Beispiel lässt sich nicht drucken. [...] der Korrespondent, der hieran nicht denkt, und sich folglich gehen lässt, ist für einen Kleinen Zirkel interessanter, während er unschuldiger weise dem Publikum sehr platt scheinen könnte“. An Rahel Levin Varnhagen, 10. 10. 1799, ungedruckt, SV 38. 
schreiben, wie es der Preßbengel verlangt“.262 Und doch hat seine Freundin für den Pressbengel, sogar die Presse geschrieben und ihre Pseudonyme waren für Zeitgenossen durchaus auflösbar. ${ }^{263}$ Es wäre für das Verständnis der Salongesellschaft interessant zu wissen, ob auch andere Beteiligte dieses Konzept einer ausgesuchten Öffentlichkeit vertraten und inwieweit die Salongesellschaft als eigene Öffentlichkeit empfunden wurde.

\section{Fazit - Geschlechterdebatten im Brief}

Gustav von Brinckmann hat keinen veröffentlichten Beitrag zur Geschlechtscharakterdebatte geleistet, wohl aber wurden ihm manche Veröffentlichungen und Begegnungen zum Anlass einer längeren brieflichen Rezension oder eines Verses auf die Geschlechter. Implizit regte er auch Geschlechterdebatten an, da seine Lektüretipps zahlreiche Texte enthielten, die diese Fragen erörterten. Er stritt sich über Richardson und Rousseau, zu den Schwestern von Lesbos oder Lucinde forderte er nachdrücklich Kommentare seiner weiblichen Briefpartnerinnen ein und leitete diese an andere Freundinnen weiter. Die größere Anzahl von Aussagen über Frauen-Rollen mag an seiner besonderen Wertschätzung dieses Geschlechtes liegen, allerdings lag er damit ganz im Trend der Zeit. Die hier untersuchten Frauen haben sich ebenfalls nicht offiziell an der Geschlechterdebatte beteiligt, wohl aber in ihren Briefen zu den Texten der beteiligten Männer und zu Brinckmanns Position deutlich Stellung bezogen. Brinckmann und seine hier untersuchten Freundinnen zeigten weitgehend dieselben Ambivalenzen gegenüber Geschlechterstereotypen: Während die Staël alle Beteiligten faszinierte, attestierten ihr beinahe alle einen „männlichen Geist“. Umgekehrt hinderte die Existenz zahlreicher selbstdenkender eigenständiger Frauen Mitglieder der Salongesellschaft nicht, ein Ideal der gebildeten Weiblichkeit, nicht gelehrter Frauen, zu propagieren. Bildung war erstrebenswert, sollte aber nicht allzu „öffentlich“ gezeigt werden.

Gustav von Brinckmann arbeitete keineswegs an der Beseitigung der Ungleichheit der Geschlechter, dazu reizte ihn die Dichotomie zu sehr. Aber er erkannte und missbilligte die stärkere Abhängigkeit der Frauen von der gesellschaftlichen Meinung und leugnete diesen Unterschied im Ernstfall nicht. Gegenüber diesem eingestandenen Geschlechtsunterschied beim Schreiben thematisiert Brinckmann bei „Frauen von Geist“ keine Differenz nach Herkommen und Stand, zumindest nicht in ihrer Rolle als Gesprächs- und Korrespon-

262 Gustav von Brinckmann an Karl August Varnhagen, 29. 5. 1833, ungedruckt, SV 38.

263 So waren die Kürzel, unter denen sie veröffentlichte, dem Publikum bekannt. Vgl. Kinkshofer 2001, S. $267 \mathrm{f}$. 
denzpartnerinnen. (Wie die folgenden Kapitel zeigen, kehrte das Standesbewusstsein bei der Betrachtung der Geselligkeiten nach 1801 zurück.) Allen vier Frauen ist gemeinsam, dass sie sich seine Huldigungen gefallen ließen, sich aber explizit gegen die Konzeption einer allzu „sanften Weiblichkeit“ wehrten, da sie ihrer Lebenspraxis nicht entsprach.

\section{Vom „moralischen Kanapee“ zum „Judensofa“ - Der Wiedereinzug der Kategorie ,jüdisch“ in den Briefwechsel Brinckmann-Voss}

Während einige wesentliche Themen des Briefwechsels zwischen Brinckmann und Voss nicht nur kontinuierlich verhandelt, sondern auch über zehn Jahre durchgängig ähnlich bewertet werden (Luises „Tugend“ und Gastfreundschaft, Goethe, Jean Paul, der Vorzug kleiner „Theetische“ gegenüber großen Gesellschaften), sind in der diskursiven Behandlung jüdischer Bekannter und Freundinnen Brüche zu konstatieren, die allerdings nicht, wie bisher angenommen, auf eine grundsätzliche persönliche Distanz des Salongastes zu diesen Frauen deuten, sondern vor allem auf (wieder) verschärfte Trennlinien in der Berliner Gesellschaft. Dieses Kapitel verfolgt die Entwicklung der Diskussion über jüdische Bekannte von den „Vertrauten Freundinnen“ [V.3.1] zur „Judenkultur“ [V.3.2] und letztlich zum „Judenschimpf“ [V.3.3].

\section{1 „Vertraute Freundinnen“}

In Brinckmanns Briefen an Luise von Voss wurden Kommentare zu Rahel Levin Varnhagen, Dorothea Veit Mendelssohn Schlegel, Henriette Mendelssohn und Marianne Meyer Eybenberg regelmäßig mit „Meine Freundin ...“ eingeleitet. ${ }^{264}$ In der ersten Phase des Briefwechsels (1797-1800) kam in seinen Briefen retrospektiv eine allgemeine Wertschätzung dieser Freundinnen zum Ausdruck. Sie wurden durchweg positiv erwähnt, für die Bekanntschaft mit Ihnen wurde geworben und sie wurden nicht als jüdische Frauen gekennzeichnet. Das Wortfeld „Jude/jüdisch“ ist im Briefwechsel mit Luise von Voss und Karoline von

264 Wie in Kap. III und IV dargestellt, lässt sich verschiedenen brieflichen Äußerungen entnehmen, dass Gustav von Brinckmann seit seinem ersten Berliner Aufenthalt 1789/90 zumindest Henriette Herz und Dorothea Mendelssohn Veit Schlegel kannte und spätestens seit 1792 regelmäßiger Gast mehrer jüdischer Familien war, u. a. der Levins, der Herzens, der Itzigs, der (Aaron) Meyers. 
Berg bis Mitte 1801 gar nicht vorhanden, ebenso wenig die Kategorie jüdisch. ${ }^{265}$ Der Leseeindruck der ersten Jahre muss lauten: Brinckmann, der nach eigenem Bekennen ohne den Umgang mit geistreichen Frauen nicht leben konnte, machte diese gern miteinander bekannt und unter seinen „alten Freundinnen“ befanden sich - bedingt durch die gesellige Struktur in Berlin vor 1800 - viele Frauen aus jüdischem Hause.

An die genannten Frauen wird dabei zu unterschiedlichen Gelegenheiten, in unterschiedlichen Funktionen erinnert. Rahel Levin Varnhagen tritt vor allem mit Aphorismen in Erscheinung, insbesondere dann, wenn es Gustav von Brinckmann darum ging, sich selbst auf originelle Weise zu erklären und er dafür eine Gewährsfrau brauchte, die ihn schon lange kannte. ${ }^{266}$ Nicht selten schrieb er längere Zitate aus ihren Briefen für Luise von Voss ab, die er einleitete mit: „Die kleine Levin schrieb mir neulich etwas sehr treffendes hierüber, das mir recht deutlich bewieß, wie richtig mich diese scharfsinnige Freundin beurtheilt“.267 Hier trifft Ursula Isselsteins Formulierung, Brinckmann „prahle“ mit Rahel, durchaus zu, er prahlte allerdings noch mehr mit anderen Frauen: ${ }^{268}$ Wesentlich detaillierter als mit Levin Varnhagen beschäftigte sich Gustav von Brinckmann in diesem Briefwechsel bis 1801 mit dem Charakter und dem Schicksal der Töchter Mendelssohns. ${ }^{269}$ So schrieb er schöne Stellen aus Henriette Mendelssohns Briefen ab und warb kontinuierlich für die Bekanntschaft. Im Sommer 1798 scheinen die Frauen sich getroffen zu haben, denn im Oktober schrieb Brinckmann: „Ich kann Ihnen meine Freude darüber, dass Ihnen Henriette Mendelson so gut gefällt, nicht lebhaft genug schildern. Ich liebe dies Mädchen wie die lieblichste und beste meiner Schwestern, und ich habe vielleicht nie eine aufrichtigere Freundin gehabt“. ${ }^{270}$ Mögli-

265 Auch zeitgenössische Synonyme wie „alttestamentarisch“ oder „mosaisch“ werden nicht verwendet. Weder die Situation der Juden in Preußen noch dadurch bedingte individuelle Lebenssituationen werden thematisiert.

266 Als Brinckmann sie Luise von Voss gegenüber erstmals erwähnte, muss sie mit dieser schon bekannt gewesen sind: „Die kleine Levin hat [...] immer behauptet, ich möchte nur selbst immer das Leben zehnfach feuren als nöthig wäre, blos um einst einen Heiligen Schein zu bekommen [...]. “ Gustav von Brinckmann an Luise von Voss, 17. 5. 1798, ungedruckt, GSA 5/26,1.

267 Gustav von Brinckmann an Luise von Voss, 12. 4. 1799, ungedruckt, GSA 5/26,2.

268 Isselstein 1997, S. 205.

269 Sowohl Henriette als auch Dorothea, „der Veit“, widmete er im Laufe der Jahre wiederholt mehrere Seiten, um „ihr ganzes Wesen“ für Luise von Voss ans Licht zu bringen. Ein ausführlicher Vergleich der beiden Schwestern nach Verstand und Charakter findet sich bereits im Brief Gustav von Brinckmanns an Luise von Voss, 16. 11. 1798, ungedruckt, GSA 5/26,1.

270 Gustav von Brinckmann an Luise von Voss, 16. 11. 1798, ungedruckt, GSA 5/26,1. 
cherweise hat sich Brinckmann für diese „Schwester“ besonders verantwortlich gefühlt, denn zur selben Zeit diskutierte er mit seiner anderen Brieffreundin, Henriettes späterer Schwägerin Lea Mendelssohn Bartholdy, die Möglichkeiten einer näheren Bekanntschaft. ${ }^{271}$ Zwischen Luise von Voss und Henriette Mendelssohn muss es zu einem leider nicht erhaltenen Briefwechsel gekommen sein, denn Brinckmann bat seine aristokratische Freundin, diesen auch über die Entfernung nach Wien aufrecht zu erhalten. ${ }^{272}$

Während Brinckmann für Henriette Mendelssohn warb, in dem er auf ihre zarte Veranlagung trotz eines harten Schicksals hinwies, versuchte er in ähnlicher Weise Luise von Voss' Urteil über Dorothea Mendelssohn Veit Schlegel abzumildern, in dem er auf deren selbstständigen Geist verwies. ${ }^{273}$ Höflich, aber deutlich, wies er ein zu hartes Urteil der Gräfin zurück: „Aber Sie, meine Gnädigste! beurtheilen die arme V. doch immer etwas $\mathrm{zu}$ hart. Ich würde schwerlich wagen, Ihnen zu widersprechen, wenn wir sie beide gleich genau kannten; [...] allein ich kenne die V. schon seit vielen Jahren, und schätze sie als eine meiner besten Freundinnen“. ${ }^{274}$ In seinen eigenen Worten „seufzte“ Brinckmann „nicht selten über ihre disharmonische Lage“.275 Auf die Idee, die „Disharmonie“ oder „Zerrissenheit“ dieser Frauen auf die allgemein schwierige Situation gebildeter und besonders jüdischer, gebildeter Frauen um 1800 zurückzuführen, beziehungsweise darauf, dass ein Grund für die Sprünge in ihrem Lebenslauf das Weiblichkeitsideal war, dem auch aufgeklärte Männer wie Brinckmann selbst anhingen, kam er zu keiner Zeit. ${ }^{276}$ Brinckmann sah

271 Die schüchterne Lea Mendelssohn Bartholdy wurde von Brinckmann darin bestärkt, die Freundschaft mit Henriette Mendelssohn zu suchen. Am 14.4. 1798 schrieb sie an Brinckmann: „Ich weiß nicht welches dunkle, selige Vorgefühl mir sagt, wir würden uns verstehen und lieben können“, und am 26.5.1798, sie sehe Henriette Mendelssohn jetzt in der Singestunde, in: Klein 2005, S. 104.

272 „Ich bitte Sie mit einem recht brüderlichen Interesse dieser lieblichen Emigrantin auch in der Entfernung Ihre Freundschaft zu erhalten, und selbst Ihren Briefwechsel mit ihr nicht aufzugeben." Gustav von Brinckmann an Luise von Voss, 18. 12. 1799, ungedruckt, GSA 5/ 26,2 .

273 „Viele thun der Veit so sehr Unrecht, daß sie glauben, sie habe weniger Verstand, im Gegentheil, sie hat einen sehr eigenthümlichen, sogar bis zur förmlichsten Sofisterei gewandten Geist.“ Gustav von Brinckmann an Luise von Voss, 16. 11. 1798, ungedruckt, GSA 5/26,1.

274 Brinckmann kannte Dorothea Veit Schlegel seit seinem ersten Berlinaufenthalt 1789/90. In der KSFA sind sehr persönliche Briefe Dorotheas an den Diplomaten überliefert. Luise von Voss und „die Veit“ lernten sich nach Aussage der letzteren im Sommer 1798 kennen. Dorothea Mendelssohn Veit Schlegel an Gustav von Brinckmann, 2. 2. 1799, in: KFSA, Bd.24, S. 226.

275 Gustav von Brinckmann an Luise von Voss, 18. 12. 1799, ungedruckt, GSA 5/26,2. 276 Bei Dorothea Mendelssohn Veit Schlegel sprach er von einer „Inkonsequenz der Empfindungen“, bei Henriette Mendelssohn wiederholt von ihrer zerrissenen oder 
die Ursache für die schwierige Lage „der Veit“ in ihrer impulsiven Veranlagung und vor allem in ihrem Verhältnis zu Schlegel, den er intellektuell zwar schätzte, aber moralisch für unzurechnungsfähig hielt.

Zwei weitere jüdische Bekannte wurden, auch als ehemalige Gastgeberinnen, diskutiert: Die in Kapitel IV erwähnte Sophie Fränkel Pobeheim und Marianne Meyer Eybenberg - letztere war ein besonderer Fall, da sie mit Luises Mutter, Frau von Berg, bereits befreundet war, bevor Brinckmann diese kennenlernte. In diesem Fall konnte daher Brinckmann „die Mariane“ und seine eigenen Verse nutzen, um Rahel Levin Varnhagen und „die Berg“ miteinander bekannt zu machen. ${ }^{277}$ Im Briefwechsel Brinckmann-Voss wurde „unsere Freundin Mariane“ zunächst nur bei Gelegenheit diskutiert. ${ }^{278}$ Erst der plötzliche Tod ihres Mannes, des Amtskollegen und Freundes Brinckmanns, Heinrich Fürst Reuß, 1799, machte ihr Schicksal in allen seinen Korrespondenzen zum Thema. Anscheinend äußerte sich Luise von Voss kritisch, denn im folgenden Brief formulierte er vorsichtig: „Ihre Bemerkungen über Mariane tun mir eigentl. weh, den ich halte sie für gegründet. [...] wer M. vorher nicht gut ist, beurtheilt sie darnach doch härter, als sie verdient. Ihrem Charakter fehlt von jeher Verschmelzung; heterogene Züge liegen oft $\mathrm{zu}$ nah; die edleren sind aber doch eigentl. die herrschenden“. ${ }^{279}$

Bemerkenswert ist diese Schilderung insofern, weil sie eine Formulierung vorwegnahm, die bei seiner Theorie über den „egyptischen Styl“ einiger Jüdinnen wieder auftauchen sollte, betreffend die Schärfe der Kontraste. 1799 allerdings wurde die mangelnde „Verschmelzung“ noch ohne jede antijüdische Assoziation verwendet, Meyer Eybenberg keineswegs als „egyptisch“, sondern als Witwe eines Fürsten diskutiert. Es war dem Diplomaten wichtig, ihren richtigen Titel zu wissen, den er Luise von Voss herauszufinden bat, bevor er überhaupt ein Beileidsschreiben aufsetzen könne. Bemerkenswert ist auch, dass in diesem Zusammenhang Brinckmann erstmalig Kritik am Verhalten Luise von Voss' übte, die keinen Kontakt mehr zu Marianne Meyer Eybenberg hatte: „Aber was heißt das: Sie hätten sie nicht selbst gesehen? - Die ganze Zeit ihres Witwenstandes nicht? - Dies würde mir misfallen“.280 Zur Verteidigung der Witwe schrieb er weiterhin, dass „sie 10 Jahre lang das Glück des Fürsten

„disharmonischen Lage“; Gustav von Brinckmann an Luise von Voss, 30. 1. 1799 und 18. 12. 1799, ungedruckt, GSA 5/26,2.

277 Zu Brinckmanns Rolle in der Kontaktvermittlung zwischen von Berg und Levin Varnhagen s. Lund 2010.

278 Ihre Schwester, Sara Meyer Grotthus, taucht in den zehn Jahren des Briefwechsels nur einmal auf.

279 Gustav von Brinckmann an Luise von Voss, 22. 4. 1799, ungedruckt, GSA 5/26,2.

280 Gustav von Brinckmann an Luise von Voss, 12. 4. 1799, ungedruckt, GSA 5/26,2. 
gemacht, u. dieser Verbindung doch ihre ganze Existenz aufgeopfert hat. Es giebt gewisse Unbilligkeiten, die mich immer empören, weil sie zugleich so gemein sind“.281

Wieder in Berlin stand Brinckmann vor der Notwendigkeit, Prioritäten zu setzen, da ein - leider nicht mehr zu bestimmendes - Ereignis Marianne Meyer Eybenberg und das Haus Berg auseinandergebracht hatte. $\mathrm{Zu}$ dem Tee seiner alten Freundinnen mit Luise von Voss wurde Meyer Eybenberg daher nicht gebeten. „In die Gesellschaft im Allgemeinen hätte sie gepasst, da aber die Gräfin meine kleine Zelle in einenn Tempel verwandelt, $\mathrm{u}$. Mariane sich in der lezten Zeit gegen Sie beide ein wenig profan benommen hat, so halte ich sie dieser Ehre nicht eigentlich werth“.282 Dieser und die folgenden Briefe Brinckmanns lassen sich in zwei Richtungen lesen, als Verteidigung Marianne Meyer Eybenbergs vor allzu heftiger Kritik und als Verteidigung seiner selbst, dass er noch mit ihr umging. Brinckmann schrieb an Karoline von Berg eine lange kritische Charakteristik über die Eitelkeiten ihrer ehemaligen Freundin, wusste sich aber zugleich dankbar für schöne Teestunden im Hause Meyer:

Sie ist meine Freundin gewesen zu einer Zeit, wo ich sehr freundesbedürftig war, $u$. wo ich mir sie freiwillig so sehr, wie möglich idealisierte, um nur alle Empfindungen meines kränklichen Herzens anbringen zu dürfen. Dies werde ich nie vergessen, und keine Gelegenheit möchte ich unbenuzt lassen, um ihr zu beweisen, dass ich noch ihr aufrichtiger Freund bin. ${ }^{283}$

Festzuhalten ist, dass er bei aller einschmeichelnder Kritik an seine neuen Freundinnen zu keinem Zeitpunkt auf Meyer Eybenbergs jüdische Herkunft referierte, noch ihr Verhältnis mit dem Prinzen Reuß als eine aus Ehrgeiz geschlossene Ehe, ein ,sich hoch Heiraten' missdeutete. Wenn Barbara Hahn schreibt, dass „,in keinem Bericht von Diners oder Teegesellschaften, von Einladungen in seinem Hause oder Besuchen bei Freunden [...] ein Hinweis darauf [fehlt], wer jüdisch ist oder nicht“, ist dem für den Briefwechsel BrinckmannVoss in dieser Absolutheit nicht zuzustimmen. In den Briefen bis Mitte 1801, in etwa 200 der insgesamt 360 Texte gibt es keinerlei solche, explizite oder implizite, Hinweise. ${ }^{284}$

281 Gustav von Brinckmann an Luise von Voss, 26. 4. 1799, ungedruckt, GSA 5/26,2. Dass man Marianne Meyer Eybenberg die Erbschaft vorenthalten wollte, fand er „grausam und schlecht“. Ebd.

282 Gustav von Brinckmann an Karoline von Berg, 8. 10. 1801, ungedruckt, GSA 5/1.

283 Gustav von Brinckmann an Karoline von Berg, 12. 10. 1801, ungedruckt, GSA 5/1.

284 Hahn 2002, S. 94. An dieser Stelle muss allerdings nochmals betont werden, dass Aussagen zu einem Briefwechsel eines Salongastes bereits durch eine andere seiner Korrespondenzen relativiert werden können. Wie in Kap. IV geschildert, erwies sich Brinckmann Dreiecksbriefwechsel mit seinen Jugendfreunden Gentz und Humboldt als Vertreter oder zumindest Connoisseur eben der Vorurteile, die er gegenüber der 


\section{2 „Judenkultur“ - Zwischen Wortspiel und Ressentiment}

Mit Blick auf seine „Bulletins“ zur Geselligkeit wurde festgehalten, dass sich Brinckmanns gesellschaftlicher Umgang nach 1801, auch aus dienstlichen Gründen, änderte. Die Schwerpunktverlagerung des geselligen Engagements erklärt aber noch nicht, wie es zur Äußerung der zitierten antijüdischen Ressentiments kam. Die Langzeitanalyse des Briefwechsels mit den beiden Aristokratinnen ergibt kein zu datierendes plötzliches Aufflackern eines neuen oder alten Antisemitismus, sondern es lässt sich ein schleichender Wiedereinzug der Kategorie ,jüdisch“ in die Sprache und Gedankenwelt Brinckmanns (und seiner Bekannten) ausmachen. Gewissermaßen wurde ihm die jüdische Herkunft zahlreicher Bekannter wieder zunehmend präsent, ebenso wie ihre rechtliche und soziale Situation, die er aber nicht politisch kommentierte, sondern mit der er sich nur ,im Salonton' auseinandersetzte. Bezeichnenderweise taucht der Begriff Jude erstmals im Briefwechsel in einem Wortspiel auf: „Sehen Sie nur, liebe Gräfin!, daß Ihr Schuzdichter - das Wort ist freil. nach Schuzjude gebildet, und wahrlich meine Muse bedarf Ihres Schuzes zum wenigsten eben so sehr, wie jenes unglückliche Volk eines fürstlichen ..“.285

Auch dieses Sprachspiel bezeichnet für sich genommen noch keine Distanzierung von jüdischen Freunden. Die Gesamtschau mehrerer Briefwechsel des Diplomaten ergibt hier ein komplexeres Bild: Wie im Dreiecksbriefwechsel zwischen Humboldt, Gentz und Brinckmann dargestellt, nahm Brinckmann zugleich Teil an einer Kommunikation zwischen Männern, die an einigen Freundinnen „das Jüdische“ deutlich und durchgehend als „das Andere“ markierte. Wie im Querschnittskapitel gezeigt, gehörten verbale Anspielungen auf die Religion zum alltäglichen Sprachgebrauch der Salongesellschaft, auch der jüdischen Beteiligten. Im Briefwechsel mit Weimarer Intellektuellen schließlich verglich Brinckmann sich selbst gleich mehrfach mit dem jüdischen Volk, und Weimar mit Jerusalem, wohin sich sein Blick sehnsuchtsvoll richte. ${ }^{286}$ Während

moralisierenden Gräfin zurückwies. Der Diplomat Brinckmann wird so zu einem hervorragenden Beispiel eines begabten Briefschreibers, der sich im Stil der Erwartungshaltung seiner jeweiligen Adressaten anpassen konnte.

285 Gustav von Brinckmann an Luise von Voss, 26. 6. 1801, ungedruckt, GSA 5/26,4. Im Oktober überlieferte er ein Teegespräch aus dem Hause Voss, bei dem die Gräfin den Titel „Schuzschwede“ verliehen habe. An Karoline von Berg, 8. 10. 1801, ungedruckt, GSA 5/1. 286 Nach seinem kurzen Besuch bei Goethe schrieb er 1799: „[...] ich wende seitdem mein Angesicht nach Weimar, wie die Juden nach Jerusalem." Es ist denkbar, dass er vergaß, dass er den Vergleich schon verwendet hatte, oder aber dass er ihm besonders gefiel, denn er schrieb 1803: „Seit meinem Aufenthalt in Weimar sehne ich mich in der That nach diesem gelobten Land zurück wie das alte Bundesvolk nach Jerusalem“, und 1804: „Das Andenken jener seligen Tage in Weimar [...]. Nach diesem gelobten Lande kehr’ ich noch immer, wie das alte Bundesvolk nach Palästina, meine traurigen Blicke.“ Gustav von Brinckmann an 
die Metapher hier je nach Perspektive verehrungsvoll oder anbiedernd wirkt, können ähnliche Stilmittel in Briefen an seinen ältesten Freund Friedrich Schleiermacher diese Funktionen nicht haben. Eine quantitative Analyse der dort verwendeten Metaphern und Vergleiche ergibt einen großen Anteil von Sprachspielen aus dem religiösen, auch christlichen Bereich. Ebenso wie er Literatur einmal mit Manna für die Juden verglich, so verglich er sich dem agnus dei, wenn er zu sehr von Migräne oder beruflichem Stress heimgesucht wurde. Das mag dazu gedient haben, den protestantischen Theologen in Schleiermacher zu provozieren, aber Anspielungen dieser Art finden sich auch zahlreich im Briefwechsel mit Rahel Levin Varnhagen oder sogar an Luise von Voss: „Ich schwöre Ihnen , daß ich bald anfangen werde, mich für das Lamm Gottes zu halten, welches der Welt Sünden trägt, denn zwischen meinen Leiden und meinen eigenen Sünden scheint gar nicht kein Verhältnis zu sein““.287 Es ist daher zu fragen, ob - für die Zeit bis 1801/02 - religiöse Metaphern aus dem Bereich der Religion und Anspielungen auf das Alte und Neue Testament nicht zum vielseitig einsetzbaren Stilrepertoire eines aufgeklärten klassizistischen Dichters gehörten? Und es stellt sich dann zugleich die Frage, was diesen veranlasste, dieselbe Sprache ab einem gewissen Zeitpunkt mit antijüdischem Inhalt zu füllen.

1801 wurde mehrfach in dem Briefwechsel Brinckmann-Voss von Juden als gesellschaftlicher Gruppe oder „Szene“ gesprochen, zunächst aber nur als Zitat von Bekannten, vor allem von Friedrich von Gentz, von dessen gesellschaftlichem Ehrgeiz er sich distanzierte. Gentz' unter IV. dargestellte ,Mahnungen', nicht zuviel mit Juden umzugehen, kolportierte Brinckmann genüsslich weiter:

Von Genz bekomm’ ich alleweile ein Billet, worin er mir vorwirft, daß ich ihn vernachlässige [...]: „Das einzige, was mich tröstet, ist daß ich immer mehr und mehr glaube, daß es weder Juden noch Gelehrte sind, die mir Ihren Umgang entziehen, sondern daß ich nur Personen nachstehen muß, denen ich lieber und williger weiche, deren Liebenswürdigkeit groß und entschieden ist; die von Juden durchaus nichts, und von den Gelehrten nur das an sich haben, was diesen eigentlich ihren Werth geben würde, wen es sich in Ihnen jemals in seiner völligen Reinigkeit entwikeln könnte. [...]“288

Johann Wolfgang von Goethe, 29.11. 1799 und 4. 10. 1803, sowie an Karoline von Wolzogen, 16. 5. 1804, in: Geiger 1896 (a), S. 30, 35 und 41.

287 Gustav von Brinckmann an Luise von Voss, 17. 3. 1799, ungedruckt, GSA 5/26,2. Die Parallelisierung von Krankheit und repräsentativen Anforderungen, als den zwei möglichen Gründen für sein Nichtkommen, war sprichwörtlich zwischen Brinckmann und seinen Freunden, so fragte ihn Rahel Levin Varnhagen vorsichtig: „Haben Sie Migräne oder Schweden?“ An Gustav von Brinckmann, 31. 8. 1797, in: GW I, S. 170.

288 Dies und das folgende Zitat Gustav von Brinckmann an Luise von Voss, 7. 7. 1801, ungedruckt, GSA 5/26,4. 
Brinckmann kommentierte dies Zitat aus dem Brief Gentz nicht, sondern deutete es als Kompliment an die Voss: „Die oben unterstrichenen Stellen sind wirkl. sehr hübsch, und mit dieser Charakteristik Ihrer Gelehrsamkeit bin ich völlig zufrieden.“

Zwei Wochen später waren nicht Juden und Gelehrte, sondern Juden und Schlegel Gentz' Schreckbild. Wie Brinckmann seiner Gastgeberin mitteilte, löste das Gerücht, wonach Schlegel bei Bergs verkehrte, bei Gentz Panik aus: „Ich dachte wir wären durchaus en bonne societè? Nächst unmittelbaren Juden giebt es nichts schrecklicher, als diese mittelbaren; diese Tyrannen der Literatur! Widerrufen sie doch dieses grausame Wort, als einen unschuldigen Spaß! War es aber Ernst - das ich immer noch nicht hofen will - so verschliessen Sie diese meine Aeusserungen ja in sich“!289

Statt Gentz' Wunsch zu erfüllen, kolportierte Brinckmann diese Äußerungen eben der Gräfin, zusammen mit seiner bemerkenswerten Antwort, er habe Gentz beruhigt, „daß gedachter Schl. eben kein besonderer Protége von Ihnen Beiden ist, und von dem Grafen ist er ein völliger Enthusiast, seit ich ihm versichert, daß er die Judenkultur förmlich haßt“.290

Auch wieder ,nur‘ als Zitat kam hier ein Begriff ins Spiel, der mehr Fragen aufwirft, als sich aus diesem Briefwechsel beantworten lassen. Anscheinend war zu diesem Zeitpunkt in diesem Kreis „Judenkultur“ eine eindeutige Anspielung. Dennoch war Brinckmanns Position hier noch die des Beobachters. Deutlich wird das in der Beschreibung des oben erwähnten Soupers Ende des Jahres $1801 \mathrm{zu}$ Ehren Fanny von Arnsteins, das sich gewissermaßen schneller herumsprach, als die Gastgeberin einladen konnte: Brinckmann kritisierte dabei deutlich „Gentz, der mit gewöhnlicher Feigheit - welches nicht etwa ein Schreibfehler für Feinheit ist - alle Parteien befriedigen wollte, und daher den Ungebetenen versicherte: ,es sei aus reiner Achtung für sie, weil man sich nicht getraute, sie mit Juden zusammenzubitten““.291

In seiner Beschreibung des Soupers legte Brinckmann, wie zitiert, Wert darauf, dass er Gentz' Besorgnis über die Mischung von Juden und Adligen nicht teilte. Auch wenn Brinckmann sich aber Ende 1801 auf die Ebene des Diplomaten zurückzog, der „schlechte Karten“ zu spielen wisse, wurde zugleich deutlich, dass zu diesem Zeitpunkt jüdische Herkunft für ihn eine solche

289 Friedrich von Gentz an Gustav von Brinckmann, zitiert in dessen Brief an Luise von Voss, 21.7. 1801, ungedruckt, GSA 5/26,4. Brinckmann zitiert hier wörtlich und unredigiert das Billet Friedrich von Gentz' vom selben Datum, vgl. Wittichen 1910, S. 76, lediglich „mittelbar“ war im Original auch unterstrichen.

290 Gustav von Brinckmann an Luise von Voss, 21. 7. 1801, ungedruckt, GSA 5/26,4. 291 Gustav von Brinckmann an Karoline von Berg, 19. 10. 1801, ungedruckt, GSA 5/1. 
mögliche schlechte Karte geworden war. ${ }^{292}$ Zwischen 1802 und 1804 wurden seine „alten Freundinnen“ dann zu seinen „jüdischen Freundinnen“, etwa wenn er schrieb, bei ihm in der Wohnung sei ,jetzt alles so konfus, daß ich es, ohne Beleidigung meiner vielen Freundinnen, nicht einmal eine Judenwirtschaft nennen darf“.293 „Judenwirtschaft“, „Judenkultur“: Brinckmann „zitierte“ die Begriffe, verwendete sie aber. ${ }^{294}$ Besonders auffallend veränderte sich die Diskussion über Henriette Mendelssohn. 1798 hatte er bei Luise von Voss noch für die Freundschaft mit Henriette geworben, „was diese recht eigentlich charakterisirt, ist eine schöne Seele, [...] ein moralischer Aristokratismus, den weder Stand noch Unglück, noch der Volksdespotismus heterogener Verhältnisse niederzudrücken vermag“.295 1801 sprach Brinckmann nicht mehr von der Überwindung der Verhältnisse, sondern erklärte ihre Lebenssituation explizit mit ihrer jüdischen Herkunft und daher für unlösbar: „Ich habe nicht leicht ein Mädchen gekant, die das Ohngefehr mit so zarter und edler Organisazion in so widrige Verhältnisse geschleudert hätte. Es ist schrecklich daß diese eine Jüdin wurde; denn eben deswegen ist für sie keine Hülfe“. ${ }^{296}$ Lässt sich dieser Kommentar noch als Kritik an den Verhältnissen lesen, aus denen eine Jüdin nicht herauskäme, griff Brinckmann in seiner Kritik nach 1802 deutlich

292 Wenig später benutzte Brinckmann selbst in einer Beschreibung eines anderen Diners bei Rahel Levin Varnhagen, das ihm missfallen hatte, erstmals „Jüdinnen“ als Gruppenbezeichnung: „Gualtieri und einige Jüdinnen, trieben bis in die Nacht ein Getobe, das mit dem Namen von Jugendlichkeit gar sehr geehrt sein konnte." An Luise von Voss, 4. 11. 1801, ungedruckt, GSA 5/26,4. Dies war das erste Mal in diesem Briefwechsel, dass der Diplomat von seinen Bekannten als Jüdinnen sprach. Zunächst stand diese Gruppe neben anderen: „Da das Leben nicht zu allem zureicht, so sehe ich jetzt ausser diesen vornehmen Zirkeln, und ausser meiner diplomatischen Tete a tete, in der Regel weder Christen noch Juden, noch Schauspielerinnen.“ An Luise von Voss, 27. 6. 1802, ungedruckt, GSA 5/26,5.

293 Gustav von Brinckmann an Luise von Voss, 10. 4. 1804, ungedruckt, GSA 5/26,7. 294 Auch wenn man ihm dabei keine absichtsvolle Schmähung unterstellt, bleibt zu konstatieren, dass er solche Wortbildungen vor 1801 nie verwendet hatte, auch wenn sein Umfeld, in persona etwa Wilhelm von Humboldt, es durchaus tat. Wenn es sich hierbei um eine Anlehnung an die „Umgangssprache“ handelt, so unterlief sie dem sprachbegabten Diplomaten auffällig erst und gehäuft nach 1801.

295 Vor „Stand“ steht durchgestrichen „Verhältnisse“, vor Volksdespotismus „Disharmonie“. Die Beschreibung fährt fort: „Die Grenzlinien zwischen ihren trefflichsten Eigenschaften, und manchen kleinen Schwächen ihres Charakters, sind immer so zart und so leise angedeutet, daß ich mich immer lieber selbst täuschte; um mich so lange wie möglich noch diesseits zu wähnen, weil ich so ungern, auch nur bei mir selbst, etwas an ihr tadelte. Wirklich sind diese kleinen Schwächen auch nur unhübsch; und ich komme immer darauf zurück, dass ich nie etwas moralisch-bürgerliches in ihr gefunden. Ihre Vorliebe für den Demokratismus ist selbst von Stande." Gustav von Brinckmann an Luise von Voss, 16. 11. 1798, ungedruckt, GSA 5/26,1.

296 Gustav von Brinckmann an Luise von Voss, 20. 9. 1801, ungedruckt, GSA 5/26,4. 
auf antijüdische Klischees zurück. Mitte 1802 definierte er erstmals selber einen antijüdischen Begriff, so

muß ich Ihnen schon noch einen Judenverdruß mittheilen, der mir alleweil schwer auf dem Herzen liegt. Jette Arnstein steht neml. auf dem Punkt - nachdem Sie Grafen und Baronen, Christen und Atheisten, und überhaupt Pretendenten aus allen Klassen ausgeschlagen hat - einen sehr reichen Juden zu heirathen - Ich kenne den Menschen nicht, aber es ist sicher eine dumme Partie. ,Der reichere Jude, heißt es im Nathan, war mir nie der bessere Jude'!297

Die Deutlichkeit dieser Formulierungen verlangt eine Kontextanalyse: Brinckmanns Wut liest sich anders, wenn man weiß, dass er selbst zu Henriette Arnsteins „Pretendenten“, also langjährigen Verehrern gezählt hatte. Seine enttäuschte Liebe erklärt zwar diese wieder auftauchenden Ressentiments keineswegs, es ist aber auffallend, in welchen Momenten der Erregung oder Frustration auf diese zurückgegriffen wurde. Ähnlich wütend zeigte er sich über einen „Judendoktor“, den die Familie Levin für ihre kranke Tochter dem bekannten Arzt Karl Johann Christian Grappengießer plötzlich vorzog, und der verhinderte, dass Brinckmann sie sehen konnte. ${ }^{298}$

Notwendig im Gesamtzusammenhang des jeweiligen Briefes zu lesen sind ebenfalls die Zitate des Jahres 1805, in denen etwa vom „Auswurf der Gemeinheit“ die Rede ist, der sich auf ihren Umgang, nicht auf die Person Rahel Levin Varnhagens bezog, wie die Vollversion des Zitates zeigt:

Durch die Abreise des Prinzen Louis und seines Serails ist Gottlob bei der kleinen Levin eine Art von Windstille entstanden, und ich fange an zu hoffen, daß diese in sovielen Rücksichten interessante Person wieder von Zeit zu Zeit nicht bloß Augenblicke, sondern ganze Stunden der Besonnenheit haben wird. Wenn dies der Fall ist, wünsche ich immer recht ihren Umgang. Seit so vielen Jahren sind wir so eingesprochen, daß es nicht leicht einen Gegenstand giebt, über den ich mich mit ihr nicht gern unterhielte; so unendlich verschieden auch unsre Ansichten sind.[...] Aber ich kann ihnen keinen Begriff machen von dem Auswurf an Gemeinheit, der diesen Winter über ihrer Gesellschaft herrschte. ${ }^{299}$

Auch bei diesem Zitat wird die Eifersucht auf Prinz Louis Ferdinand, in dessen „Serail“, i. e. die Schauspielerin Pauline Wiesel, Brinckmann selbst verliebt war, zur Wut auf Rahel Levin Varnhagen beigetragen haben. Über diese „Gemeinheit“ konnte sich aber Brinckmann nach eigener Aussage mit Rahels

297 Gustav von Brinckmann an Luise von Voss, 30. 5. 1802, ungedruckt, GSA 5/26,5. Doppelte Unterstreichung im Original.

298 Gustav von Brinckmann an Luise von Voss, 30. 5. 1802, ungedruckt, GSA 5/26,5. 299 Gustav von Brinckmann an Luise von Voss, 28. 4. 1805, GSA 5/26,8, der letzte Teilsatz in: Hahn 1997, S. 231. 
Schwester Rose Levin, verheiratete Asser, hinweg trösten, die deren ganzer Gegensatz sei. Brinckmann schloss diesen Brief mit einem Zitat Rahel Levin Varnhagens selbst:

Die kleine Levin behauptet immer im Scherz: Jetzt sei ich erst dort [im Hause Levin, H. L. L.] in meinem Element; weil ich gleich viel Sinn für die Tugend und das Laster hätte. Das Pikante der Zusammenstellung wäre ganz eigentlich meine Sache, und nun hätte ich sie und ihre Schwester so recht als eine sprechende Antithese vor Augen. Sie sehen doch, daß wir die Dinge wenigstens unter uns mit dem rechten Namen nennen. ${ }^{300}$

Eben sein Gefallen an Rose war es dann, das zu dem zweiten vielzitierten Brief führte: „Verzeihen Sie mir meine orientalische Redefiguren, denn seit einigen Tagen lebe ich einzig mit dem auserwählten Volke.“ Der Anschlusssatz daran lautete aber: „Gestern Abend war bei mir ein Thee von beinah 20 Personen, wobei Baron Dedem und ich die einzigen Getauften waren“.301 Das heißt, der Arrangeur dieser „orientalisch“ genannten Gästemischung war Brinckmann selbst!

Diese Kontextanalyse soll die Ressentiments Brinckmanns nicht beschönigen. Das grundlegende Zitat deutet in voller Länge auf eine fast anthropologische Betrachtungsweise Brinckmanns: Die von Brinckmann ,neu entdeckte‘ Rose Levin Asser

und Henriette Mendelson besizen von allen Jüdinnen, die ich kenne, die meiste Grazie; denn Allen übrigen fehlt, ich möchte sagen, ohne Ausnahme, jener Schmelz einer künstlerischen Vollendung, den man bei vorzüglichen Weibern so ungern vermisst. Die meisten Jüdinnen verrathen, möchte ich sagen, einen gewissen Egyptischen Styl, eine Härte der Umrisse, welche der ganzen Figur etwas unbeholfenes giebt; ob ich ihnen gleich von einer anderen Seite mehr Kraft und Eigenthümlichkeit zugestehe, als den gewöhnlichen Nachahmungen unserer französischen Kunstpfuscher. Unsere berühmte Levin ist das wahre Musterbeispiel dieses Egyptischen Styls, wovon ihre jüngere Schwester beinah keine Spur verräth. ${ }^{302}$

Wenn auch Brinckmanns Formulierung an die grob überzeichneten Judenfiguren in zeitgenössischen satirischen Zeichnungen denken lässt, besteht ein wesentlicher Unterschied zwischen dieser Form von Distanzierung und dem rassischen Antisemitismus etwa seines Zeitgenossen C. W. F. Grattenauer. ${ }^{303}$ Antijüdische Äußerungen stehen bei Brinckmann neben der fortgesetzten persönlichen Wertschätzung einzelner Personen. Es gibt keine absoluten Aussa-

300 Gustav von Brinckmann an Luise von Voss, 28. 4. 1805, ungedruckt, GSA 5/26,8.

301 Gustav von Brinckmann an Luise von Voss , 2. 5. 1805, auch in: Hahn 2002, S. 94.

302 Gustav von Brinckmann an Luise von Voss , 2. 5. 1805, auch in: Hahn 2002, S. 70. 303 Vgl. dazu IV 
gen, keine Aburteilung der ganzen Familie. Der Widerspruch wird aber auch nicht aufgehoben. Am deutlichsten wird der sprachliche Wandel vielleicht sogar in einer eigentlich positiv gemeinten Rezension eines Abends bei der „Kleinen“:

„Wenn ich abends ausgehe, ist es beinah täglich nach dem Schauspiel zu der kleinen Levin; Sie hat zwar wie immer einen sehr gemischten Zirkel; aber diese geistreiche kleine ist auch alleweile so äusserst brillant, daß ich alle Tage mein Urtheil über ihre Einzigkeit bestätigt finde. Aufrichtig kann ich Ihnen doch versichern, daß vor diesem Judensofa an Einem Abend mehr Wiz, Verstand und Einfälle vergeudet wird, als in 3 unserer Asembleen“. 304

Dieses Zitat muss sich parallel lesen lassen mit einem Billet an Rahel Levin Varnhagen aus den Anfangsjahren ihrer Bekanntschaft:

„Wahrlich Ihr Gespräch ist für mich oft ein wahres moralisches Kanapee, denn ich liebe nun Einmal sehr die Bequemlichkeit; und was ich sonst lange in mir wirthschaften musste, um so alles herauszufinden, was ich zu meiner Beruhigung brauchte. Verzeihen Sie diesen Unsinn und erlauben Sie mir mit freundschaftlichster Wärme und Hochachtung Ihre Hand zu küssen. B“.305

Und noch 1799 hatte er ihr versichert: „Was wollte ich für ein Buch schreiben, wenn ich alle den Witz und den Geist besäße, der auf diesem Sopha vergeudet worden ist“"306 In seiner Begeisterung für die Originalität wie für den reich bei ihr „vergeudeten Witz“ wiederholt Brinckmann sein Kompliment an Levin Varnhagen, aber aus dem „moralischen Kanapee“ von 1793 war 1802 ein „Judensofa“ geworden.

\section{3 „Scherzende Laune“ oder „Judenschimpf“?}

In den Folgejahren bis 1808 ist die Verwendung des Begriffs und der Kategorie „jüdisch“ bei Brinckmann mindestens doppelbödig zu nennen: Warnungen vor zuviel christlichem Fanatismus stehen antijüdische Anspielungen und Klischees gegenüber. ${ }^{307}$ Als er Karoline von Berg einen Bankier empfehlen sollte,

304 Gustav von Brinckmann an Luise von Voss, 10. 10. 1802, ungedruckt, GSA 5/26,5. 305 Gustav von Brinckmann an Rahel Levin Varnhagen, 10. 6. 1793, ungedruckt, SV 38. 306 Gustav von Brinckmann an Rahel Levin Varnhagen, 6. 3. 1799, ungedruckt, SV 38. 307 So schrieb er am 23. 12. 1802 an Karoline von Berg: „Die Idee der Menschwerdung der Gottheit ist eine recht schöne, humane Idee, aus der sich in Genialischen Köpfen etwas hätte machen lassen. Von Jüdischen Fanatikern musste sie freilich bald verhunzt werden und ich bin weit davon entfernt, mich nach den ersten Christen zurückzusehnen. Sobald sie Sekte machten waren sie schon unerträgl. Und es zielte alles auf die Mönchsversammlung, durch Ertödtung der Sinnlichkeit ab. Die christliche Religion lässt sich nur schön denken.“ Ungedruckt, GSA 5/1. 
konnte er sich die Frage nicht verkneifen, ob es denn ein Jude sein müsse, da ein Friedländer sie sicher „nicht übergesezlich“ bezahlen werde. ${ }^{308}$ In ein und demselben Brief konnte er spotten, dass August Wilhelm Schlegel seine Vorlesungen „vor jungen Berliner Offizieren, Juden und Weibern“ halte (also eigentlich einer ,typischen Salonmischung'), aber zugleich eine selbstironische Reihung aufmachen, in „der Gentz u. ich u die übrigen - Juden!!, Humboldten so unverantwortlich streng" fanden. ${ }^{309}$

Wesentlich ist in diesem Zusammenhang ein Zitat von Rahel Levin Varnhagen selbst, die zwischen „Judenhaß“ und „Judenschimpf“ unterschied (und sich damit der Existenz beider Phänomene bei ihren Zeitgenossen durchaus bewusst war). 1802, als auch Brinckmanns Briefe sich antijüdisch färbten, schrieb sie diesem über einen Bekannten: „Finden Sie es nicht komisch dass H. v. Pitag bey seinem Judenschimpf - denn Judenhaß ist es noch nicht - von einem Juden immer in den andern fällt"?310 Vergleichbar legte Brinckmann explizit Wert auf den Unterschied zwischen seinen eigenen „scherzend“ genannten Spötteleien und dem „ernsten Geschäft“ etwa der Gräfin Schlabrendorf, „die Juden und die Bürgerlichen noch tief unter die Klasse Negern herabzustossen“.311 Denn diese ehemalige Freundin Rahel Levin Varnhagens „deklamirt mit einer sprudelnden Beredsamkeit gegen die revoluzionäre Aufklärung, welche solche aus ihrem gebührenden Schmuz hätte empor heben wollen“. Von dieser Art der Hetze distanzierte Brinckmann sich deutlich, nannte die Schlabrendorf ein moralisches „Monstrum“ und positionierte sich selbst auf einer gewissermaßen gemäßigten Position. ${ }^{312}$ Dafür, dass diese Unterscheidung im weiteren Zirkel um Rahel Levin Varnhagen nicht unüblich war, spricht auch

308 Gustav von Brinckmann an Karoline von Berg, 15. 1. 1808, ungedruckt, GSA 5/1. 309 Gustav von Brinckmann an Karoline von Berg, 12. 12. 1802, ungedruckt, GSA 5/1. Hervorhebung im Original.

310 Rahel Levin Varnhagen an Gustav von Brinckmann, 6. 10. 1802, ungedruckt, BA V. Die Identität des Herrn Pitag war leider nicht zu ermitteln. Im Briefwechsel kommt er sonst nicht vor.

311 Gustav von Brinckmann an Karoline von Berg, 10. 6. 1802, ungedruckt, GSA 5/1. 312 „Humboldt und ich die bisweilen mit eben so scherzender Laune gegen die Juden, wie für den hohen Adel sprachen, haben ihr auf einmal ihres Herzens unverdächtige Gesinnungen entlockt, und zu unserm Erstaunen gefunden, was wir im 18. Jahrhundert kaum mehr mögl. wähnten, daß diese stiftsfähige überchristliche Gräfin, in der That die ganz krassen Vorurtheile, die man sonst nur in Satire als Karikatur aufstellte, in vollem Ernst hezt und vertheidigt. - Seitdem ist sie mir als eine Art von moralischem Monstrum, wozu sie sich überhaupt in mehrerer Rücksicht nicht übel qualifizirt, ordentl. merkwürdig geworden.“ Gustav von Brinckmann an Luise von Voss, 10. 6. 1802, ungedruckt, GSA 5/26,4. 
ein Brief Friedrich Schlegels, der ihr gegenüber offen vom „Judenhass“ im Hause Tieck / Bernhardi sprach. ${ }^{313}$

Brinckmanns Briefe an Luise von Voss zeigten zugleich seine eigene, nach 1802 zunehmend ambivalente Haltung gegenüber der Situation der Juden in der Berliner Gesellschaft, wie einen Stimmungsumschwung in dieser Gesellschaft selbst. War es 1801 noch peinlich, die jüdische Herkunft von Gästen zu bemerken (und stand Gentz noch alleine mit seinen gewisperten Befürchtungen), so konnten es sich 1805 nicht mal mehr Mitglieder des Hofes erlauben, Persönlichkeiten der jüdischen Gemeinde einzuladen. Nach Brinckmanns Bericht bekam sogar eine preußische Prinzessin, Luise von Radziwill, Absagen, weil sie zu einer Theateraufführung jüdische Gäste eingeladen hatte. ${ }^{314}$

Die Prinzessin hatte nehml. zur ersten Vorstellung, wobei die Königin zugegen war, mehrere von den Gesandten und ihren Frauen nicht gebeten, statt dessen aber Msl Fromm, Msls Wide[ch?]man, Msl Levin und mehrere Schauspielerinnen. Darum haben nun die heute gebetenen Personen vom Corps Diplom. alle absagen lassen, wovon ich, unschuldiges Kind, nichts gewusst. Indessen ganz unrecht haben sie wohl nicht. ${ }^{315}$

Zwar deutet Barbara Hahn mit Recht seinen Nachsatz so, dass er die Absagen eher akzeptabel denn kritikwürdig fand. ${ }^{316}$ Allerdings muss man zeitgleiche kritische Aussagen Brinckmanns zur Prinzessin Radziwill dazu lesen, wonach er ihrer Art, Menschen zu mischen, grundsätzlich misstraute, und zwar wegen ihrer „vornehmen Ansicht der meisten Menschen, als blosse Figuranten auf der Bühne, wo sie sich einen hübschen Spaß bereitet“. 317 Es ist also nicht ganz sicher, ob Brinckmann die Mischung als solche oder das Motiv der Gastgeberin

313 „An der Jungfernbrücke* kann das dummste ganz herrlich gedeihen; nichts ist zu dumm für solche Kluge, also auch Judenhaß der Art.“ Friedrich Schlegel an Rahel Levin Varnhagen, 1. 4. 1802, KFSA, Bd.25, S.345. In der Briefabschrift, d. h. von Karl August Varnhagen, wurde ein * eingefügt mit einer teilweise gestrichenen Fussnote: „Wo Bernhardi wohnte und W.Schlegel [...] (seine Frau die Schwester Tiecks und wohl auch Tieck selbst).“ Die Herausgeber der KFSA gehen davon aus, dass im Hause Berhardis, wo A. W. Schlegel zu Gast war, möglicherweise auch dessen Freund, der Antisemit Grattenauer verkehrte. Ebd., S. 669.

314 Die Memoiren der Prinzessin selbst berichten nicht über dies Ereignis, was aber nicht verwundert, da sie sich vor allem auf Familien- und Politikgeschichte konzentrieren. Weder spielen hier einzelne jüdische Persönlichkeiten noch die Situation der Juden als solche eine Rolle. Vgl. Luise von Preussen. Fürstin Anton Radziwill. Fünfundvierzig Jahre aus meinem Leben (1770-1815), hrsg. und mit Anmerkungen und Personenverzeichnis versehen von Fürstin Radzwill, geb. von Castellane. Aus dem Französischen übersetzt von E. von Kraatz, Braunschweig 1912.

315 Gustav von Brinckmann an Luise von Voss, 28. 4. 1805, hier zitiert nach dem Original, GSA 5/26,8.

316 Hahn 2002, S. 94.

317 Gustav von Brinckmann an Luise von Voss, 5. 5. 1805, ungedruckt, GSA 5/26,8. 
ablehnte. Die eigentliche und schwer zu beantwortende Frage ist aber, bis zu welchem Grad Brinckmanns antijüdische Äußerungen seiner eigenen (berufs)biografischen Entwicklung oder der gesellschaftlichen geschuldet waren.

Bemerkenswert in puncto Stimmungsumschwung um 1802 ist die Reaktion der Familie Levin auf eine schwere Erkrankung ihrer ältesten Tochter, wie Brinckmann sie schilderte. Eine lange Schwächephase, die er „Zerrüttung des Nervensystems“ nannte, wurde von der Familie auf ihr zu großes gesellschaftliches Engagement zurückgeführt - besonders mit nichtjüdischen Freunden. „Sie darf noch niemanden sehen, als ihre nächsten, sie Tag und Nacht umgebenden Verwandten; und diese haben sich in den Kopf gesezt, daß ihr bisheriger Umgang mit lauter exzentrischen Christen an allem Unheil schuld sei. [...] Humboldt, Genz und einige andere sind dabei heftig angeklagt worden“.318 Humboldt selbst kommentierte die ungewollte Quarantäne auf die für ihn typische anzügliche Art: „Von der Levi läßt man jetzt sagen: sie sey sehr wohl, dürfe aber niemand, der nicht beschnitten sey, sprechen“.319 Leider konnte bisher zu diesem Vorgang keine Parallelquelle aus der Familie Levin gefunden werden. Wenn Brinckmanns und Humboldts Darstellung aber zutrifft, deutet sie eine zunehmend distanzierte Haltung auch von jüdischer Seite an.

Der „Auswurf an Gemeinheit“ war zugleich der letzte Ausbruch von Gemeinheit im Schreiben Brinckmanns. Im Falle des Diplomaten, nicht unbedingt der Berliner Gesellschaft, kam es nach $1807 \mathrm{zu}$ einem weiteren Umschwung. Bei gleichbleibenden ,Vorzeichen', also gleichbleibender Sprachwahl, ändert sich die Gesamtbewertung noch einmal. Nicht nur an Rahel Levin Varnhagen selbst gingen nach 1807 verherrlichende Reminiszenzen an ihr „Dachstübchen“, das er als seine Bildungsstätte bezeichnete. Erstmals äußerte er sich Gräfin Voss gegenüber zur Judengesetzgebung und kommentierte die Pläne der Reformer böse: „Beiläufig: Der Minister Stein fasst die Juden noch viel ärger auf als der Graf und will selbst von keiner Ausnahme hören; die Besten sollen nur etwas später, aber eben so hoch gehangen werden“.320 Im

318 Gustav von Brinckmann an Luise von Voss, 30. 5. 1802, ungedruckt, GSA 5/26,8. Allerdings scheint die Mutter es in ihrer Wut übertrieben zu haben, besonders Humboldt gegenüber „machte sie unter anderm den komischen Vorwurf: ,Er sei zwar ein sehr gelehrter Mann, aber doch ausgemacht ein empfindsamer Schwärmer!!, der ihrer Tochter zuerst den Kopf verdreht habe.' Sie können denken, wie dies den H. amüsierte.“ Ebd. Humboldts durchaus kritisches Verhältnis zu Rahel Levin Varnhagen hat von diesem Vorwurf sicher nicht profitiert.

319 Wilhelm von Humboldt an Gustav von Brinckmann, 29. 5. 1802, in: Leitzmann 1939,

S. 131.

320 Gustav von Brinckmann an Luise von Voss, 20. 1. 1808, ungedruckt, GSA 5/26,11. Brinckmann bezog sich vermutlich auf die Reform der Städteordnung 1808, die kommunale Ehrenämter für Juden vorsah. 


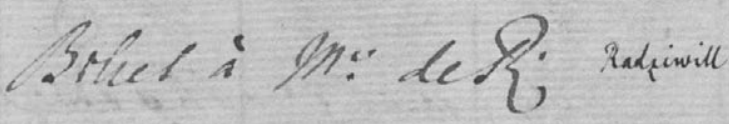

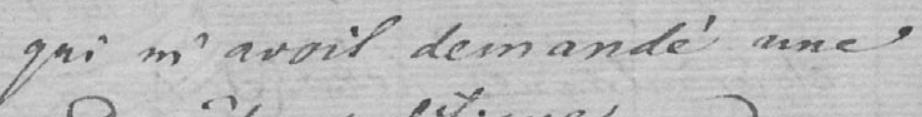

Depizge nobliquel.

He Quni faut hane absolianent, Inicefee', de las Datiligue?

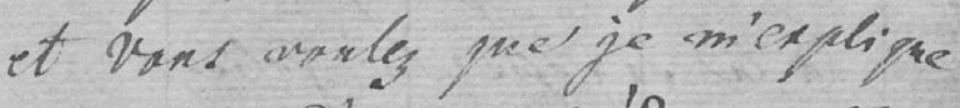

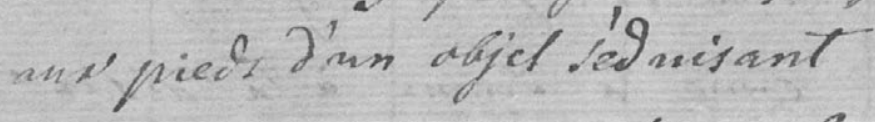
en langage, Siplamatipne?

hais caiment negligert" Amany efles nawreles de. Gythese, paur ne punter qued stela gane? of be wiench dal Mimisieré?

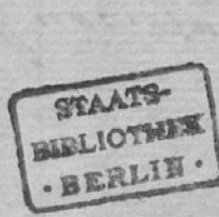

Abb. 25: Gast vieler offener Häuser - Billet Brinckmanns an Luise von Radziwill. 
selben Brief zitiert Brinckmann dann seitenweise aus einem Brief Rahel Levin Varnhagens, mit einer Begründung, die mottogebend für den Gesamtbriefwechsel sein könnte: „Und selbst auf die Gefahr des Verspottens über meine Jüdelei - [...] schreibe ich Ihnen noch einige Bruchstücke ab, Sie sollen wenigstens begreifen, liebe Gräfin, warum ich gerade so viel auf die Kleine halte“.321

Aus der Sicht der Nachlebenden hätte Rahel Levin Varnhagen den Wettstreit der Salonièren unstreitig gewonnen, da Brinckmann zu dem vertrauten Tonfall der ersten Jahre zurückkehrte, ihr auch über die Entfernung, von Schweden aus, brieflich und persönlich verbunden blieb und letzthin $\mathrm{zu}$ ihrer Bekanntwerdung wesentlich beitrug, während der Kontakt zu Luise von Voss und Karoline von Berg langsam einschlief.

Für den aktiven Diplomaten mit deutschnationaler Gesinnung spielte das Haus Berg-Voss eine wesentliche Rolle, für den kosmopolitischen Privatmann mit Wohnsitz in Schweden weniger. Eine Verherrlichung der Individualität seiner Gastgeberin, wie bei Rahel Levin Varnhagen, fand bei Luise von Voss nicht statt.

Wie sich Brinckmann aber verhalten hätte, wäre seine Amtszeit in Berlin verlängert worden und hätte ihn beispielsweise sein Jugendfreund Schleiermacher etwa in die Deutsche Tischgesellschaft eingeladen - bleibt historische Spekulation.

\section{Fazit. Revolution und Ästhetik - Zu den Kategorien Form und Stand bei Gustav von Brinckmann}

\section{Grenzlinien und ihre Überschreitungen}

Wenn auch Brinckmann seine Fahrt nach Paris als „empfindsame Reise“ bezeichnete und sich als „Pilger“,322 so pilgerte er doch, anders als viele Reisende der 1790er-Jahre, nach Paris nicht als Ort der Revolution, sondern zu den Ruinen einer alten Kultur: „Mein wundes Herz zittert vor dem Steinpflaster der Kultur, das in Frankreich alles geebnet, hart und platt gemacht““.323 Zwar berichtete er Luise von Voss mehrfach, dass er gern die Revolution diskutiere, verließ dabei aber nie den Standpunkt des distanzierten Beobachters und

321 Gustav von Brinckmann an Luise von Voss, 20.1. 1808, ungedruckt, GSA 5/26,11. 322 Auf die „empfindsame Reise“ legte er anscheinend Wert. Er verwendete den Begriff mehrfach, z. B. gegenüber Lea Mendelssohn Bartholdy, 17. 2. 1798, ungedruckt, BA M, und gegenüber Luise von Voss, 25. 2. 1798, ungedruckt, GSA 5/26,1; „Ihr armer Pilger“, Ebd. 323 Gustav von Brinckmann an Luise von Voss, 28. 2. 1798, ungedruckt, GSA 5/26,1. 
formbewussten Aristokraten. ${ }^{324}$ Er sprach selbstironisch und nicht nur Levin Varnhagen gegenüber von seinem ,täglich wüthender zunehmenden Aristokratismus“ und davon, dass er den „Demokratenkitzel“ mancher Bekannter nicht teile. ${ }^{325}$ Auch bei Luise von Voss entschuldigte er sich scherzhaft für manchen „Auslauf aristokratischer Empfindungen“.326

Als er in Frankreich ankam, ging es ihm nicht darum, die Forderungen der Revolutionäre zu hinterfragen, sie wurden nicht diskutiert. Nicht ohne Grund nutzte Brinckmann später mehrfach die Metapher vom Kostüm der Revolution, das die Franzosen kleide, die Deutschen aber nicht. 327 Noch vor dem Grenzübertritt und unter dem Eindruck eines freundlichen Empfanges am Weimarer Hof hatte er Luise von Voss gegenüber eine Art ,Glaubensbekenntnis` zum Thema Form und Stand formuliert, das in der Folgezeit für ihn Gültigkeit behalten sollte:

Ich hasse die schimäre Gleichheit der Stände auch deswegen weil so viele Verhältnisse dadurch verloren gehen würden, die nicht wenig zur vielseitigen Bildung unsers Charakters beitragen. Es giebt für den Geist wie für den Körper gewisse heilsame Formen, die nur für denjenigen drückend sind, der nicht Gewandtheit genug besizt oder erlernen will um sich mit Grazie innerhalb der selben zu bewegen. ${ }^{328}$

„Grazie“ war, wie erwähnt, ein zentraler Begriff des Brinckmannschen Denkens. Der anschließende Absatz verrät seinen grundlegend ästhetischen Ansatz: „Ohne Regel u. Gesetz des Tanzes würde in dem engen Zaum unserer Säle das Spiel der körperlichen Bewegungen allen Reiz, alle Ordnung verlieren, u. eigentlich von selbst unmöglich werden. Gerade dies scheint mir der Fall mit unsern äussern Sitten in der bürgerlichen Gesellschaft.“ Nach Brinckmanns Auffassung waren gewisse „Grenzlinien“ eine notwendige Voraussetzung für die „gesellschaftliche Anmut“. Gerade weil ein Fürst über den Ständen stand, billigte ihm Brinckmann eine verbindende Aufgabe zu:

324 „Sie glauben überhaupt nicht, wie gern ich diese unerschöpflichste aller Begebenheiten jetzt mit Menschen aus allen Klassen zur Sprache bringe. Es ist mir nemlich äusserst viel daran gelegen, diese vielseitigste aller Begebenheiten auch aus allen möglichen Gesichtspunkten zu betrachten.“ Gustav von Brinckmann an Luise von Voss, 8. 3. 1798, ungedruckt, GSA 5/26,1.

325 Gustav von Brinckmann an Rahel Levin Varnhagen, 27. 6. 1797, ungedruckt, SV 38.

326 Gustav von Brinckmann an Luise von Voss, 25. 2. 1798, ungedruckt, GSA 5/26,1.

327 So schreibt er mit Bezug auf Mainz und die Mainzer Republik: „Sie glauben nicht wie übel das neue Costume die Deutschen kleidet, wie natürlich es hingegen den Franken steht." Gustav von Brinckmann an Karoline von Berg, 6. 3. 1798, ungedruckt, GSA 5/1. 328 Dies und die folgenden Zitate: Gustav von Brinckmann an Luise von Voss, ungedruckt, 25. 2. 1798, GSA 5/26,1. 
[...] so lange die öffentliche Meinung noch nicht unwiderruflich den schönen Zauber der Ehrfurcht gelöst hat, der nur noch um die Thronen schwebt, so kann dieser von denkenden Fürsten sehr glücklich benuzt werden, um ihrer Nächstenliebe, ihrem Wohlwollen und ihren Talenten selbst eine Glorie zu ertheilen, [...] nur der Fürst kann unbeneidet, ich möchte sagen, pflichtmässig, so alles um sich versammeln, den Zirkel gleichsam schliessen, und streitende Interessen und Verhältnisse, wenigstens in grössere Harmonie bringen, wenn auch nicht wirklich vereinigen.

In diesem Text, der sich wie ein Plädoyer zur Wahrung der Standesunterschiede liest, machte Brinckmann aber zugleich einen Unterschied zwischen dem moralischen Wert einer Person und dem ihr zufällig erteilten Rang: „Und gerade den denkendsten, vorzüglichen Menschen, kann deucht mich eine von Zufall ertheilte Würde am wenigsten drückend erscheinen.“

Angesichts der realen gesellschaftlichen Verhältnisse scheint seine Forderung ziemlich abstrakt, dass man gesellschaftliche Ränge als Zufallsprodukt nicht ernst nehmen müsse. Nicht ernst nehmen kann den Rang schließlich nur, wer von ihm nicht beeinträchtigt ist. An dieser Stelle sei nur erinnert an Rahel Levin Varnhagens Schwierigkeiten, sich einer Person ihres Interesses bloß zu nähern, ohne selbst eine „Geschäftsperson“ zu sein. Auch sie hatte den Anspruch, Menschen nach ihrem moralischen Gehalt zu beurteilen, einem Diplomaten aristokratischer Herkunft fiel es aber sicherlich leichter, über Rangunterschiede hinwegzusehen, und so schloss Brinckmann sein ,Bekenntnis':

Ich bin von jeher zu stolz gewesen, um mich dadurch gedemütigt zu fühlen, dass ein anderer ohne Verdienst vornehmer ist als ich, und wenn der Zufall sich gar mit persönlichem Wert verbindet, so huldige ich dem letztern mit doppeltem Vergnügen. Glücklicher Weise ist der sittliche u. geistige Werth der Menschen von den äussern Umständen weniger abhängig, und hieraus entsteht innerhalb der bürgerlichen Formen, noch eine ganz eigene Rangordnung, die ebenso bestimmte Grenzlinien hat.

Dieser letzte Satz ist besonders aufschlussreich, da er ihn kurz nach seinem Abschied aus Berlin, möglicherweise als Summierung seiner Berliner Erfahrungen schrieb. Es ist nicht klar, ob seine Freunde diese Überzeugung teilten, dass auch in eine scheinbar gleichberechtigte Gesellschaft eine eigene Rangordnung wieder hineingetragen werde. Selbst aber sollte er mehrfach, zur Charakterisierung bestimmter Personen, auf den Begriff eines „moralischen Aristokratismus“ $\mathrm{zu}$ sprechen kommen, der ihm zumindest zeitweise den angeborenen ersetzen konnte. ${ }^{329}$ Gerade an dieser Neubewertung der Begriffe wird deutlich, dass bei Brinckmann die ästhetische Beurteilung Vorrang vor einer nach tradi-

329 In dieser Formulierung z. B. an Luise von Voss, 16. 11. 1798, ungedruckt, GSA 5/26,1. 
tionellen Werten hatte. Ganz ähnlich verhielt er sich auch bei der Beurteilung anderer gesellschaftlicher Aus- oder Umbrüche, beispielsweise bei geistreichen Frauen. In demselben Brief, in dem er die Formschönheit des Standesunterschieds hervorhob, konnte er die schriftstellerische Tätigkeit einer Frau positiv werten, versicherte aber zugleich, dass sie auch „weibliche Würde“ besäße. ${ }^{330}$ Wie unter V.2 diskutiert, stellten ihn seine Freundinnen Levin Varnhagen und de Staël mit ihrem unkonventionellen Umgang und gesellschaftlichen Ansprüchen vor manche legitimatorische Herausforderung, die er in mehreren Anläufen schließlich meisterte.

\section{Ehestand und Konversion}

Überraschend liberal scheint die Haltung aller hier untersuchten Korrespondierenden zu Ehe und Ehestand. Anders formuliert sind Konversion und Eheschließung als rechtlich möglicher, wenn auch hürden- und folgenreicher Weg der Annäherung für Paare unterschiedlicher Herkunft ein möglicher Prüfstein für die Liberalität des Salons. Hier scheiden sich Tonfall und gelebte Praxis deutlich. Einerseits wurde über einzelne Verheiratungen deutlich gelästert, und die Ehe an sich wurde als korrumpierende Einrichtung betrachtet, die nur als Mittel zum Zweck, etwa zur Etablierung einer bürgerlichen Existenz, wahrgenommen werden sollte. Dazu gehört Rahel Levin Varnhagens berühmtes Zitat, „sie könne nicht heiraten, weil sie nicht lügen könne“.331 Bezeichnend ist auch der wiederholte Vorschlag Brinckmanns, Rahel Levin Varnhagen möge doch seinen Vorgesetzten heiraten, damit sie endlich „,von Stand“ sei, 332 oder die ironische Besprechung ihrer Verbindung zum Baron Karl von Finckenstein, die Brinckmann in erster Linie als zeitlich unpassend abtat: „Das sind die wahren Mißheirathen, die einem verhindern, zur rechten Zeit nach Paris zu reisen. Man liebe doch so viel man will, aber Heirathen ist immer etwas Plumpes, und sogar für die Zuschauer eben so langweilig wie für die Schauspieler selbst“. 333 Berichte über außereheliche Affären wurden keineswegs heimlich oder in Andeutungen eingeflochten, sondern die Vor- und Nachteile verschiedener Beziehungen ausführlich diskutiert. Einige Affären wurden sogar sehr positiv bewertet, weil sie einen guten Einfluss auf den moralischen Charakter

330 Gustav von Brinckmann an Luise von Voss, 25. 2. 1798, ungedruckt, GSA 5/26,1.

331 Rahel Levin Varnhagen an Gustav von Brinckmann, 9. 3. 1799, in: GW I, S. 180.

332 Dabei ist sein Argument die Altersschwäche des Vorgesetzten, der sie bald zur Witwe machen würde. „Dabei wären Sie Baronesse ohne sich scheiden zu lassen, und könnten nun die Soupès und Thes geben die er aus ökonomischen Gründen nicht geben will.“ 30. 7. 1795, ungedruckt, SV 38.

333 Gustav von Brinckmann an Rahel Levin Varnhagen, 25. 11. 1799, ungedruckt, SV 38. 
der Beteiligten hätten. Gustav von Brinckmann brachte es, unwidersprochen, auf den Punkt, dass Ehe eigentlich nur die Voraussetzung für die Scheidung sei:

Es ist mir im Grunde recht ärgerlich, meine beste Freundin! daß Sie sich noch nicht können scheiden lassen. Dies ist kein Scherz, es ist vielmehr so sehr Ernst, daß es eben deswegen auf der anderen Seite wieder spaßhaft wird. [...] Bei der Scheidung erholt man sich wieder, ist frischer und lustiger wie zuvor, die gesellschaftliche Erziehung ist gewisser Massen erst vollendet. Sie wären Madam, Ihre Thees eine Treppe niedriger, - kurz es wäre alles in Ordnung, wie Sie es mir vor ein Par Jahren schon versprochen, aber nicht Wort gehalten haben. ${ }^{334}$

Hier wurde das Ehemodell einer jüdischer Frau mit einem nichtjüdischen Mann, das nicht nur in der Forschung für besonders salonrelevant gehalten wurde, sondern einen wesentlichen Lebenseinschnitt für die Frauen bedeuten konnte, ironisch und scheinbar lapidar abgehandelt. Obzwar Brinckmann die Ehe mit einem Witzwort den Blattern verglich: „Je eher je besser, desto weniger Narben“, wird in dem Zitat zugleich klar, wie sehr eine Eheschließung zur „Verbürgerlichung“ beigetragen hätte, in diesem Fall als Weg von der Mansarde in die Belletage.

Abgesehen von den praktischen Vorteilen einer Ehe gab es durchaus Bindungen, auch lebenslange, die den Schreibenden auch emotional erstrebenswert schienen. Die Achtung vor gewissen Freundschaften war immens, die Diskussionen zwischen Brinckmann und seinen Freundinnen wurden bewusst intim gestaltet bzw. galt Intimität der Unterhaltung, das „Eingesprochen sein“ zwischen Freunden als hart zu erarbeitender Wert - Intimität in der Partnerschaft, „die gepriesene eheliche Liebe, über das ekelhafte angewöhnen an männliche Pantoffeln und Schlafmützen,“ als verabscheuenswert und zu Recht nur zu ,affektiren“.335

Die für solche Ehen vollzogenen Konversionen wurden ebenfalls auffallend oft mit einem Scherz abgetan bzw. galt es, wie dargestellt, als gute ,aufgeklärte‘ Praxis, im Umgang mit dem Thema Witz zu zeigen und, wie im Folgenden Lea Mendelsohn Bartholdy, die protestierenden „Waßerscheuen“ nicht allzu ernst zu nehmen.

Was sagen Sie denn zu Ihrer Doktorin? [...] Denkbar wars immer, dass Ihre Flies, wenn sie Ihnen eine Untreue machte, sie sich dadurch entschädigte, dass sie einen Ihrer Landsleute zum Erben ihres Herzens einsetzte [...]. Sie können denken, dass die Waßerscheuen

334 Gustav von Brinckmann an Rahel Levin Varnhagen, 7. 1. 1799, ungedruckt, SV 38. 335 Gustav von Brinckmann an Rahel Levin Varnhagen über Jeanette Ephraim Stieglitz, 14. 7. 1794, ungedruckt, SV 38. 
schreien, oder geschrien haben, denn jetzt beschäftigen sie schon wieder hundert andre Gegenstände. ${ }^{336}$

Als bezeichnend für den Berliner jüdischen Salon um 1800 muss das in diesem Zusammenhang erwähnte Gesellschaftsspiel gelten, bei dem es darum ging, einander zum Charakter passende Buchtitel zuzurufen, ein Spiel, in dem sich die ehemalige Fließ gut bewährte: „Ich fand es freimüthig u hübsch von ihm, dass er ihr, in dem Spiel wo man einer Person den Titel irgend eines passenden Buches geben muß, Leichtsinn u gutes Herz sagte, $\mathrm{u}$ recht witzig von ihr, die auch sich selbst das befreite Jerusalem so leicht hinwarf“". ${ }^{337}$ Brinckmann bestätigte, dies sei „erzwizig“, wiederum mit Witz: „Auch ist meine Doktorn wahrlich so übel nicht. Nur dass ich sie doch immer lieber zur Doktorn wie zur Frau hätte, wiewol die kleine Levin mir versichert ich würde mit der Fließ in der Ehe sehr gut leben. Dies ist sehr möglich, aber ich möchte doch noch besser leben". 338

Andererseits und aller Liberalität zum Trotz fand eine Frau, die sich nicht „von Jerusalem befreien“ lassen wollte, in der Salongesellschaft wenig Verständnis. Dorothea Mendelssohn Veit Schlegel bemerkte mehrfach, dass ihre Entscheidung, unverheiratet zu bleiben, um ihren Sohn behalten zu können, die Berliner irritierte wie ein „Roman ohne Schluss“..339 Dies lässt keineswegs Rückschlüsse auf eine leichtfertige Haltung der ,Romanheldinnen' selbst zu, es deutet nur darauf, dass in der Kommunikation zwischen jüdischen Frauen und nichtjüdischen Gästen potentielle Glaubens- oder Identitätskonflikte nicht thematisiert wurden.

Was bei dieser betont nicht bürgerlichen, nahezu pragmatischen Herangehensweise an Taufe und Ehe dann wiederum überrascht, ist die Tatsache, wie wenig die beteiligten gut situierten Männer eine Eheschließung ihrer Standesgenossen, geschweige denn ihrer selbst, mit Rahel Levin Varnhagen in Betracht

336 Lea Mendelssohn Bartholdy an Gustav von Brinckmann, 10. 12. 1798, ungedruckt, BA M. 337 Lea Mendelssohn Bartholdy an Gustav von Brinckmann, 10. 12. 1798, ungedruckt, BA M. „Leichtsinn und gutes Herz" war bemerkenswerterweise ein Lustspiel der zeitgenössischen, frauenpolitisch engagierten Autorin Marianne Ehrmann. Das „befreite Jerusalem“ zielt vermutlich auf das Drama von Torquato Tasso.

338 Gustav von Brinckmann an Lea Mendelssohn Bartholdy, 9. 2. 1799, diese Stelle ungedruckt, BA $M$.

339 „Es scheint die Berliner können nicht ruhen - sie können ebenso wenig ein Leben als einen Roman sich ohne geschloßnen Schluß denken, und nehmen nun gar bey mir die heilige Taufe als völligen Ruhestand und Auflösung an. Wie wäre es wenn sie mich todt seyn liessen? so wären sie aus der Ungewissheit, und mir geschähe auch ein kleiner Dienst damit. “ Dorothea Mendelssohn Veit Schlegel an Friedrich Schleiermacher, Frühjahr 1799, in: KFSA, Bd. 25, S. 15. 
zogen, bzw. wie leichtherzig sie mit der Tatsache umgingen, dass Baron Finckenstein sich zur Ehe nicht entschließen konnte. Übrig blieben für die „theuerste Freundin“ aus eben der ,jüdischen Familie‘: explizites Bedauern und gute Ratschläge, sich abzulenken - nicht einmal teilnehmendes Mitleid. Ob Habitués wie Brinckmann und Burgsdorf die Folgen des Unverheiratetseins für eine knapp 30-jährige jüdische Frau schlicht unterschätzten oder diesen Zustand des „über“ der Ehe Stehens für wirklich emanzipiert angesehen und damit stark idealisiert haben, bleibt fraglich. Burgsdorf lebte de facto den Double Standard der Zeit und heiratete nach zahlreichen Affären und einigen unehelichen Kindern spät seine Cousine. Brinckmann blieb lebenslang unverheiratet.

\section{Die schimäre Gleichheit der Stände}

Dass Gustav von Brinckmann bei aller Freude an geistreicher Unterhaltung ohne Rücksicht auf die Herkunft, auf die korrekte Form gegenüber Rang und Stand Wert legte, könnte ihn als typischen Vertreter und Verteidiger seiner Klasse ausweisen. Ein Vergleich seiner Äußerungen in verschiedenen Lebensbereichen deutet aber eher darauf hin, dass er ein Verteidiger der Form und eines gewissen ästhetischen Anspruches war. An Frauen aller Klassen und Kulturen schätzte er Geistreichtum wie Grazie, und „freigeistige Amazonen“ schreckten ihn vor allem, weil sie letzterer entbehrten. In der Literatur wusste er das Genie eines Friedrich Schlegel zu schätzen, verabscheute aber dessen Hang zur Formlosigkeit, etwa in der Lucinde, die er als Disziplinmangel deutete und bei der er - als einer der wenigen männlichen Leser - die Doppelbödigkeit des Frauenbildes erkannte. Übertreibung in jedem Bereich - außer in seiner eigenen Galanterie - verabscheute er. Formbewahrung ohne Inhalt konnte er ebenso vernichtend beurteilen wie das Gegenteil: von den leeren Gesprächen mit einigen Vertreterinnen der vornehmen Welt zog er sich zunehmend zurück, die Originalität einer Rahel Levin Varnhagen verteidigte er bis zuletzt, trotz seines „horreurs“ vor ihrer zu gemischten Geselligkeit. Scheinbare Ungereimtheiten des Lebenswandels, wie bei der Ehekrise „der Veit“, oder des Charakters, wie bei Henriette Mendelssohn, verteidigte er ausführlich, stellte sich explizit gegen die Meinung der Gräfin Voss und berief sich dabei auf seine längere Kenntnis der Frauen. Die jüdischen Salonfrauen wurden im Briefwechsel mit Luise von Voss vom ersten Jahr an wie selbstverständlich erwähnt, nicht selten als gemeinsame Bekannte ausführlich diskutiert. Ihre jüdische Herkunft wurde dabei in den ersten Jahren nicht nur überhaupt nicht erwähnt, Brinckmann empfahl diese Frauen der jungen Aristokratin mehrfach und nachdrücklich als Gesprächspartnerinnen und Freundinnen.

Obwohl sich sein Stil in den Jahren 1802-1805 deutlich antijüdisch färbte, bewahrte ihn möglicherweise der Ekel vor jeglichem Fanatismus vor wirklichen 
antisemitischen Überzeugungen. So wie er die Konversion ,seiner“ Doktorin Fließ mit Humor genommen hatte, so schilderte er ihre zunehmende christliche Frömmelei am Lebensende mit Befremden, vermochte aber ihr darunter liegendes, intensives Talent zur Freundschaft zu schätzen.340 Was den Grad seiner jeweiligen Empörung und die Sprache, in der diese transportiert wird, betrifft, muss noch auf einen anderen brieflichen Aufruhr hingewiesen werden: die Diskussion über den Katholizismus einiger Freunde, beispielsweise der Schlegels. In der gesellschaftlichen Konsequenz natürlich nicht vergleichbar, ist sprachlich interessant, dass der feinsinnige Diplomat auch hier auf mittelalterliche Klischees zurückgriff.

In seinen Briefen an Luise von Voss und Rahel Levin Varnhagen zeigt sich Brinckmann als gleichermaßen gut vernetzter und gefälliger Weltmann wie als vertrauter Freund mit Interesse am persönlichen Gespräch. Allerdings liegt die Phase besonders intensiven Umgangs mit „der Kleinen“ in den Jahren vor Brinckmanns Abreise nach Paris. Nach seiner Rückkehr macht er einen deutlichen Unterschied zwischen der Persönlichkeit Rahel Levin Varnhagens selbst und dem Umgangston in ihrem Zirkel. Die zunehmende Distanzierung von ihrem ,Salon' ist sowohl seinen Briefen an die Aristokratinnen wie denen an Rahel Levin Varnhagen selbst abzulesen. Es kann in diesem Falle nicht die Rede davon sein, dass Brinckmann als Gast der jüdischen Salons einer aristokratischen Freundin gegenüber seinen jüdischen Umgang prinzipiell relativieren und sich davon grundsätzlich distanzieren müsste. Da er sich und Luise von Voss gegenüber kontinuierlich Rechenschaft gegeben hatte, sowohl über seine grundsätzliche Begeisterung wie seine (vorübergehende?) Ablehnung, wäre eine jähe Wendung gerade seiner „strengen“ Leserin gegenüber wenig glaubhaft gewesen. Es ist vielmehr die Frage, ob und wie weit Brinckmann, Diplomat von Beruf und Stilist aus Berufung, sich einer allgemeingesellschaftlichen Veränderung des Tonfalls - und der Geisteshaltung - anpasste. Es wäre daher besonders interessant $\mathrm{zu}$ wissen, ob und wie sich sein Ton geändert hätte, wenn er weiterhin in Berlin und politisch aktiv geblieben wäre.

Das Spannungsverhältnis zwischen gesellschaftlichem Kontakt zwischen Aristokratie und gebildeten Jüdinnen einerseits und der geschärften Wahrneh-

340 „Verheiratet mit einem höchst langweiligen u. frommen Gemahl, scheint sie es mit der Christlichkeit jetzt auch ganz ernst zu meinen, geht alle Sontage in die Kirche, braucht mehrere Tage zur Vorbereithung des Abendmahl, liest Predigten u. dergl. Dies aber verträgt sich sehr gut mit kleinen weltlichen Eitelkeiten u. Haften[?] nach geistiger Bildung u.s.w. [...] Übrigens eine sehr gute Frau, Freundin ihrer Freunde, u. im Grunde doch anspruchsloser als sie manchmal, aus blosser Liebhaberei am Interessanten, erscheint." Gustav von Brinckmann an Rahel Levin Varnhagen, 10. 3. 1819, ungedruckt, SV 38. 
mung der Unterschiede andererseits, wird durch einen Brief Dorothea Mendelssohn Veit Schlegels an Brinckmann bestätigt, der beinahe mottogebend über diesem Kapitel stehen könnte:

F. v. Berg und ihre überaus liebenswürdige Tochter habe ich vorigen Sommer kennen gelernt; bey einer so kurzen Bekanntschaft habe ich aber genugsames Intereße gefunden um zu bedauern, daß wir uns nicht näher kommen werden. - Nichts Inerliches was uns trennt hoffe ich; bloß Conventionen, Stand und das Leben diesseits -“!341

341 Dorothea Mendelsohn Veit Schlegel an Gustav von Brinckmann, 2. 2. 1799, in: KFSA, Bd. 24, S. 226. Hervorhebung „Inerliches“ im Original, übrige Hervorhebung H. L. L. 